\title{
HyPEP FY-07 Report: Initial Calculations of Component Sizes, Quasi- Static, and Dynamics Analyses
}

C. H. Oh

E. S. Kim

S. R. Sherman

R. Vilim

July 2007

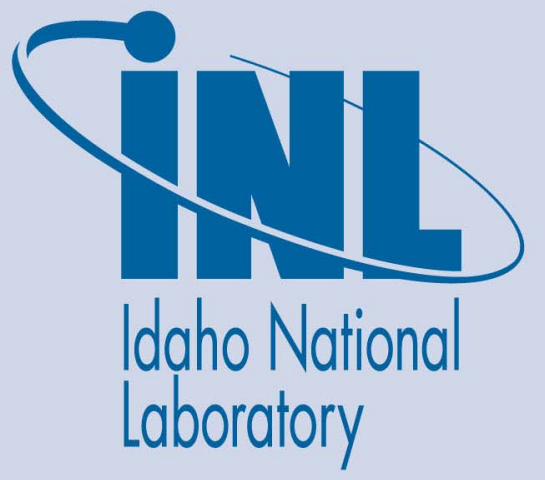

The INL is a U.S. Department of Energy National Laboratory operated by Battelle Energy Alliance 
INL/EXT-07-12937

\title{
HyPEP FY-07 Report: Initial Calculations of Component Sizes, Quasi-Static, and Dynamics Analyses
}

\author{
C. H. $\mathrm{Oh}^{1}$ \\ E. S. $\mathrm{Kim}^{1}$ \\ S. R. Sherman ${ }^{1}$ \\ R. Vilim ${ }^{2}$ \\ ${ }_{2}^{1}$ INL \\ ${ }^{2} \mathrm{ANL}$
}

July 2007

Idaho National Laboratory
Idaho Falls, Idaho 83415

Prepared for the

U.S. Department of Energy

Office of Nuclear Energy

Under DOE Idaho Operations Office

Contract DE-AC07-05ID14517 


\section{ABSTRACT}

The Very High Temperature Gas-Cooled Reactor (VHTR) coupled to the High Temperature Steam Electrolysis (HTSE) process is one of two reference integrated systems being investigated by the U.S. Department of Energy and Idaho National Laboratory for the production of hydrogen. In this concept a VHTR outlet temperature of $900{ }^{\circ} \mathrm{C}$ provides thermal energy and high efficiency electricity for the electrolysis of steam in the HTSE process. In the second reference system the Sulfur Iodine (SI) process is coupled to the VHTR to produce hydrogen thermochemically.

This report describes component sizing studies and control system strategies for achieving plant production and operability goals for these two reference systems. The optimal size and design condition for the intermediate heat exchanger, one of the most important components for integration of the VHTR and HTSE plants, was estimated using an analytic model. A partial load schedule and control system was designed for the integrated plant using a quasi-static simulation. Reactor stability for temperature perturbations in the hydrogen plant was investigated using both a simple analytic method and a dynamic simulation. Potential efficiency improvements over the VHTR/HTSE plant were investigated for an alternative design that directly couples a High Temperature Steam Rankin Cycle (HTRC) to the HTSE process. This work was done using the HYSYS code and results for the HTRC/HTSE system were compared to the VHTR/HTSE system. Integration of the VHTR with SI process plants was begun. Using the ASPEN plus code the efficiency was estimated. Finally, this report describes planning for the validation and verification of the HYPEP code. 


\section{CONTENTS}

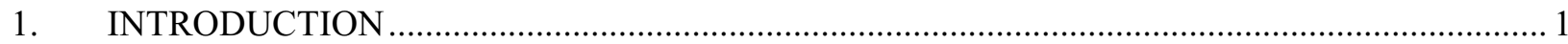

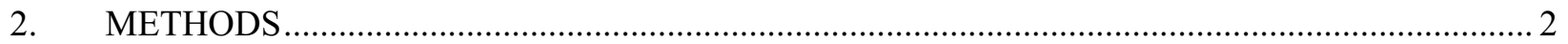

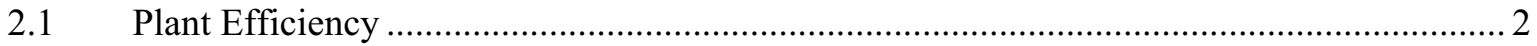

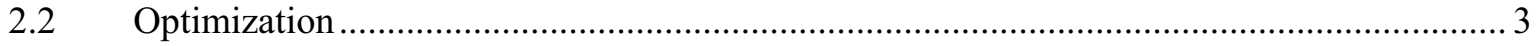

2.3 Electrolyzer Model for High Temperature Electrolysis (HTE) ….................................... 4

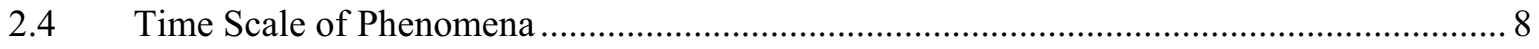

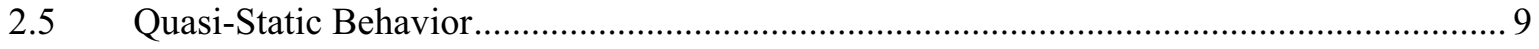

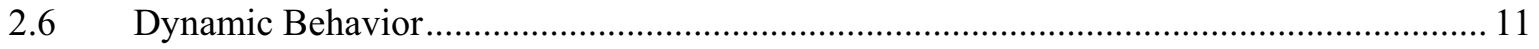

3. EFFICIENCY ANALYSIS FOR INTEGRATED SYSTEMS …........................................... 13

3.1 Direct Integration of High Temperature Steam Rankin Cycle and HTSE System.............. 13

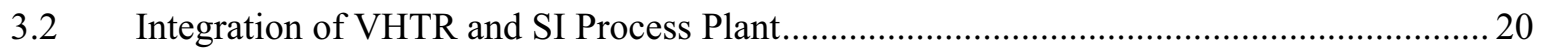

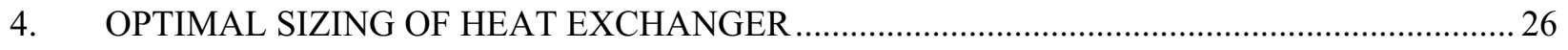

4.1 Determination of Characteristic Parameters ............................................................... 26

4.2 Scaling Analysis of Compact Heat Exchanger Size and Cost ........................................ 30

4.3 Optimum Sizing Model For Minimum Cost of Compact Heat Exchanger ........................ 35

4.4 Reference IHX Conditions and Input Parameters ......................................................... 40

4.5 Optimum Sizing of Compact Heat Exchanger for Reference IHX ................................. 43

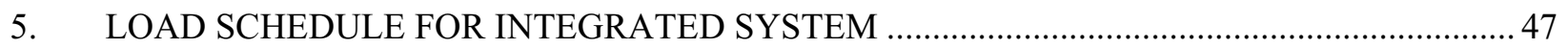

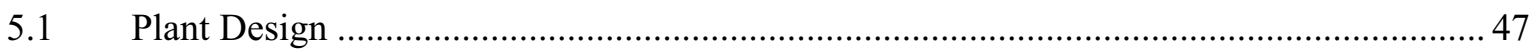

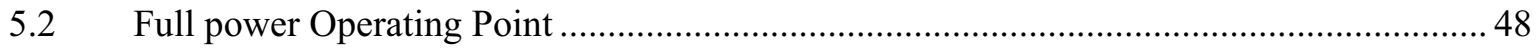

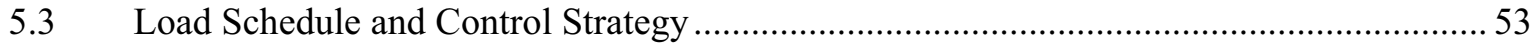

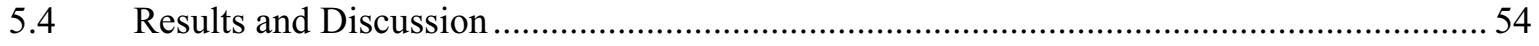

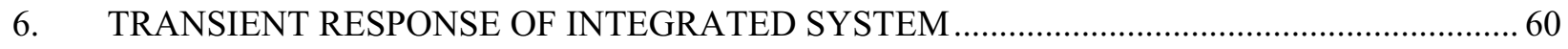

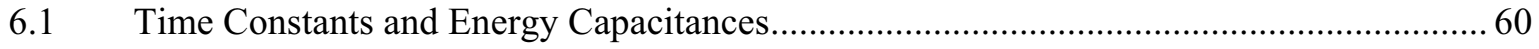

$6.2 \quad$ Load Change 


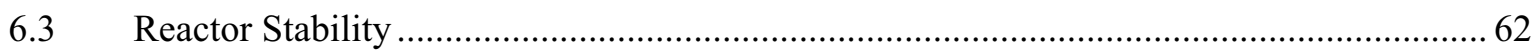

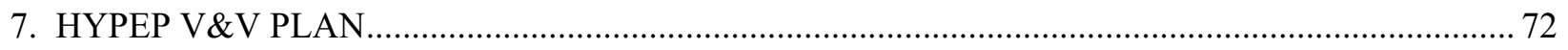

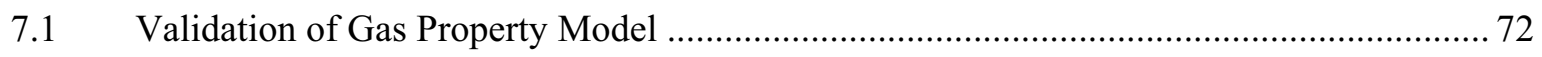

7.2 Validation of System Component Model ................................................................... 78

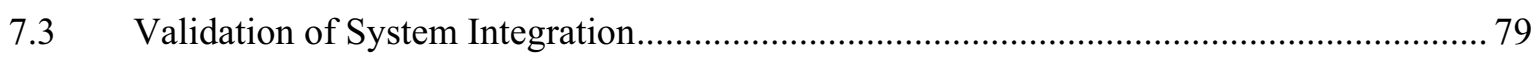

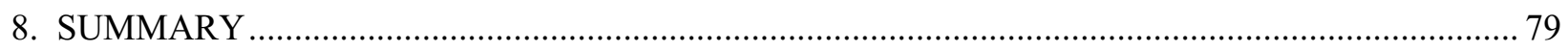

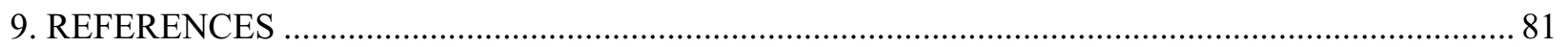




\section{HyPEP FY-07 Report: Coupling Model Development}

\section{INTRODUCTION}

The Next Generation Nuclear Plant (NGNP), a very High temperature Gas-Cooled Reactor (VHTR) concept, will provide the first demonstration of a closed-loop Brayton cycle at a commercial scale of a few hundred megawatts electric and hydrogen production. The power conversion system (PCS) for the NGNP will take advantage of the significantly higher reactor outlet temperatures of the VHTR to provide higher efficiencies than can be achieved in the current generation of light water reactors. Besides demonstrating a system design that can be used directly for subsequent commercial deployment, the NGNP will demonstrate key technology elements that can be used in subsequent advanced power conversion systems for other Generation IV reactors. In anticipation of the design, development and procurement of an advanced power conversion system for the NGNP, the system integration of the NGNP and hydrogen plant was initiated to identify the important design and technology options that must be considered in evaluating the performance of the proposed NGNP. This study is part of DOE's Nuclear Hydrogen Initiative (NHI) Program and is intended to provide DOE with key information to support the process of making research and procurement decisions for the NGNP system integration.

The HyPEP computer code is being developed to calculate and optimize electrical and hydrogen generation efficiencies in support of the NGNP [Oh et al. 2006a]. This report describes recent work on three tasks in the HyPEP work scope. They are: 1) sizing of components for achieving optimal efficiency in the combined plant, 2) development of a control scheme for managing partial power operation, and 3) analysis of transient behavior for assessing plant stability and response time. The calculations for full power operation described in this report will be used to benchmark HyPEP.

All three of the above tasks are part of a larger plant design task that extends beyond the three year HyPEP work scope. It is helpful to describe this larger task and to place the three subtasks in context. There are three goals or performance related objectives that enter into designing for the production of hydrogen from nuclear power. In the vernacular of the nuclear industry they are production, operability, and safety and successful navigation of each leads to a plant design and a set of Technical Specifications for operating the plant. Briefly, production is the task of generating hydrogen product in an economical manner at full power operation. Operability is the task of meeting time varying demands for hydrogen production originating with the customer just beyond the plant fence while at the same time staying within equipment limits. Safety is the task of ensuring the plant is stable and can be shut down in a safe manner following an off-normal event or equipment failure. Engineering analyses are needed to support all three of these tasks.

Some initial results on operability are described in this report. Operability is a function of the inherent characteristics of the plant and the control system and, hence, can be managed through analysis at the design stage. An important objective is to ensure that process variable values during operation do not unduly limit plant service time through excessive mechanical stress or creep in components. At a basic level operability can be gauged through 1) the plant load schedule and 2) the plant response to a step change in load demand. The load schedule specifies values of all plant process variables at each power level over the normal operating range. In the case of VHTR, process variables having operating limits are temperatures in fuel and reactor structures and pressure and temperature of the coolant in heat transport piping. The load schedule takes in startup and shutdown as well as normal load for meeting production demand. In existing commercial nuclear power plants the production range is typically 25 to 100 percent of full power. The plant safety analysis draws a distinction between the load schedule for startup/shutdown and for production. In item two above, the plant response to a step change in load change provides the magnitude of the perturbations to plant variables and the rate at which perturbations 
die away. The change in load may arise either at the grid or within the plant as a result of an upset. The goal is to show deviations do not reduce operational life through thermal fatigue. It must also be shown that the deviations have a natural tendency to die away, otherwise the plant may be unstable and the ability to follow the design load schedule will be compromised.

In the wider context of nuclear hydrogen in the national energy mix of the future, specifications for plant operability do not yet exist. It is a consequence of not knowing what a particular plant must be capable of delivering in terms of an electricity and hydrogen mix. In a conventional electric-only generating plant the product is not easily stored so operational flexibility to change power to meet varying electricity demands must be provided. In a chemical plant, however, the product can be more easily stored so there is not as great a need for partial power operation. The plant typically runs at full power with short term variations in demand buffered by drawing from or adding to stored inventory of the chemical product. The appropriate product mix for a nuclear-hydrogen plant - hydrogen only or co-generation - is the subject of future systems integration work. The optimum mix of hydrogen and electricity will depend in part on future markets for hydrogen and electricity on a daily, seasonal, yearly, and geographic basis. At this time it is uncertain what future energy markets will be and, hence, what variable mix of electricity and hydrogen is needed for optimum economic performance. As a consequence the degree of operational flexibility needed is uncertain. It is assumed that the sole product of the plant is hydrogen in the absence of other information and on the basis that the combined VHTR-HTSE plant has a high efficiency when operated in this mode.

Results on production are also described in this report. They involve heat exchanger sizing for optimal efficiency at full power. Safety is to be examined in the future and will involve determining the protection systems needed to maintain safe conditions following operator error or a failure of a component or control system.

\section{METHODS}

\subsection{Plant Efficiency}

The efficiency of each proposed configuration was estimated using HYSYS [Aspen Technology 2001], a process optimization code used in the chemical and oil industries.

The power conversion unit (PCU) cycle efficiency, $\eta_{P C U}$, used in this study is defined as [Oh et. al 2006]:

$\eta_{\mathrm{PCU}}=\frac{\text { Electric power output }}{\text { Reactor themal power }-\mathrm{H}_{2} \text { process power }}=\frac{\sum \mathrm{W}_{\mathrm{T}}-\sum \mathrm{W}_{\mathrm{C}}-\mathrm{W}_{\mathrm{S}}-\sum \mathrm{W}_{\mathrm{CIR}}}{\mathrm{Q}_{\mathrm{th}}-\mathrm{Q}_{\mathrm{H} 2}}$

where $\sum \mathrm{W}_{\mathrm{T}}$ is the total turbine workload, $\sum \mathrm{W}_{\mathrm{C}}$ is the total compressor workload, $\mathrm{W}_{\mathrm{S}}$ is the plant stationary load, $\sum \mathrm{W}_{\mathrm{CIR}}$ is the circulator workload in the primary, intermediate, and, if present, ternary loops and includes, for example, the recycle and make-up water pumps and the $\mathrm{H}_{2}$ and sweep water circulators, $\mathrm{Q}_{\mathrm{th}}$ is the reactor thermal power, and $\mathrm{Q}_{\mathrm{H} 2}$ is the thermal power supplied to the hydrogen generating plant. For the efficiency calculations, we report the overall cycle efficiency, which is defined as 
$\eta_{\text {overall }}=\frac{\sum \mathrm{W}_{\mathrm{T}}-\sum \mathrm{W}_{\mathrm{C}}-\mathrm{W}_{\mathrm{S}}-\sum \mathrm{W}_{\mathrm{CIR}}-\sum \mathrm{Q}_{\mathrm{HTSE}}+\mathrm{Q}_{\mathrm{H} 2}^{\prime}}{\mathrm{Q}_{\text {th }}}$

where $\sum \mathrm{Q}_{\mathrm{HTSE}}$ is the electric power requirement for electrolysis and $\mathrm{Q}_{\mathrm{H} 2}^{\prime}$ is the hydrogen production mass flow rate times the specific energy content of the hydrogen.

\subsection{Optimization}

For this calculation, the process optimization was carried out using HYSYS process modeling software. HYSYS has an optimization tool that is built in to integrate the simulation model of the system. The optimization program searches for the maximum value of a given objective function subject to a number of imposed constraints. Figure 2-1 shows a two-dimensional design space with defined regions. The goal is to maximize $f(x 1, x 2, x 3, \ldots)$ where $x 1, x 2, x 3$ are independent variables such as mass flow, pressure, temperature, etc. For the optimization, the $\mathrm{x}$ variables are manipulated within a specified range of a lower and upper bound. The regions in Figure 2-1 are defined by a feasible design space within functional constraints and an infeasible design space outside of the constraint boundaries [Mckellar 1992]. Functional constraints are material and energy balances, for example, positive pressure drop in every stream in the direction of flow, positive power in turbine and compressor, temperature requirements at the inlet and outlet of the heat exchangers, etc. The function, $\mathrm{f}$, is the objective function which is defined as the overall plant efficiency above. Constant values of the objective function define contours on the design space. Figure 2-2 shows design space of 2-D design vector showing optimal design points. First, the initial calculation should be in the feasible design space and the search continues towards a direction in the design space until a maximum is reached. A new direction is found and the search continues in that direction as long as the objective function value increases. Once a maximum is reached, the search continues towards the optimal design point. However, if the optimal design point is outside of the feasible design space, the closest contour to the optimal solution that coincides with the constraint boundary can be the optimal solution within the constraints specified.

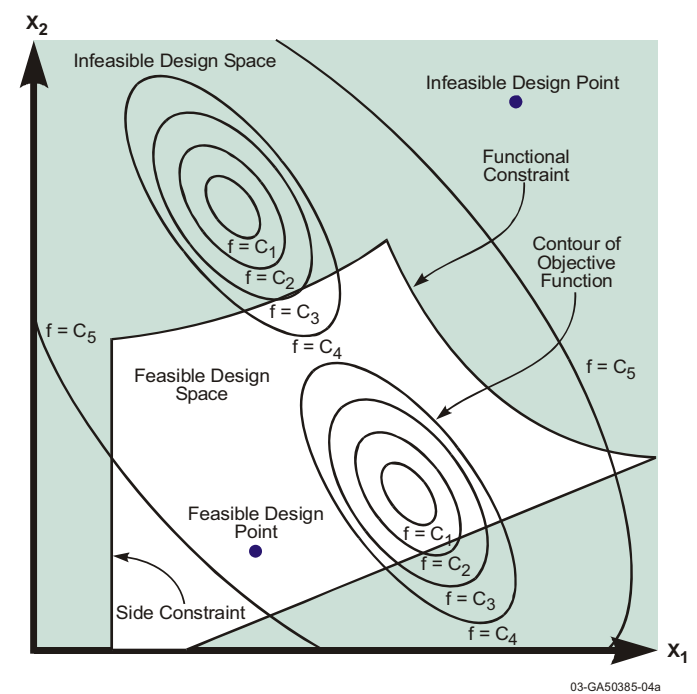

Figure 2-1. Design space with designed regions.

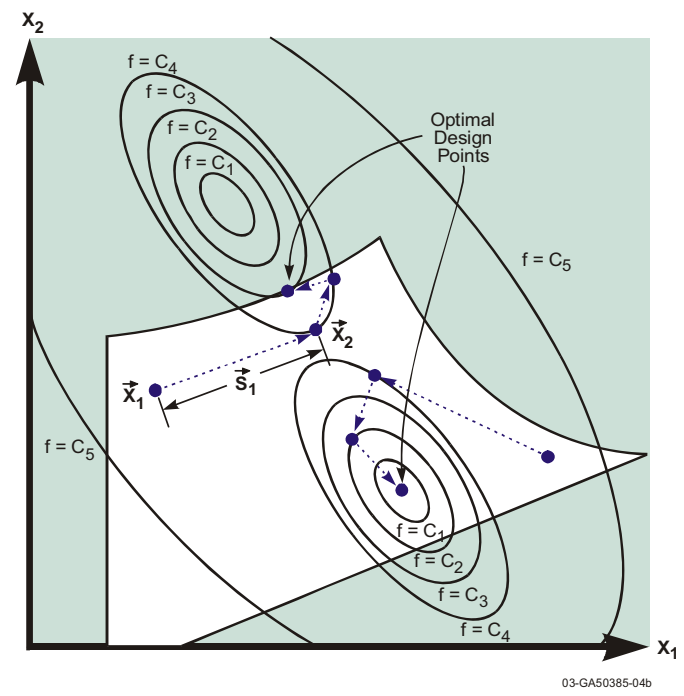

Figure 2-2. Potential optimal solutions. 


\subsection{Electrolyzer Model for High Temperature Electrolysis (HTE)}

In the electrolyzer model [Oh et al. 2006a], the oxygen stream produced at the anode is assumed to mix with a sweep gas stream that is introduced at the anode. The combined stream then exits the electrolyzer. The hydrogen stream produced at the cathode is assumed to mix with a feed stream that is introduced at the cathode. The feed stream is composed of water vapor to be electrolyzed, hydrogen gas for maintaining reducing environment, and possibly an inert gas, presently assumed to be nitrogen.

\subsubsection{Energy Equation}

An energy balance on the electrolyzer gives

$$
\sum_{i} \dot{n}_{P-i} H_{P-i}\left(T_{P}, P\right)=\sum_{i} \dot{n}_{R-i} H_{R-i}\left(T_{R}, P\right)+Q+W
$$

where

$$
\begin{array}{lll}
\dot{n} & = & \text { species mole flow rate } \\
\mathrm{H} & = & \text { enthalpy per mole } \\
Q & = & \text { rate of heat transfer to the electrolyzer, } \\
W & = & \text { rate of electrical work supplied to the electrolyzer, } \\
T & = & \text { temperature } \\
\mathrm{P} & = & \text { pressure }
\end{array}
$$

and where we have used subscripts $R$ for reactants and $P$ for products. Their mass flow rates are defined

$$
\begin{gathered}
m_{\mathrm{H}_{2} \mathrm{O}-\mathrm{o} \text {-cath }} h_{\mathrm{H}_{2} \mathrm{O}}\left(T_{o}, P\right)+m_{\mathrm{H}_{2}-\mathrm{O}-\text { cath }} h_{\mathrm{H}_{2}}\left(T_{o}, P\right)+m_{\mathrm{N}_{2}-\mathrm{O} \text {-cath }} h_{\mathrm{N}_{2}}\left(T_{o}, P\right) \\
m_{\mathrm{O}_{2}-\mathrm{o} \text {-anode }} h_{\mathrm{O}_{2}}(T, P)+m_{\text {sweep-o-anode }} h_{\text {sweep }}\left(T_{o}, P\right)= \\
m_{\mathrm{H}_{2} \mathrm{O}-\mathrm{i} \text {-cath }} h_{\mathrm{H}_{2} \mathrm{O}}\left(T_{i}, P\right)+m_{\mathrm{H}_{2}-i-\text { cath }} h_{\mathrm{H}_{2}}\left(T_{i}, P\right)+m_{\mathrm{N}_{2}-i-\text { cath }} h_{\mathrm{N}_{2}}\left(T_{i}, P\right) \\
m_{\mathrm{O}_{2}-i \text {-anode }} h_{\mathrm{O}_{2}}\left(T_{i}, P\right)+m_{\text {sweep-i-anode }} h_{\text {sweep }}\left(T_{i}, P\right)+Q+W
\end{gathered}
$$

where

$$
\begin{array}{lll}
m & = & \text { species mass flow rate }(\mathrm{kg} / \mathrm{s}), \\
h & = & \text { specific enthalpy }(\text { Joules } / \mathrm{kg}),
\end{array}
$$

and where subscripts $i$ and $o$ represent inlet and outlet, respectively.

\subsubsection{Species Mole and Mass Flow Rates}

The species mole flow rates entering and leaving the electrolyzer are related to the current density through the relationships 


$$
\begin{aligned}
& \dot{n}_{\mathrm{H}_{2} \mathrm{O}-\mathrm{O}-\mathrm{cath}}=\dot{n}_{\mathrm{H}_{2} \mathrm{O}-\mathrm{i}-\mathrm{cath}}-\frac{i \mathrm{~A}}{2 \mathrm{~F}} \\
& \dot{n}_{\mathrm{H}_{2}-\mathrm{o}-\mathrm{cath}}=\dot{n}_{\mathrm{H}_{2}-i-\mathrm{cath}}+\frac{i \mathrm{~A}}{2 \mathrm{~F}} \\
& \dot{n}_{\mathrm{O}_{2}-\text { o-anode }}=\dot{n}_{\mathrm{O}_{2}-i \text {-anode }}+\frac{i \mathrm{~A}}{4 \mathrm{~F}} \\
& \dot{n}_{\text {sweep-o-anode }}=\dot{n}_{\text {sweep-i-anode }} \\
& \dot{n}_{N_{2}-o-c a t h}=\dot{n}_{N_{2}-i-c a t h}
\end{aligned}
$$

where

$$
\begin{array}{lll}
i & = & \text { current density }\left(\operatorname{amps} / \mathrm{m}^{2}\right), \\
A & = & \text { electrode surface area, }\left(\mathrm{m}^{2}\right) \text { and } \\
F & = & \text { Faradays constant. }
\end{array}
$$

The species mass flow rates and mole flow rates are related as follows: For an individual species

$$
\dot{m}_{k-o}=A_{k} \dot{n}_{k-o} \text { and } \dot{m}_{k-i}=A_{k} \dot{n}_{k-i}, \quad k=H_{2} O, H_{2}, O_{2} \text {, and } N_{2} \text {. }
$$

where $A_{k}$ is the atomic weight of species, $k$ in $\mathrm{kg}$ per mole, subscript $o$ is the outlet and $i$ is the inlet.

\subsubsection{Cell Voltage and Electrical Work}

The voltage drop across the electrolyzer is the sum of the electrode Nernst potential and the resistance of the cell. In estimating the resistance, the activation and the concentration overpotentials are lumped in with the cell internal resistance. The cell voltage is then assumed given by

$$
\mathrm{V}_{\text {cell }}=\overline{\mathrm{V}}_{\text {Nernst }}+\mathrm{i} \cdot \mathrm{ASR}
$$

where

$$
\begin{array}{ll}
\overline{\mathrm{V}}_{\text {Nernst }}= & \text { is the Nernst potential, and } \\
\operatorname{ASR} & =\quad \text { is the area-specific cell resistance }(\text { ohms-m²). }
\end{array}
$$

The electrical work done in the cell is

$$
W=V_{\text {cell }} \cdot i \cdot A
$$

The active species giving rise to the Nernst potential satisfy the chemical balance equation

$$
\mathrm{H}_{2} \mathrm{O}(\mathrm{g}) \rightarrow \mathrm{H}_{2}(\mathrm{~g})+\frac{1}{2} \mathrm{O}_{2}(g)
$$

The change in Gibbs free energy for this reaction carried out at temperature $\mathrm{T}$ and pressure $\mathrm{P}$ is 


$$
\Delta G(T, P)=\Delta G_{f}(T, P)+R T \ln \left[\frac{f_{H_{2}} f_{O_{2}}{ }^{\frac{1}{2}}}{f_{H_{2} O}}\right]
$$

where $f$ is the molar fraction of a species and $\Delta G_{f}(T, P)$ is the Gibbs free energy in forming the products at temperature $T$ and pressure $P$ minus the same for the reactants, that is,

$$
\Delta G_{f}(T, P)=G_{f-H_{2}}(T, P)+1 / 2 G_{f-O_{2}}(T, P)-G_{f-H_{2} O}(T, P) .
$$

where $\left.G_{f-i}(T, P)\right)$ is the Gibbs free energy on a per mole basis of forming species $i$ at conditions $T$ and $P$. In turn $\Delta G_{f}(T, P)$ is written in terms of $\Delta G_{f}^{0}(T)=\Delta G_{f}\left(T, P_{S T D}\right)$ where $P_{S T D}=0.101 \mathrm{MPa}$. Then setting the change in Gibbs free energy equal to the electrical work done the voltage developed by the cell is

$$
\mathrm{V}_{\text {Nernst }}=\frac{-1}{2 \mathrm{~F}}\left[\Delta G_{f}{ }^{0}(T)+R T \ln \left[\left(\frac{f_{H_{2}} f_{O_{2}}{ }^{\frac{1}{2}}}{f_{H_{2} O}}\right)\left(\frac{P}{P_{S T D}}\right)^{\frac{1}{2}}\right]\right]
$$

where $P_{S T D}=0.101 \mathrm{MPa}$ and $P$ is the cell pressure. Then the average value of $\mathrm{V}_{\text {Nernst }}$ was calculated using the following equation.

$$
\begin{aligned}
& \overline{\mathrm{V}}_{\text {Nernst }}=\frac{1}{2 \mathrm{~F}\left(\mathrm{~T}_{\mathrm{P}}-\mathrm{T}_{\mathrm{R}}\right)\left(\mathrm{y}_{\mathrm{o}, \mathrm{O} 2, \mathrm{~A}}-\mathrm{y}_{\mathrm{i}, \mathrm{O} 2, \mathrm{~A}}\right)\left(\mathrm{y}_{\mathrm{o}, \mathrm{H} 2, \mathrm{C}}-\mathrm{y}_{\mathrm{i}, \mathrm{H} 2, \mathrm{C}}\right)} \times
\end{aligned}
$$

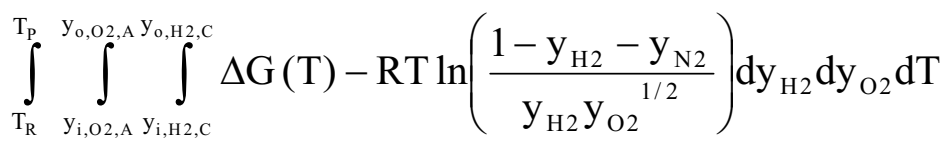

The mole fractions at any point in the electrolyzer are related to the molar mass flow rates at that point through

$$
\begin{array}{ll}
f_{\mathrm{H}_{2} \mathrm{O}-\text { cath }}=\frac{\dot{n}_{\mathrm{H}_{2} \mathrm{O}}}{\dot{n}_{\mathrm{H}_{2} \mathrm{O}}+\dot{n}_{\mathrm{H}_{2}}+\dot{n}_{\mathrm{N}_{2}}} & f_{\mathrm{H}_{2} \text {-cath }}=\frac{\dot{n}_{\mathrm{H}_{2}}}{\dot{n}_{\mathrm{H}_{2} \mathrm{O}}+\dot{n}_{\mathrm{H}_{2}}+\dot{n}_{\mathrm{N}_{2}}} \\
f_{\mathrm{O}_{2} \text {-anode }}=\frac{\dot{n}_{\mathrm{O}_{2}}}{\dot{n}_{\text {sweep }}+\dot{n}_{\mathrm{O}_{2}}} & f_{\text {sweep-anode }}=\frac{\dot{n}_{\text {sweep }}}{\dot{n}_{\text {sweep }}+\dot{n}_{\mathrm{O}_{2}}} .
\end{array}
$$

The current density and active cell area are then specified, yielding the total operating current. Care must be taken to insure that the specified inlet gas flow rates and total cell current are compatible. The minimum required inlet steam molar flow rate is the same as the steam consumption rate, given by:

$$
\dot{N}_{i, H 2 O, \min }=\Delta \dot{N}_{H 2 O}=\frac{I}{2 F} N_{c e l l s}=\frac{i A_{c e l l}}{2 F} N_{c e l l s}=\Delta \dot{N}_{H 2}
$$


which is of course also equal to the hydrogen production rate.

Once the total and per-cell hydrogen production rates are known, the outlet flow rates of hydrogen and steam on the cathode side and oxygen on the anode side can be determined. The flow rates of any inert gases, the anode-side sweep gas, and any excess steam or hydrogen are the same at the inlet and the outlet. Once all these flow rates are known, the summations in Equation (2-3) can be evaluated. The product summation must be evaluated initially at a guessed value of the product temperature, $T_{P}$.

Matlab (Mathworks 2006) was used to calculate Equations (2-3) through (2-15). Figures 1-3 through 1-5 illustrate the calculated results. Figure 2-3 contains two curves. One curve shows the required electrical work with current density at a fixed total current. The other curve shows the required number of cells to obtain the current density. As shown in this figure, electrical work increases with current density because higher current density results in higher operating voltage as shown in Equation (2-8) and Figure 2-4.

However, the number of cells is reduced by the increase of current density. Therefore, economically, the increase of current density increases the operating cost, but reduces the capital cost. Therefore, the operating condition of the current density should be carefully determined under various economic considerations. To obtain the optimal operating current density, further optimization analysis is recommended.

Figure 2-5 shows the variation of product temperature with total electric current. Basically, the water splitting process is an endothermic reaction. Therefore, without additional heat, the product temperature is reduced. In Figure 2-5, we can see the temperature reaches a minimum between 5 and 15 amperes. At the higher current density, we can see the temperature gradually turns upward. It is due to the ohmic heating by the cell internal resistance. The heating rate also increases with the current density causing the product gas temperature rise.

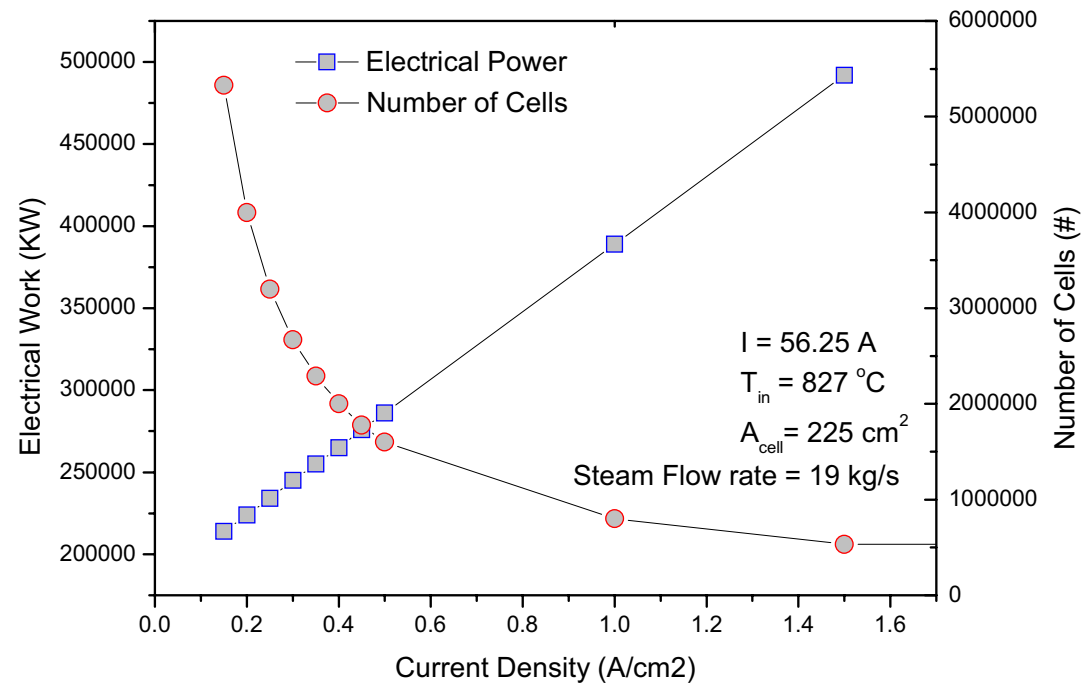

Figure 2-3. Required electrical work and number of cells with current density at the constant current. 


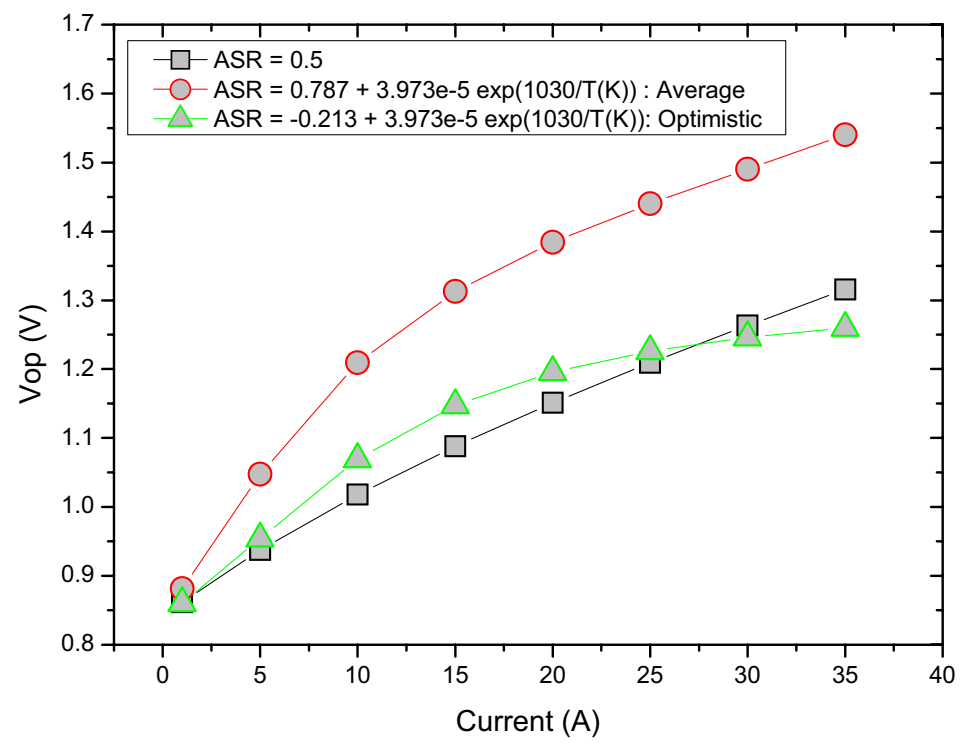

Figure 2-4. Variation of cell operating voltage with current for different stack area-specific resistance (ASR).

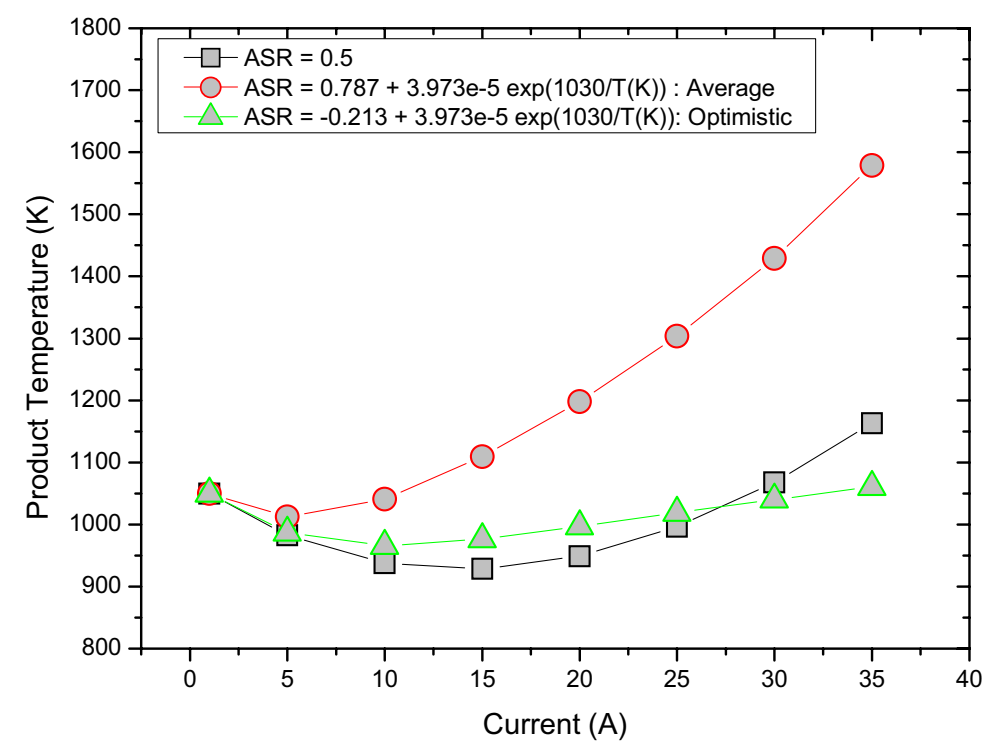

Figure 2-5. Variation of product temperature with current for different ASR.

\subsection{Time Scale of Phenomena}

The combined plant response is shaped by the time constants of the various components. The time constants and where they appear in the flow paths for the transport of the conserved quantities can provide insight into the time behavior of the overall plant. 
The time response of each component is given by the ordinary differential equation

$$
\frac{d}{d t} y=\frac{-1}{\tau}[y+F[u(t)]]
$$

where $u(t)$ is the forcing function, $y$ is the observed process variable, $\mathrm{F}$ is a function of $u$, and $\tau$ is the time constant. The role of the time constant is made evident by applying a step input to the component. If the initial state is given by

$$
y\left(0^{-}\right)+F\left[u\left(0^{-}\right)\right]=0
$$

then the component response for a step in $F$ applied at $t=0$ is

$$
\frac{y(t)-y(\infty)}{y\left(0^{-}\right)-y(\infty)}=e^{\frac{-t}{\tau}}, \quad t>0
$$

where $y(\infty)$ designates the new steady state. One sees that the observed variable moves to the new steady state with time constant $\tau$.

Analytic expressions for time constants and energy capacitances for the major components in a coupled VHTR and HTE plant are derived in Vilim (2006).

\subsection{Quasi-Static Behavior}

\subsubsection{Full Power Operating Point}

A full power operating point must be designed that meets production goals and satisfies material limits including creep and thermal stresses. Previous work (Oh 2006 and Oh 2007) addressed the design of equipment for meeting these objectives. The simulation codes HYSYS and GAS-PASS were used to calculate this full power condition. Also included in this calculation were the powers of active control elements including pump, compressor, turbine, and electrolyzer. The purpose of the load schedule is to specify how the output of these elements changes with load. The specification must satisfy the material limits mentioned earlier. This can be achieved using the method described below.

\subsubsection{Load Schedule}

The dependence of process variables on the power level of the plant is given by the load schedule. Typically the plant load schedule is designed to maintain constant temperature at the hottest points in the plant (eg. reactor outlet) over all power while at load. What can be achieved from the standpoint of 1) the number of independently controllable actuators needed to achieve constant temperature at a given number of points and 2) the values actuator outputs need to assume to achieve a result is described below. One sees that a steady-state code equipped with the proper features can be used to determine the actuator properties needed to achieve a desired load schedule.

Each of the components in the plant in the steady state satisfies an equation of the form 


$$
0=[y+F[\underline{u}(t)]]
$$

where

$$
\begin{array}{ll}
\underline{u}(t) & =\text { vector of input forcing functions, } \\
F & =\text { function of } u(t) \\
y & =\text { component output. }
\end{array}
$$

Assume for the sake of exposition that there are three control variables: two flowrates, $w_{1}$ and $w_{2}$, and rod reactivity, $\rho$. Coupling the equations for all components leads to a system of equations for the plant state vector expressed in terms of the control variables (assuming constant properties)

$$
\left[T_{1} T_{2} \ldots T_{n}\right]^{T}=A_{o}\left(w_{1}, w_{2}, \rho\right)^{-1} b_{o}\left(w_{1}, w_{2}, \rho\right)
$$

where the $T_{i}$ are temperatures, $A_{o}$ is a matrix whose elements are functions of the control variables, and $b_{o}$ is a vector.

The control variables are written as linear functions of the plant power

$$
\begin{aligned}
& w_{1}=m_{1} P+b_{1} \\
& w_{2}=m_{2} P+b_{2} \\
& \rho=m_{3}\left(P-P_{0}\right)
\end{aligned}
$$

where $m_{1}, m_{2}, m_{3}, b_{1}$, and $b_{2}$ are constants.

Differentiating the above set of equations with respect to power gives a set of load schedule coefficients that defines the load schedule about an operating point

$$
\left[\frac{d T_{1}}{d P} \frac{d T_{2}}{d P} \cdots \frac{d T_{n}}{d P}\right]^{T}=A_{1}\left(m_{1}, m_{2}, m_{3}, T_{1}, T_{2}, \ldots, T_{n}\right)^{-1} b_{1}\left(m_{1}, m_{2}, m_{3}\right)
$$

One sees from the above equation that three load coefficients can be arbitrarily assigned through the three parameters $m_{1}, m_{2}$, and $m_{3}$. This expression holds at a particular power. It can be applied repeatedly at different power to achieve the load schedule desired for three temperatures. In general, assigning values to $n$ temperatures over the load range will require $n$ actuators.

Building a capability for designing a load schedule using a dynamic simulation code would involve assigning desired values for the process variables on the left-hand side of Eq. (2-19) at a given power and then solving for the unknowns on the right-hand side. This would be repeated for power over the normal at-load operating range.

\subsubsection{Startup}

The same concept of using actuators to manage temperatures and power applies for design of the startup schedule. However, in any one component there may now be multiple physics regions that must be passed through one after the other. In the reactor, the core passes from being initially subcritical, then critical with delayed neutrons, and finally critical with delayed neutrons and temperature feedback. In a 
boiler the water is initially subcooled, then becomes saturated with unity quality at the exit, and finally possibly superheated at the exit. A condenser passes through analogous regions. A helium turbine may initially function as a compressor driven by the generator until temperatures and pressures reach the point where the turbine produces work.

Essentially a load schedule must be developed for each physics region the plant passes through during startup. Simulation of this requires model switching as each region is passed through. As a result calculation of plant startup is more complex. The need for model switching will need to be provided for in the future simulations.

\subsection{Dynamic Behavior}

\subsubsection{Reactor Stability}

For safety reasons stability is an important aspect of nuclear plant design. A physical system is stable if the transition to a new state, as driven by altered forcing function values, is marked by a smooth and nonoscillatory transition. Stability can be qualitatively assessed by examining the system response to a step change in an input variable. Since a step is composed of an infinite set of frequencies it excites all modes of the system. The stability can also be assessed by more formal methods that examine eigenvalues of the system linearized about an operating point. (Depiante, 1994) Below we examine the physical processes that govern the response of the reactor to a change in the load. A simple expression is derived for predicting how reactor stability trends with plant parameter values.

There is a natural tendency for reactor power to follow a change in heat sink load. An increase in load reduces heat sink outlet temperature which propagates to reduce reactor core inlet temperature, adding reactivity which increases power. The resulting core outlet temperature increase propagates back to the heat sink providing additional heat to meet the increase in power. The potential for oscillations arises if the heat sink does not attenuate this temperature front. In this case the front moves on to the core where it raises inlet temperature and causes reactor power to decrease. One sees that there is the potential for core power to alternately increase and decrease as the reactor inlet and outlet temperatures change out of phase with each other. The degree to which core power oscillations are dampened is a function of the attenuation of the temperature front at the heat sink and the size of the reactivity inlet temperature coefficient.

A simple reactivity balance shows how stability trends with integral reactivity parameters. The reactor power in the asymptote is related to the flowrate and inlet temperature through

$$
0=A(P-1)+B\left(\frac{P}{W}-1\right)+\mathrm{C} \delta T_{i}
$$

as derived in Vilim (2006). The change in reactor outlet temperature expressed as a function of change in reactor inlet temperature is then

$$
\delta T_{\text {out }}=\left(1-\frac{C \Delta T_{c-100} / B}{\frac{A}{B}+1}\right) \delta T_{i}
$$


where normalized flowrate has been set to unity. If the expression within the parentheses is negative, then a change in inlet temperature in one direction leads to a change in outlet temperature in the opposite direction. Hence, to the extent the heat sink passes through without attenuation a primary hot leg temperature front associated with an increase in reactor power due to an initial reactivity addition, the reactor power will begin to decrease on negative temperature reactivity a time later equal to the propagation time around the primary system. For oscillations to occur, this time must be long enough that the initial reactor power increase (due to the original reactivity addition) begins to equilibrate, typically a few tens of seconds. Thus, oscillations are favored if: 1) the heat sink does not attenuate primary hot leg temperature fronts, 2) the loop propagation time is more than a few tens of seconds, and 3) the expression in parentheses in Eq. (2) is negative. The amplitude of these oscillations will increase as $C \Delta T_{c-100} / B$ becomes a larger positive number and $A / B$ a smaller positive number provided the ratio of the two remains more than unity. The period of the oscillations will be roughly twice the loop propagation time.

This simple analysis provides guidance on the phenomena that should be modeled in a systems code used to calculate the dynamic response of the coupled plant and from this its stability.

\subsubsection{Time Response}

The plant transient behavior is assessed in part by the plant response to a sudden change in demand. Examples of such changes are a step change in hydrogen or electricity demand. The time taken to come into equilibrium with the new demand condition, termed the response time, and the interim deviation compared to that if the change were carried out quasi-statically, termed the overshoot, are important. The response time is important for meeting production goals while the overshoot is important for safety-related integrity of structures.

Analyses based on component time constants and thermal capacitances can provide a measure of response time and overshoot. Further, these two parameters provide some insight into what is controlling plant response and provide an adjunct to detailed transient simulation. The time constants and thermal capacitances control how long before the core and heat sink powers come back into equilibrium after a change in conditions. A change in local conditions at one heat source/sink flows through a series of processes each with a characteristic time constant before reaching the other heat source/sink where the temperature and flow changes create feedback that brings all processes back to equilibrium. But until equilibrium is restored, a power generation imbalance gives rise to an energy imbalance approximated by

$$
\delta E=\delta P \sum \tau_{i}
$$

where $\delta P$ is an initial step change in power and the $\tau_{i}$ are a series of process time constants through which the change must propagate before feedback effects occur to bring heat sink and core power back into equilibrium. The change in temperature caused by this power imbalance averaged among the $i$ processes is

$$
\delta T=\frac{\delta P \sum \tau_{i}}{\sum\left(\rho V C_{p}\right)_{i}}
$$

If the original and terminal plant states are on the normal plant operating curve, as is the case for the instances we will look at, then the overshoot in temperature is given by 


$$
\delta T_{o s}=\frac{\delta P \sum \tau_{i}}{\sum\left(\rho V C_{p}\right)_{i}}-\delta T_{\text {load }}
$$

where $\delta T_{\text {load }}$ is the change in temperature in going from the original to the new operating point on the plant operating curve. To make use of the above expression, one first needs to identify the propagation path for the transient and to calculate the time constant and thermal capacitances of the processes along the propagation path.

The rate of change in temperature before equilibrium is reached is from Eq. (2-24)

$$
\frac{d \delta T}{d t}=\frac{\delta P}{\sum\left(\rho V C_{p}\right)_{i}} .
$$

This simple analysis provides guidance on the phenomena that should be modeled in a systems code used to calculate the dynamic response of the coupled plant and from this its stability.

\section{EFFICIENCY ANALYSIS FOR INTEGRATED SYSTEMS}

\subsection{Direct Integration of High Temperature Steam Rankin Cycle and HTSE System}

In HTSE system, $80 \%$ of energy is provided by the process heat from VHTR and $20 \%$ by electricity. The overall efficiency is determined by the efficiency equation defined in Equation 2-2. Figure 3-1 shows two main thermodynamic cycle efficiencies with temperature; steam Rankine cycle and gas Brayton cycle. As shown in Figure 3-1, at low temperature less than 700 C, the steam Rankine cycle shows much higher efficiency than the gas Brayton cycle, but at high temperature above $700^{\circ} \mathrm{C}$, the efficiency of gas turbine cycle is much higher. It means that the gas turbine cycle is a more suitable thermodynamic cycle for hydrogen production, which requires very high temperature over $900{ }^{\circ} \mathrm{C}$ for good efficiency. Actually, at this temperature, the efficiency of the gas turbine system exceeds $50 \%$, which is much higher than the commercial PWR. In the current PWR technology, the efficiency is ranged just around $33 \sim 35 \%$. For this reason, all research on the nuclear reactor concerning with hydrogen production is now focused on the very high temperature gas cooled reactors. 


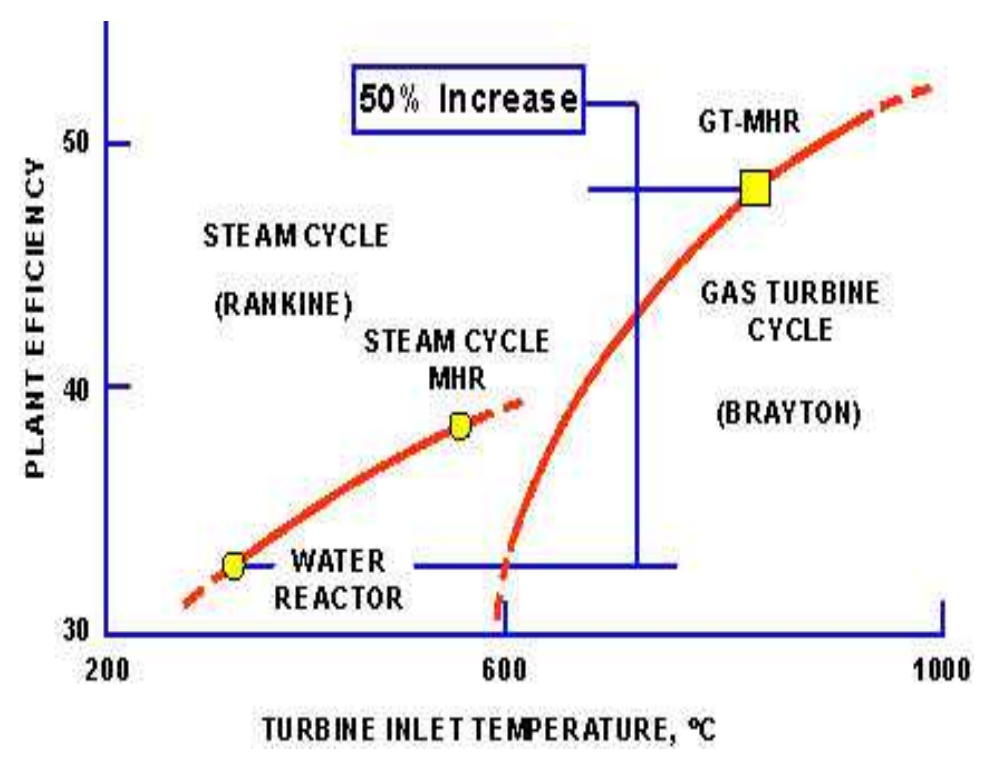

Figure 3-1. Cycle efficiency versus turbine inlet temperature

In this study, the direct integration of the steam Rankin cycle and the HTSE was investigated because of some advantages we can obtain from this system. First of all, it requires no additional intermediate heat exchange loop like VHTR/HTSE system to generate process steam required for high temperature electrolysis because the steam generated in the PCU can be directly used in the electrolysis system by simple flow split method sharing the same coolant loop. Therefore, it will make the system configuration much simpler than the integration of VHTR and HTSE system. Secondly, the steam Rankine cycle is well-proven technology, which has been used for several decades in the most commercial nuclear reactors. It means that lots of design and operating experiences have been collected so far. It will significantly reduce the uncertainties for the newly developed system. For this reason, it is worth considering the Rankin cycle as a possible candidate for the application to the hydrogen production in spite of its lower theoretical efficiency compared with gas Brayton cycle. Ultimately the cost estimate is required to select the final design along with technical issues. In this study, we directly integrated the steam Rankin cycle with hydrogen production system and evaluated the overall system efficiency by using commercial process analysis tools.

\section{$\underline{\text { System Configurations for Reference Designs }}$}

In this study, HTSE system is directly integrated with the steam Rankin cycle. Figure 3-2 shows the basic concept of the integration method. This system is a basically indirect cycle, in which the reactor primary side is separated with the secondary Rankin cycle by a heat exchanger. A key point of this system is, as mentioned in the previous section, that the generated steam in the secondary system can be directly used for an electrolyzer. Therefore, the hydrogen production and electricity generation system are sharing the same coolant loop as a one body. 


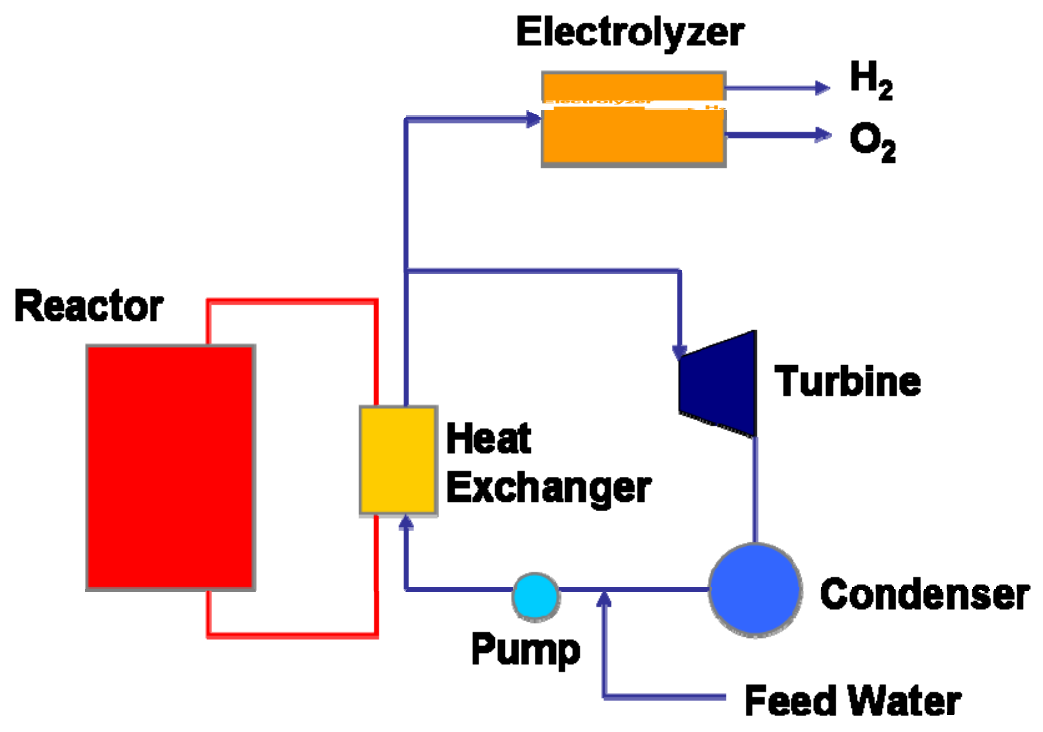

Figure 3-2. Concept of direct integration of HTRC and HTSE system

We estimated five different configurations having different heat recovery methods by using HYSYS code. Figure 3-3 through 3-7 shows the configurations and their estimated efficiencies. In this calculation, the maximum efficiency was obtained to be $41.6 \%$ at the configuration 2 shown in Figure 3-4. In this configuration, helium is used as primary coolant, and the maximum coolant temperature is fixed at $900{ }^{\circ} \mathrm{C}$. Two heat exchangers (IHX and IHX2) are used to transfer primary heat to the secondary side, and eventually generate superheated steam. Water is converted to the superheated steam at $880^{\circ} \mathrm{C}$, and it generates electricity passing through the high pressure turbine. Then, the steam at the turbine outlet is reheated by IHX 2 up to $860^{\circ} \mathrm{C}$. After that, some amount of the steam is separated by a flow splitter and provided to an electrolyzer for generation of hydrogen. The rest of the steam is re-used for generation of electricity through the low pressure turbine. To recover the water consumed in the electrolyzer, some water is continuously injected at the condenser outlet, the minimum pressure point. Comparing with the VHTR/HTSE system (Figure 3-8), a favored candidate for hydrogen production, this direct Rankine system looks much simpler. It is eventually expected to cause some capital cost reduction.

However, the following drawbacks are anticipated in this system.

\section{a. Hydrogen system contamination}

Since the secondary side and the hydrogen system are integrated as one loop, the radioactive materials can be easily released to the hydrogen production system. Tritium generated in the primary side will penetrate through the heat exchanger wall and directly mixed with the steam at the secondary side. To take care of this problem, some special measures are required at the secondary side.

\section{b. Secondary steam discharge}

In this system, the secondary working fluid is continuously released to the environment through hydrogen production system. We can put another intermediate exchange loop between primary and 
secondary side to prevent this situation, but it will make the system more complicated and reduce the efficiency.

\section{c. Thermal stress}

In this system, since the feed water temperature at the steam generator is too low (around $100^{\circ} \mathrm{C}$ ), sharp temperature gradient in the heat exchanger is expected. It might cause continuous thermal stress on the heat exchanger causing some problems.

\section{d. Steam corrosion}

Usually, steam is much corrosive at high temperature. In this system, some components like turbines and heat exchangers are operated at around $900^{\circ} \mathrm{C}$, so they are placed in the severely corrosive environment.

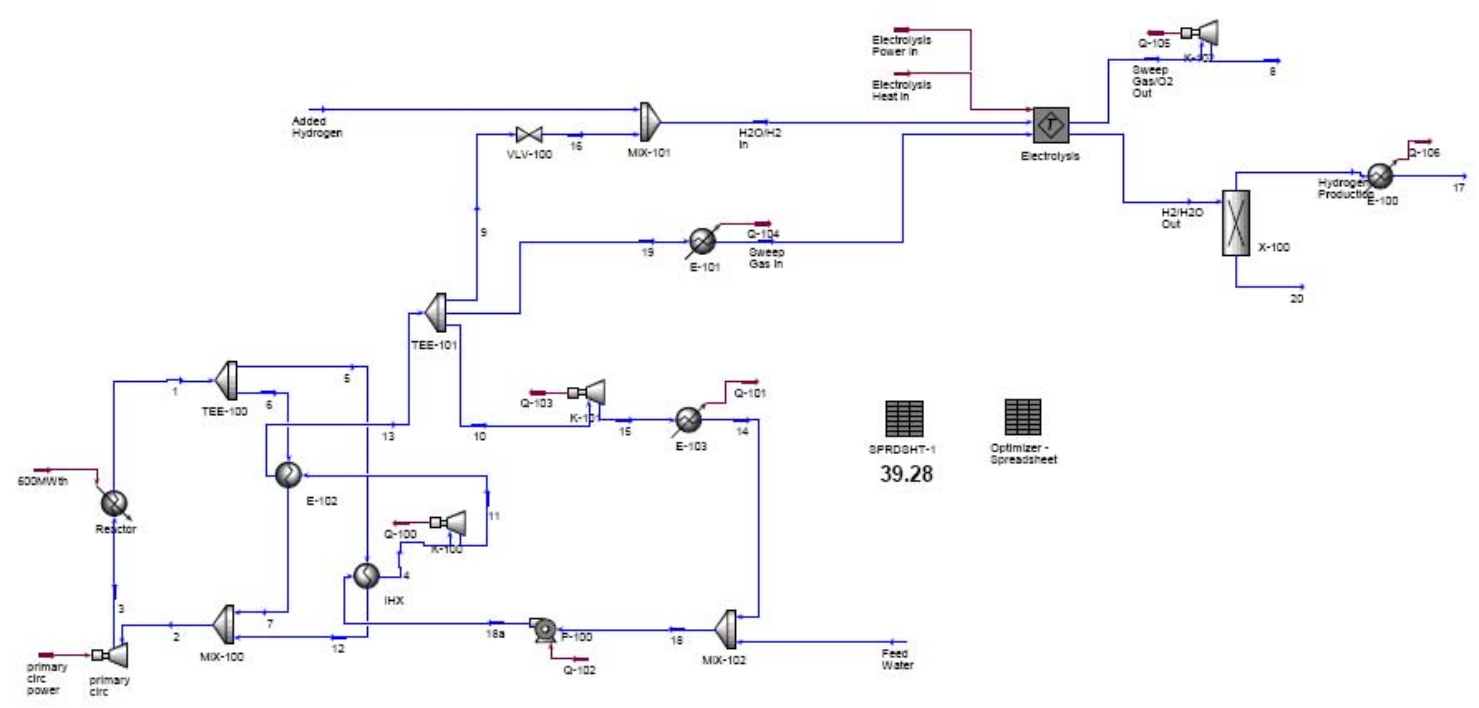

Figure 3-3. HTSR/HTSE Configuration 1 (39.28\%). 


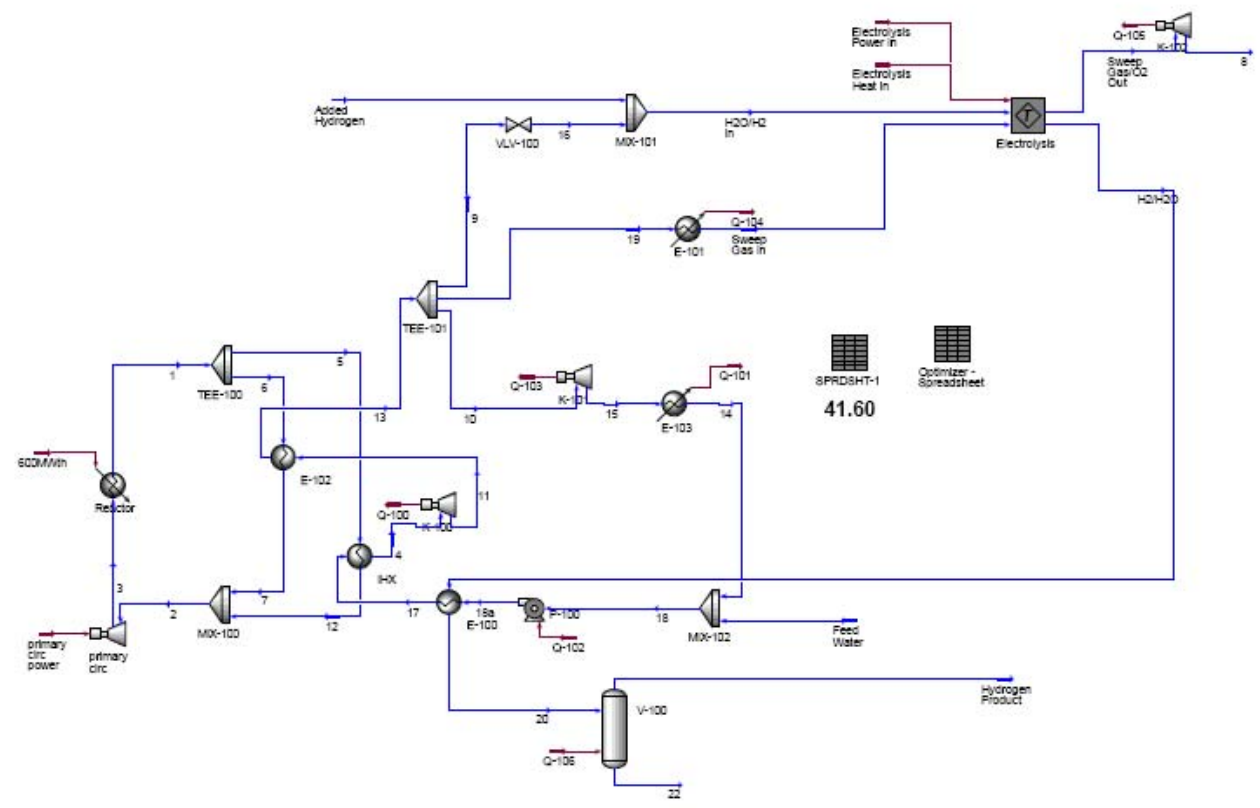

Figure 3-4. HTSR/HTSE Configuration 2 (41.60\%).

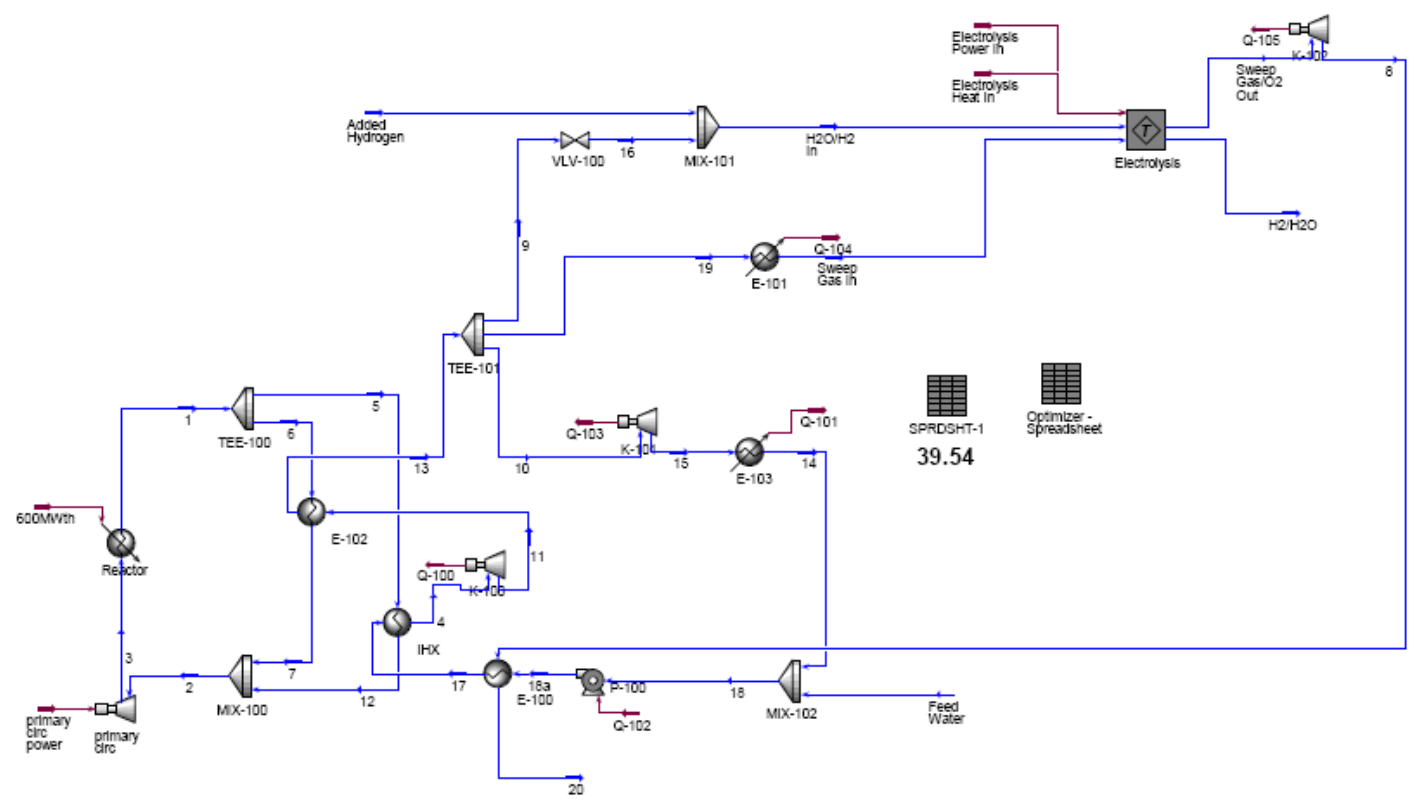

Figure 3-5. HTSR/HTSE Configuration 3 (39.54\%). 


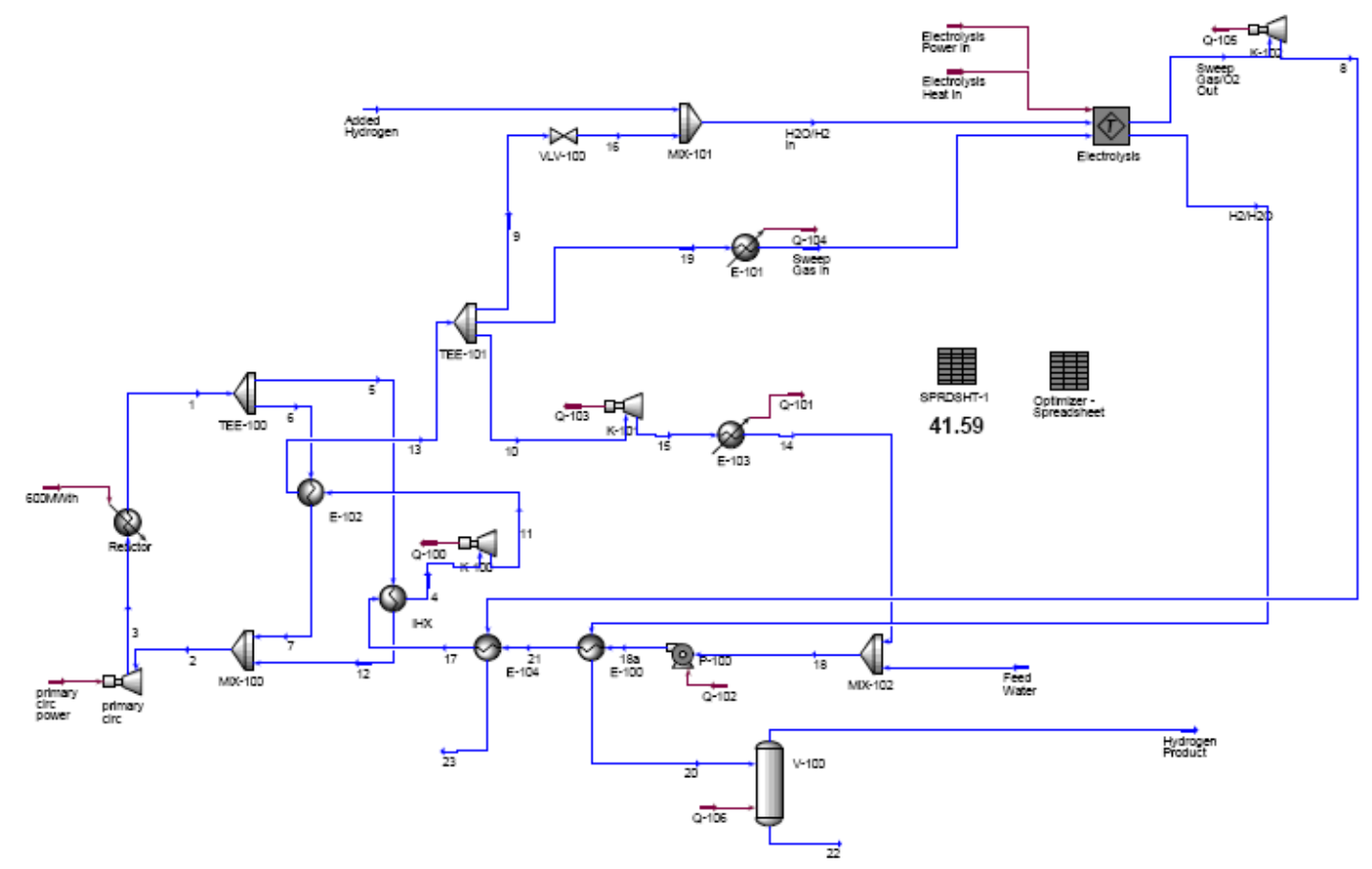

Figure 3-6. HTSR/HTSE Configuration 4 (41.59\%).

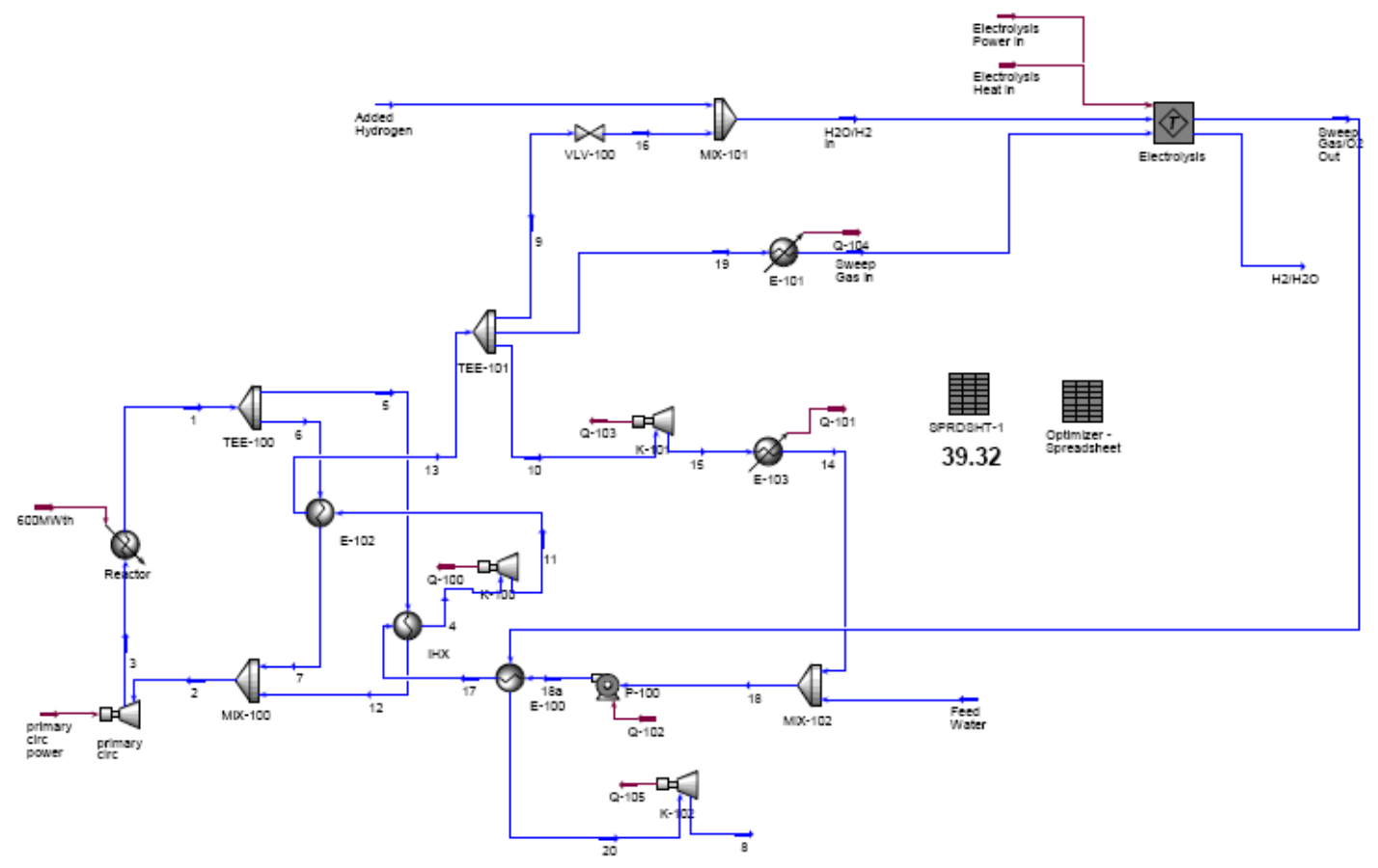

Figure 3-7. HTSR/HTSE Configuration 5 (39.32\%).

Figure 3-8 shows the VHTR/HTSE system using helium as primary coolant. This system shows much higher efficiency than the HTRC/HTSE system, since it is adapting gas Brayton cycle. For the helium primary coolant, the efficiency is reached up to $48 \%$, and for the molten salt coolant, up to $50 \%$. It has a simple PCU configuration, but a complicated HTSE system, which is necessary to maximize heat recovery from high temperature $\mathrm{H}_{2} / \mathrm{H}_{2} \mathrm{O}$ mixture and sweep gas. Therefore, VHTR/HTSE system is 
expected to require more capital cost than HTRC/HTSE system. For better estimation, more detail cost analysis is required.

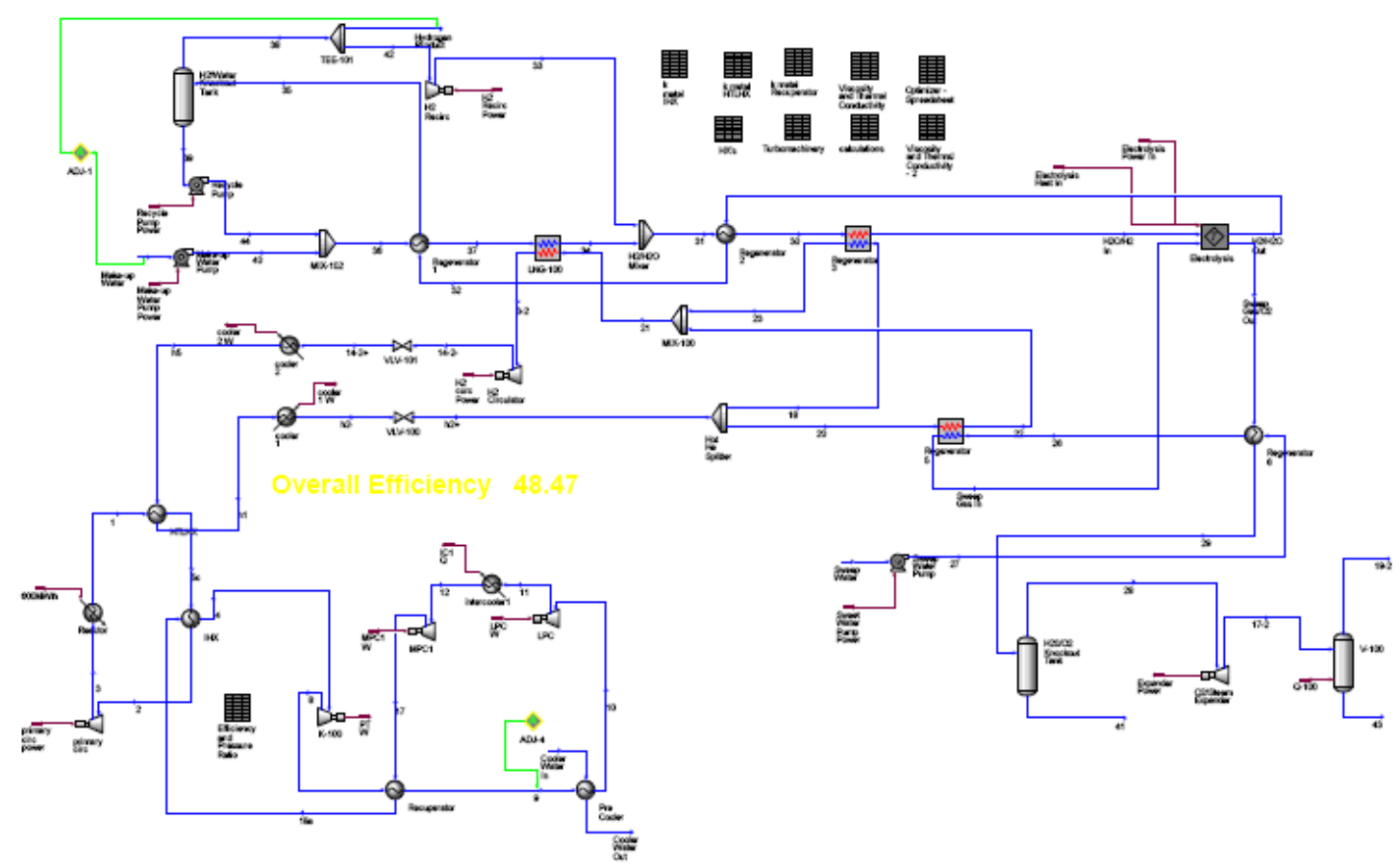

Figure 3-8. VHTR/HTSE Configuration 1 (48.47\%).

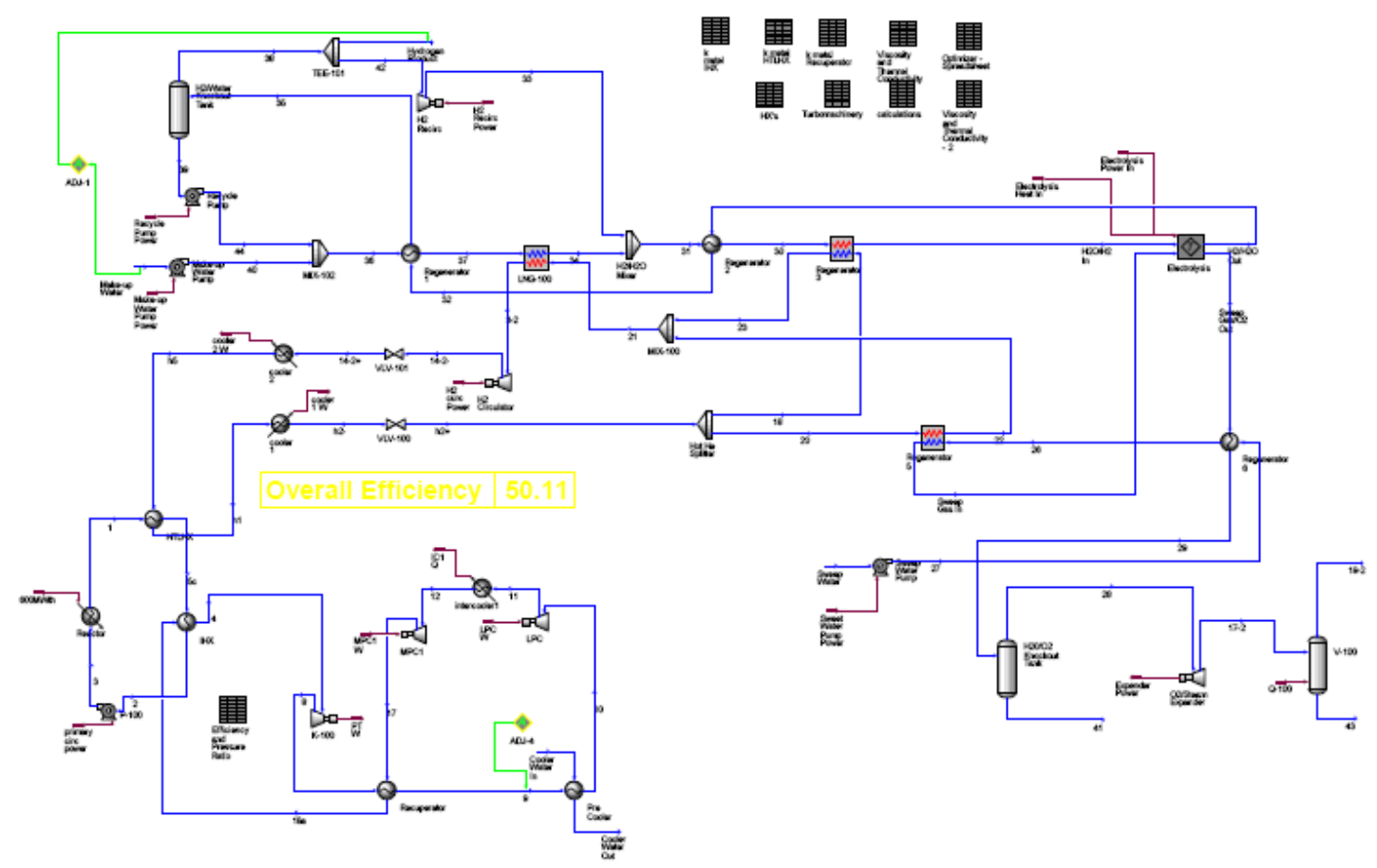

Figure 3-9. VHTR/HTSE Configuration 2 (50.11\%) 


\subsection{Integration of VHTR and SI Process Plant}

The US Department of Energy is investigating the use of a Very High Temperature Gas-Cooled Reactor (VHTR) to power the production of hydrogen via a thermo chemical Sulfur-Iodine Process (SI Process). Hydrogen production processes are still in the early stages of development and coupling this process to a nuclear reactor requires suffice separation between facilities to ensure abnormal behavior of the hydrogen production facility does not affect the safety of the nuclear power plant. An intermediate heat transfer loop is required to transport the energy from the nuclear plant's reactor to a series of reactions that constitute the SI process. The combination of a nuclear power plant with a hydrogen production facility is proposed as one of the designs for the Next Generation Nuclear Plant (NGNP).

The heat generation loop and the heat transfer loops were integrated into the Aspen Plus ${ }^{\circledR}$ SI model created by General Atomics (GA). Helium was used as the working fluid in the heat transfer loop from the nuclear reactor. The original model contained heaters, coolers, and other types of blocks with specified or calculated heat duties. The energy supplied to the system was ambiguously added through these blocks. Replacing the heaters and coolers with heat exchangers allowed the SI process model to also demonstrate the transfer of heat from the helium to the process streams. Hot helium was used to heat streams via heat exchangers in place of heaters while a combination of cool helium and cooling water was used to cool streams to the appropriate temperatures. Sensitivity analyses were used vigorously to minimize the heat lost to water and to increase the system's efficiency. The heat generation loop based off a HYSYS ${ }^{\circledR}$ example was created in Aspen Plus ${ }^{\circledR}$ to supply hot helium to the heat transfer loops. It also validated Aspen Plus ${ }^{\circledR}$ as a useful tool in modeling the SI process. Once the system is fully integrated and pieced together, the Balance of Plant (BOP) will be analyzed.

The original GA model was broken up into three sections, each focusing on a different step in the SI process. The project aims to create a heat generation loop and integrate it into the GA's SI process model. This report focuses on the creation of the Aspen Plus ${ }^{\circledR}$ heat generation, the integration of heat transport loops into the GA model, and some background research. Key milestones in this project are:

$\checkmark$ SI Process Steps Heat of Reactions Research

$\checkmark$ Development of the Heat Generation Loop in ASPEN PLUS ${ }^{\circledR}$

$X$ Helium Heat Loop Integration into:

$\checkmark$ Sulfuric Acid Decomposition GA Model

X Section III GA Model

$\mathrm{X}$ Combination of all parts into operating entire SI flow sheet

$\mathrm{X}$ System Optimization

$\mathrm{X}$ Balance of Plant Analysis Investigation

Key:

$\checkmark$ Completed

$\mathrm{X}$ Not Completed

This project thus far: (1) describes key assumptions regarding the high-temperature reactor and helium flow rates; (2) evaluates fundamental values for each step of the SI process to allow accurate efficiency calculations; (3) illustrates the construction of the heat generation loop in Aspen Plus ${ }^{\circ}$; (4) identifies strategies behind configurations for each section's heat transfer loop; (5) explains evaluations to find the most efficient setup for each section's heat transfer configuration; and (6) elaborates on the integration of helium heat transport into GA's sulfuric acid decomposition model. 


\subsubsection{Key Requirements and Assumptions}

Three temperature assumptions were required for the results obtained thus far in this analysis. These include the outlet stream temperature of the high-temperature reactor, the outlet temperature of the heat generation loop, and the maximum temperature required by the hydrogen production facility. The NGNP was assumed to produce $600 \mathrm{MW}$ of thermal power. The pressure assumed within the reactor was $7 \mathrm{MPa}$. The outlet temperature of the reactor was assumed to be $900^{\circ} \mathrm{C}$. The heat generation loop provides extra safety by putting a buffer between the nuclear reactor and the hydrogen production plant. The helium in direct contact with the nuclear reactor is contained within its own loop, such that it is never mixed or interchanged with the helium used to transport energy between the NGNP and the hydrogen production facility. According to Davis et al. (2005), the heat generation loop is expected to have an output stream of helium headed to the hydrogen production facility at $875.1^{\circ} \mathrm{C}$ and $19 \mathrm{~kg} / \mathrm{s}$. Also from the literature, heat loss during transport accounts for the $850^{\circ} \mathrm{C}$ entrance temperature into the hydrogen production facility.

Table 1. Analysis Assumption

\begin{tabular}{|l|c|}
\hline Parameter & Nominal Value \\
\hline & \\
\hline NGNP: & 600 \\
\hline Power, MW & 900 \\
\hline Outlet Temperature, ${ }^{\circ} \mathrm{C}$ & 7 \\
\hline Pressure, MPa & 0.05 \\
\hline IHX Pressure Drop, $\mathrm{MPa}$ & 231.24 \\
\hline IHX Temperature Drop, ${ }^{\circ} \mathrm{C}$ & \\
\hline & \\
\hline Heat Generation Loop: & 875.1 \\
\hline Outlet Temperature, ${ }^{\circ} \mathrm{C}$ & \\
\hline & \\
\hline Hydrogen Production & 850 \\
\hline Inlet Temperature,${ }^{\circ} \mathrm{C}$ & \\
\hline
\end{tabular}




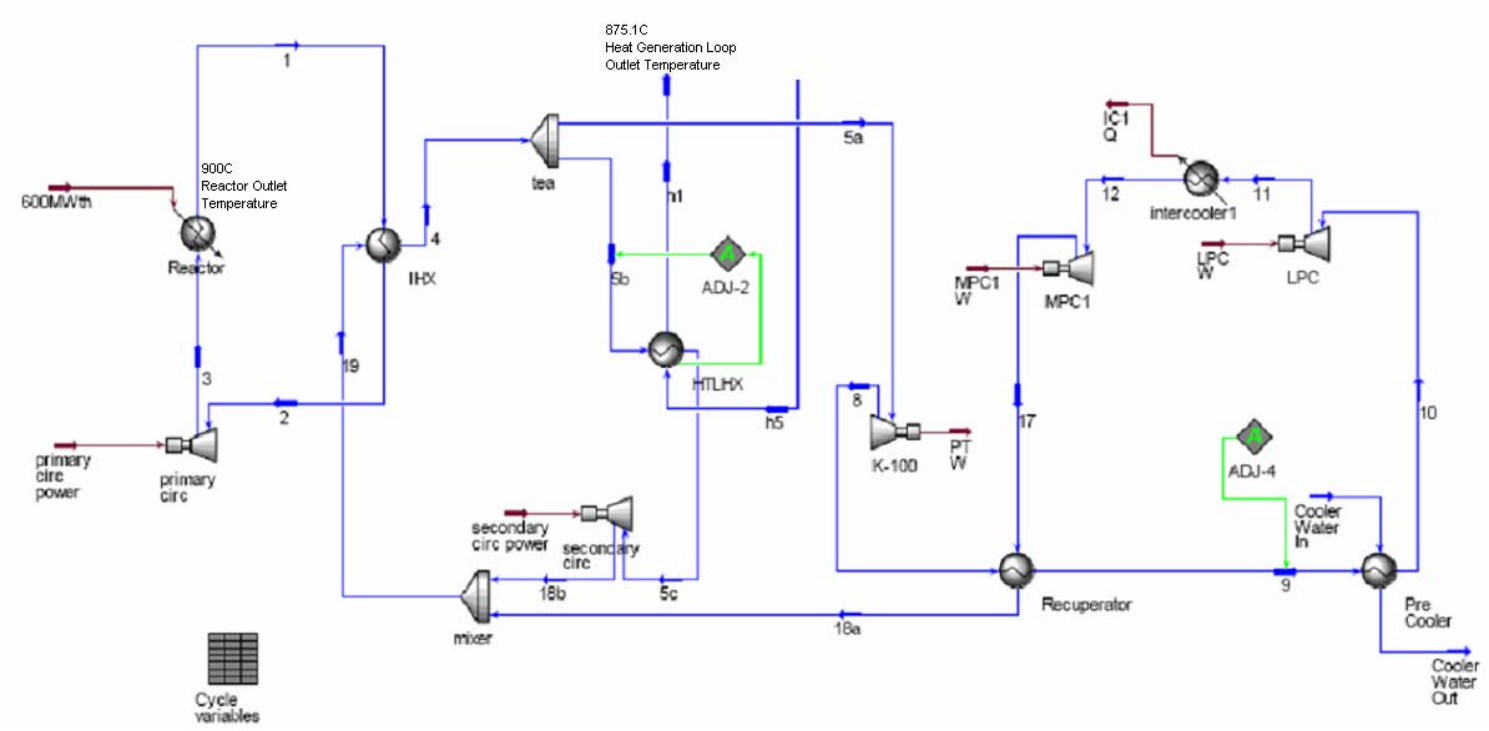

Figure 3-10. HYSYS ${ }^{\circledR}$ model of the Heat Generation Loop

\subsubsection{Heat Generation Loop}

The heat generation loop's purpose is to transfer heat effectively and safely from the NGNP reactor to the streams to the SI process. The process heat that is eventually utilized by the SI process travels from the reactor through two heat exchangers before exiting the loop. There are two main circular streams within the heat generation loop. The reactor heats helium which is then transferred via a heat exchanger. Within this heat exchanger the heat is transferred to another closed-loop helium stream. Only heat is exchanged between these two internal loops. Both parts are closed cycles that separate the helium that comes in contact with the reactor core from the rest of the system.

The heat generation loop was also created to validate Aspen Plus ${ }^{\circledR}$ as an appropriate modeling program for the SI process. An accepted example created in HYSYS ${ }^{\circledR}$ code was readily available to build this model. Stream and block data comparisons proved that Aspen Plus ${ }^{\circledR}$ could be used as a simulation engine for the SI process. Some slight variations occurred between the two models, requiring further investigation.

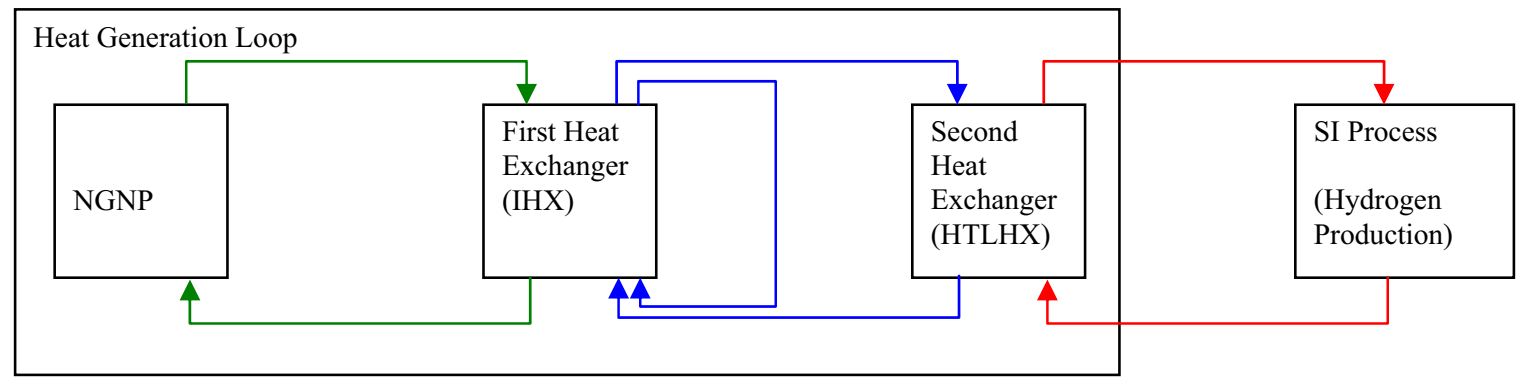

Figure3-11. Simplified Heat Generation Loop Model

The exiting stream from the NGNP is $900^{\circ} \mathrm{C}$. The cool stream of the first heat exchanger is warmed to $885^{\circ} \mathrm{C}$ by the reactor's output which is cooled to $668.76^{\circ} \mathrm{C}$. The warmed stream now is split up such that 
only $4.05 \%$ goes to the next heat exchanger. At the next heat exchanger, the stream headed for the SI process is heated to $875.1^{\circ} \mathrm{C}$. Meanwhile, the other $95.95 \%$ heads to satisfy the other purpose of the NGNP. It goes to a turbine to produce $501100 \mathrm{~kW}(501.1 \mathrm{MW})$ of electrical power. The rest of the heat generation loop pressurizes the streams and sends them back to the first heat exchanger.

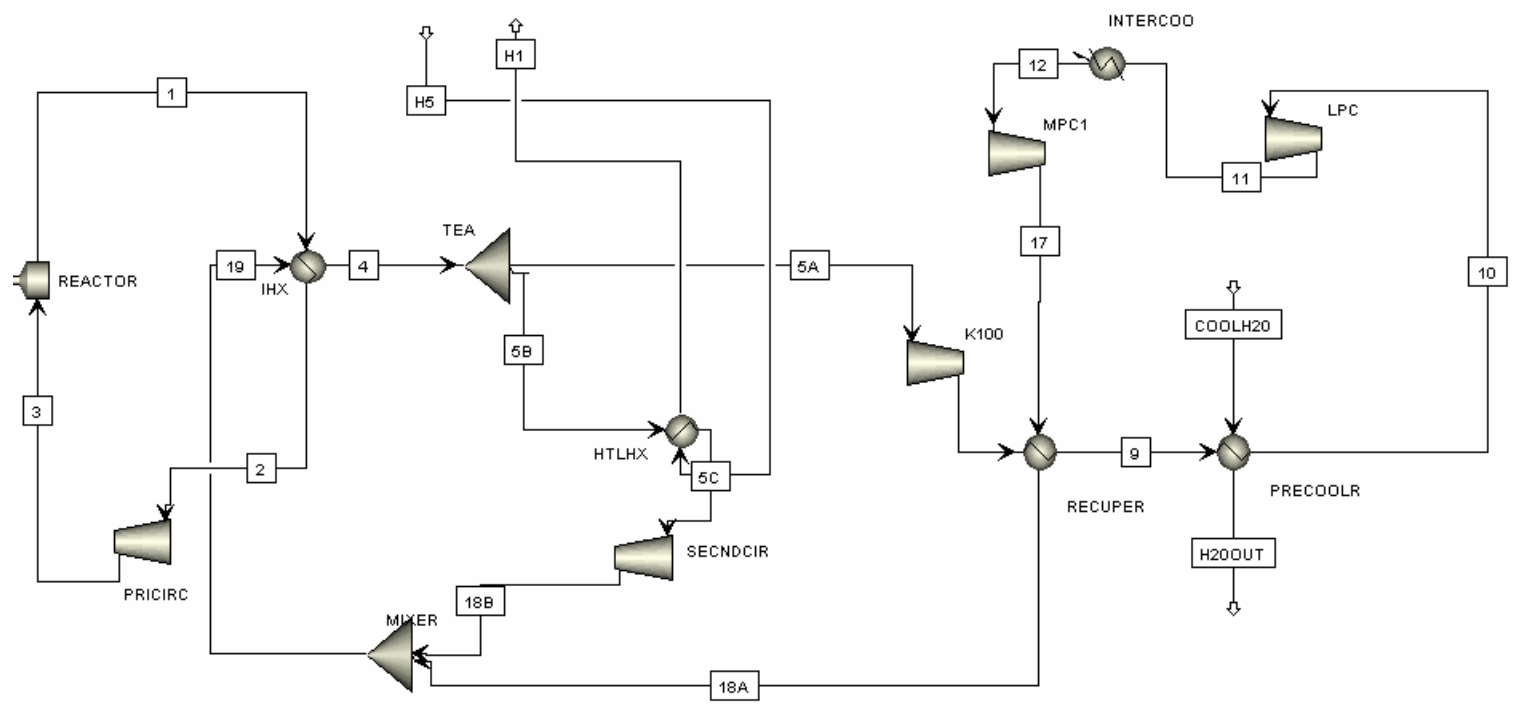

Figure 3-12. Aspen Plus ${ }^{\circledR}$ Heat Generation Loop Model

\subsubsection{Heat Transfer Models}

The purpose of the heat transfer models is to modify the GA SI process models to reflect the use of hot helium as an energy supply. Basic strategies are implemented in order to add in the hot helium streams. The heat from the helium will be used to vary the temperatures in all three sections while supplying the driving force behind both endothermic decomposition reactions. For clarity in such a complex system, the helium heat streams were colored red and cooling water streams were colored blue while the original process streams were left black. Figure 3-13 shows the SI process helium heat transfer loop.

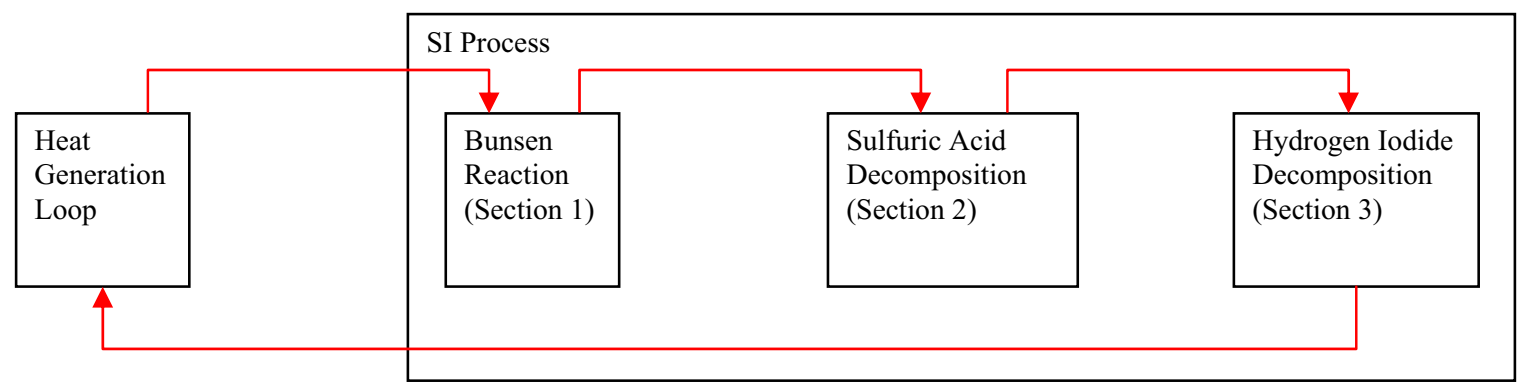

Figure 3-13. SI Process Helium Heat Transfer Loop

In order to recover some of the heat lost during the cooler blocks, the helium streams were split up to have a lower mass flow. With this lower mass flow, the streams encountered a larger temperature change in heat exchangers where they are on the hot side. By adjusting the mass flow to reflect an appropriate temperature change, these streams were used on the cold side of the next heat exchanger they 
encountered. There they reacquire heat that otherwise would have been lost from the system. If the stream had not been split up and still used to heat another fluid, the helium's exiting temperature would not be low enough to be able to acquire heat from a cooler.

Sulfuric Acid decomposition is the step in the SI process that produces the product oxygen and catalyst sulfur dioxide. It is an endothermic reaction that occurs at high temperatures. The GA sulfuric acid decomposition model was equilibrium based. It had input describing the $\mathrm{K}$ value at equilibrium based on temperature built into its Aspen Plus ${ }^{\circledR}$ code. The system ranged in temperature from $40^{\circ} \mathrm{C}$ to $900^{\circ} \mathrm{C}$. This model was worked on first because of its relative simplicity and its priority for heat. The sulfuric acid decomposition step is by far the most endothermic of all of the SI process steps. Due to this need for high temperatures, this step was designed to be heated first. It required the hottest possible stream of helium directly from the heat generation loop.

The original GA flow sheet contained many heaters and coolers to change the thermodynamic properties of the streams. These blocks ambiguously added and removed heat from the streams based on their settings and heat duties. In order to make the heat transfer from the helium to the streams, the flow sheet was edited to include heat exchangers either before the blocks that contained heat duties or replaced the heaters and coolers altogether. In total, ten heat exchangers were added to facilitate the transfer of heat from the helium.

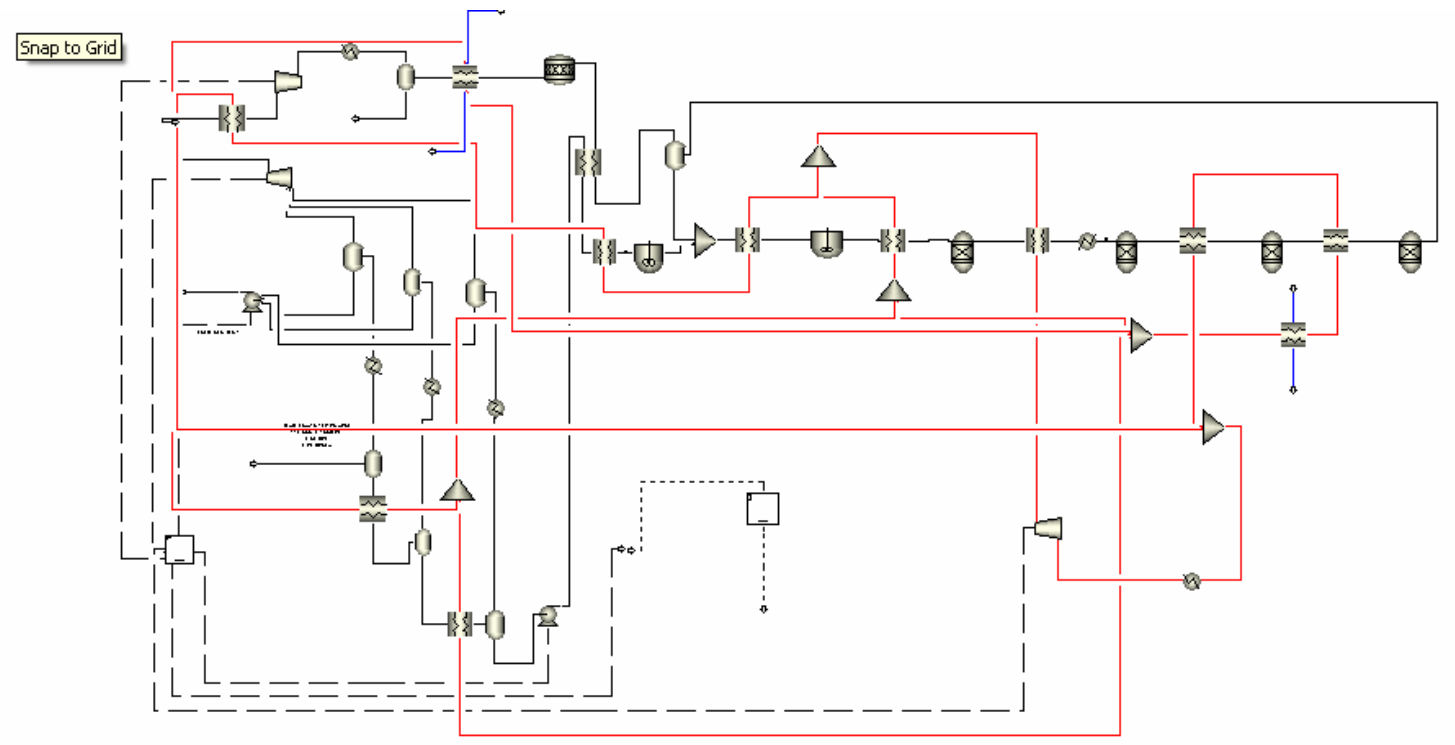

Figure 3-14. Completed GA Sulfuric Acid Decomposition Model with Helium Heating

During the initial setup, the streams were sorted based on temperature, such that the streams requiring the hottest outlet temperatures were heated first. However, it was quickly realized that the $19 \mathrm{~kg} / \mathrm{s} \mathrm{of} 850^{\circ} \mathrm{C}$ helium sustained a negligible temperature changes as it lost heat to the process fluid. Nevertheless, the streams were still ranked from highest outlet temperature to lowest to allow an increase in molar flow of the process without having to redesign the heating/cooling system. If the system was amplified by increasing the molar feed flow and products, this design should be able to be finely tuned to account for the changes due to its priority heating order.

There remains one heater directly involved in heating the process fluid. According to Davis et al. (2005), the heat transfer loops can only deliver a maximum of $850^{\circ} \mathrm{C}$ to the hydrogen production plant. The GA 
model requires $900^{\circ} \mathrm{C}$ for one of its equilibrium based reactors, meaning that the heater is required to increase the process fluid after a heat exchanger with the hottest helium by a minimum of $50^{\circ} \mathrm{C}$.

The heat generation loop was constructed in Aspen Plus ${ }^{\circledR}$ considering the stream characteristics and block layout of a provided HYSYS ${ }^{\circledR}$ model. Benefits of creating an Aspen Plus ${ }^{\circledR}$ heat generation loop model include additional details on stream properties and its ability to be integrated into the entire GA SI system. The Aspen Plus ${ }^{\circledR}$ model was created also to validate Aspen Plus ${ }^{\circledR}$ as a legitimate program to use to model the SI process. 


\section{OPTIMAL SIZING OF HEAT EXCHANGER}

In the integrated system of VHTR and HTSE, an intermediate heat exchanger (IHX), which transfers heat from the reactor core to the electricity or hydrogen production system is one key component, and its effectiveness is directly related to the system overall efficiency. In the VHTRs, the gas fluids used for coolant generally have poor heat transfer capability, so it requires very large surface area for a given conditions. For this reason, a compact heat exchanger (CHE), which is widely used in industry especially for gas-to-gas or gas-to-liquid heat exchange is considered as a potential candidate for a IHX replacing the classical shell and tube type heat exchanger. A compact heat exchanger is arbitrary referred to be a heat exchanger having a surface area density greater than $700 \mathrm{~m}^{2} / \mathrm{m}^{3}$. The compactness is usually achieved by fins and micro-channels, and leads to the enormous heat transfer enhancement and size reduction.

In the current study, we focused on the optimum sizing and cost for CHEs. The cost of a heat exchanger can be described as the summation of capital cost and operating cost. The capital cost is associated with the heat exchanger size, and the operating cost is associated with pumping power. Generally, the capital and operating costs are competitive. For example, if the size of a heat exchanger is reduced for lower capital cost, the more operating cost should be paid for due to the increased pressure drop. Therefore, the size of the heat exchanger should be carefully determined from the economic aspect. Until recently, research has been carried out for estimation of CHE heat performance and friction loss, but little attention has been given to the optimum size and cost in utilizing it in the real system. In this study, we developed an analytic model for the optimum size of the compact heat exchangers, and evaluated them for VHTR systems.

\subsection{Determination of Characteristic Parameters}

Kays and London (1984) characterized compact heat exchangers by the following geometrical parameters.

$$
\begin{aligned}
& L: \text { CHE length } \\
& H: \text { CHE height and width } \\
& V: \text { Volume of CHE }\left(V=H^{2} \cdot L\right) \\
& A_{f}: \text { Frontal area }\left(A_{f}=H^{2}, A_{f, h}=0.5 A_{f}, A_{f, c}=0.5 A_{f}\right) \\
& A: \text { Flow area }\left(A_{h}=0.5 A, A_{c}=0.5 A\right) \\
& \beta: \text { Surface area density } \\
& \sigma: \text { Ratio of the free flow area to the frontal area }\left(\sigma=A / A_{f}\right) \\
& S: \text { Heat transfer surface }\left(S=\beta \cdot V, S_{h}=0.5 S, S_{c}=0.5 S\right) \\
& d_{e}: \text { Equivalent diameter }\left(d_{e}=4 A L / S\right)
\end{aligned}
$$

All the heat transfer and friction factor calculations are based on the above geometrical parameters. Among the various types of compact heat exchangers, the PCHE manufactured by HEATRIC was investigated in this study. A PCHE is a type of compact heat exchanger, which consists of many plates into which the channels are chemically etched, followed by diffusion bonding to form a monolithic block. Figure 4-1 shows the cut through cross section of the typical PCHE showing the shape of the channels. 


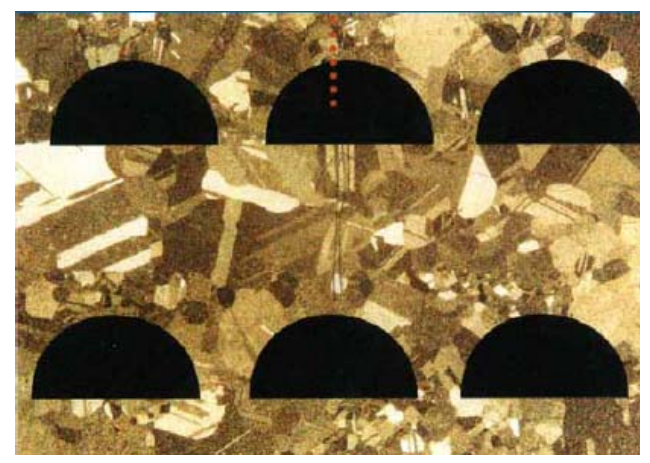

Figure 4-1 Picture of a PCHE cross section (Dewson and Grady, 2003)

Main configuration parameters for PCHE, can be calculated by the basic geometrical variables as the typical heat exchangers (Kakac (2002), Bajan and Klaus (2003)).

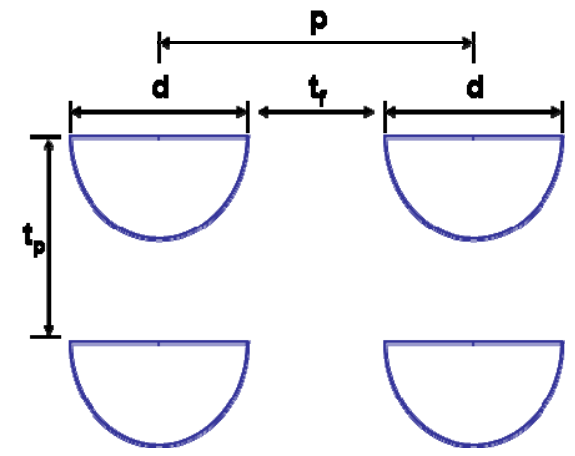

(a) cross section (front view)

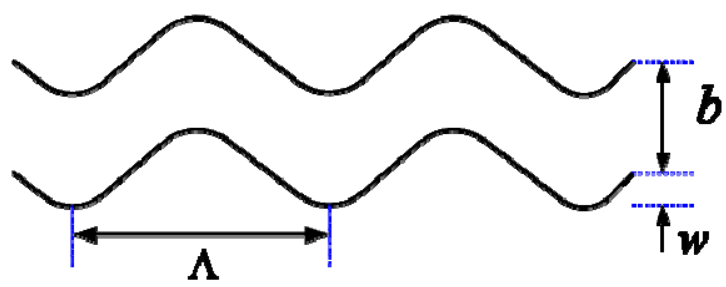

(b) channel side view

Figure 4-2 Illustration PCHE channels

Figure 4-2 shows the front section and side view of PCHE channel. In this figure, each symbol represents the followings.

$d$ : channel diameter $(\mathrm{m})$

$p:$ pitch of channel (m)

$t_{p}:$ plate thickness (m)

$t_{f}:$ fin thickness $(\mathrm{m})$

$\Lambda$ : wave length (m) 
$b:$ channel width $(\mathrm{m})-(b=d$ for PCHE $)$

\subsubsection{Wall thickness $\left(t_{f}\right)$ and pitch $(p)$}

Hesselgreaves (2001) recommends the following formula for the minimum wall thickness.

$$
t_{f}=\frac{1}{\left(\frac{\sigma_{D}}{\Delta P}+1\right) N_{f}}
$$

where:

$t_{f}:$ minimum wall thickness

$\sigma_{D}:$ maximum allowable stress

$\Delta P$ : pressure differential between hot and cold fluid

$N_{f}$ : number of fins per meter

In the PCHE, the number of fins per meter means the number of channel walls per meter (Dostal et al. 2004). Therefore,

$$
N_{f}=\frac{1}{p}
$$

According to Figure 4-2, the pitch ( $p$ ) of the heat exchanger channel can be expressed as follows,

$$
p=d+t_{f}
$$

By inserting Eq (4-2) and (4-3) into Eq (4-1), the following equation can be obtained.

$$
t_{f}=\left(\frac{\Delta P}{\sigma_{D}}\right) \cdot d
$$

This equation shows that the channel wall thickness is proportional to the design pressure and channel diameter.

\subsubsection{Surface area density $(\beta)$ and Ratio of free flow area to frontal area $(\sigma)$}

The surface area density in the PCHE can be determined as follows.

$$
\beta=\frac{S}{V}=\frac{(0.5 \cdot \pi \cdot d+d) \cdot L}{\left(d+t_{f}\right) \cdot\left(t_{p}\right) \cdot L}=\frac{(2 \cdot \pi \cdot d+d)}{\left(d+t_{f}\right) \cdot\left(t_{p}\right)}
$$

The ratio of free flow area and frontal area is determined as follows. 


$$
\sigma=\frac{\frac{\pi}{8} d^{2}}{\left(d+t_{f}\right) \cdot\left(t_{p}\right)}
$$

\subsubsection{Hydraulic diameter $\left(d_{e}\right)$}

The hydraulic diameter of PCHE can be determined by the following equation.

$$
d e=\frac{4 A}{P}=\frac{4 \cdot \frac{\pi}{8} d^{2}}{\frac{\pi d}{2}+d}=\frac{\pi d}{\pi+2}
$$

\subsubsection{Waviness $\left(\frac{b}{\Lambda}\right)$}

The waviness of the PCHE can be determined by

$$
\text { Waviness }=\frac{b}{\Lambda}
$$

For PCHE, $b$ equals to channel diameter $(d)$ in Figure 4-2.

\subsubsection{Determination of the reference configuration parameters and properties}

Table 2 summarizes the configuration parameters and properties for the reference PCHE. In this study, the reference diameter was selected to be $0.002 \mathrm{~m}$, which is recommended by HEATRIC. They found for most application that the economic thermal performance optimum channel diameter to be $2 \mathrm{~mm}$ (Dewson et al. (2003), Dostal et al. (2004)). The pitch and plate thickness were determined by Eq. (4-1) through (44). For this calculation, the minimum plate thickness $\left(t_{p}\right)$ between channels was determined to be $1.5 \mathrm{~mm}$ by recommendation of HEATRIC (Dewson et al., 2003). Finally, the calculated pitch and fin thickness were 0.0024 and $0.0015 \mathrm{~m}$, respectively. Based on the basic geometrical parameters, the characteristic parameters for a compact heat exchanger were obtained. The surface area density and ratio of free flow to frontal area were calculated to be $1714 \mathrm{~m}^{2} / \mathrm{m}^{3}$ and 0.52 by Eq. (4-5) and (4-6), respectively. The allowable stress is assumed to be $10 \mathrm{MPa}$, which is approximately half of the rupture strength of Alloy 617 at 900 ${ }^{\circ} \mathrm{C}$. Density of Alloy 617 is $7890 \mathrm{~kg} / \mathrm{m}^{3}$. 
Table 2. Configuration parameters and properties for the reference PCHE

\begin{tabular}{lcc}
\hline \multicolumn{1}{c}{ Parameters } & unit & Values \\
\hline \hline Diameter $(d)$ & $\mathrm{m}$ & 0.002 \\
Pitch $(p)$ & $\mathrm{m}$ & 0.0024 \\
Plate thickness $\left(t_{p}\right)$ & $\mathrm{m}$ & 0.0015 \\
Fin thickness $\left(t_{f}\right)$ & $\mathrm{m}$ & 0.0004 \\
Surface area density $(\beta)$ & $\mathrm{m}^{2} / \mathrm{m}^{3}$ & 1714 \\
Ratio of free flow to frontal area $(\sigma)$ & & 0.52 \\
Pins per meter $\left(N_{f}\right)$ & $\# / \mathrm{m}$ & 417 \\
Density $\left(\rho_{\text {metal }}\right)$ & $\mathrm{Kg} / \mathrm{m}^{3}$ & 7850 \\
Allowable stress $\left(\sigma_{D}\right)$ & $\mathrm{MPa}$ & 10 \\
\hline
\end{tabular}

\subsection{Scaling Analysis of Compact Heat Exchanger Size and Cost}

In the compact heat exchanger, two costs are competitive; (1) Capital cost, and (2) Operating cost. For example, the increase of flow area enhances the heat transfer capacity increasing flow velocity, but it requires more pumping power increasing the pressure drop. Therefore, the size of heat exchanger should be determined under consideration of various economic factors. In this section, we qualitatively investigated the relationship between the size and the total cost by scaling analysis. This qualitative study helps us understand how each thermal hydraulic and economic parameter is connected together.

\subsubsection{Heat Transfer}

To assess the cost of a heat exchanger, it is important fist to evaluate the heat transfer since it is highly related to its size. The heat transfer in the heat exchanger is expressed by the following equation.

$$
Q=U \cdot S \cdot \theta_{m}
$$

where:

$Q:$ total transferred heat

$U$ : overall heat transfer coefficient

$S:$ heat transfer surface area

$\theta_{m}: \log$ mean temperature

Therefore, the surface area is written as

$$
S=\frac{Q}{U \cdot \theta_{m}}
$$

Since the values of $Q$ and $\theta_{m}$ are fixed in the design condition, the surface area is proportional to the inverse of the overall heat transfer coefficient. 


$$
S \propto \frac{1}{U}
$$

In the compact heat exchanger, since heat transfer surface area is proportional to the volume, the following relation is formed.

$$
S \propto V \text { and } U \propto h \propto h_{h} \propto h_{c}
$$

where:

$V$ : compact heat exchanger volume

$h_{h}$ : heat transfer coefficient of hot channel

$h_{c}$ : heat transfer of cold channel

Therefore, the volume is inversely proportional to the heat transfer coefficient.

$$
V \propto \frac{1}{h}
$$

Generally, the heat transfer correlation can be expressed as follows,

$$
N u=\frac{h \cdot d_{e}}{k}=b \operatorname{Re}^{b} \operatorname{Pr}^{c}
$$

And, the Reynolds number and Prandtl number in the compact heat exchanger are defined by

$$
\operatorname{Re}=\frac{d_{e} G}{\mu}=\frac{d_{e} \dot{m}}{A \mu},
$$

and

$$
\operatorname{Pr}=\frac{C_{p} \cdot \mu}{k} .
$$

Where

$$
\begin{aligned}
& \dot{m}: \text { Mass flow rate }(\mathrm{kg} / \mathrm{s}) \\
& A: \text { flow area }\left(\mathrm{m}^{2}\right) \\
& \mu: \operatorname{Viscosity}(\mathrm{Pa} \mathrm{m}) \\
& C_{p}: \text { Heat capacity }(\mathrm{J} / \mathrm{kg} \mathrm{K}) \\
& k: \text { Thermal conductivity }(\mathrm{W} / \mathrm{m} \mathrm{K})
\end{aligned}
$$

Therefore, the Eq (4-13) can be rearranged as follows,

$$
h=\left[\left(\frac{b k}{d_{e}}\right)\left(\frac{d_{e} \cdot \dot{m}}{\mu}\right)^{b} \operatorname{Pr}^{c}\right] \cdot A^{-b}=F_{1} \cdot A^{-b} .
$$

It means that 


$$
h \propto A^{-b} .
$$

If we relate Eq. (4-17) to Eq. (4-12), we obtain

$$
V \propto \frac{1}{h} \propto A^{b}
$$

It means the total volume of the heat exchanger is proportional to $A^{b}$. The total volume is proportional to the flow area multiplied by the length of the heat exchanger,

$$
\begin{aligned}
& V \propto A \cdot L, \\
& L \propto \frac{V}{A}
\end{aligned}
$$

Therefore,

$$
L \propto \frac{V}{A} \propto \frac{A^{b}}{A} \propto A^{b-1} .
$$

\subsubsection{Friction Loss}

The friction loss is an important factor because higher friction loss requires more pumping power consuming additional operating cost. The friction loss in the compact heat exchanger is generally expressed by

$$
\Delta P=f \frac{G^{2}}{2 \rho} \frac{S}{A}=f \frac{G^{2}}{2 \rho} \frac{4 L}{d_{e}} .
$$

Where

$\Delta P:$ Pressure drop $(\mathrm{Pa})$

$f:$ Friction factor

$\rho:$ Density of flow $\left(\mathrm{kg} / \mathrm{m}^{3}\right)$

The general form of friction factor correlation is as follows,

$$
f=e \operatorname{Re}^{i}
$$

Inserting Eq. (4-24) into Eq. (4-23), the friction loss correlation can be rearranged as follows,

$$
\Delta P=\left[e\left(\frac{d_{e} \dot{m}}{\mu}\right)^{i}\left(\frac{\dot{m}^{2}}{2 \rho}\right)\left(\frac{4}{d_{e}}\right)\right] \cdot \frac{L}{A^{i+2}} .
$$

Therefore, 


$$
\Delta P \propto \frac{L}{A^{i+2}}
$$

If the length (L) in Eq. (4-26) is replaced with Eq. (4-22), it becomes

$$
\Delta P \propto \frac{L}{A^{i+2}} \propto \frac{A^{b-1}}{A^{i+2}} .
$$

Finally we obtains the following relation,

$$
\Delta P \propto A^{b-i-3} .
$$

\subsubsection{Cost of Compact Heat Exchanger}

To assess the total cost of a heat exchanger, it is important first to evaluate the capital cost $\left(C_{c}\right)$.

Generally, the cost of heat exchanger can be estimated based on its weight, and since the weight is proportional to the volume of the compact heat exchanger, the capital cost and volume of the heat exchanger can be related as follows.

$$
C_{c} \propto V
$$

From Eq (4-18), it becomes

$$
C_{c} \propto A^{b}
$$

Eq (4-30) means that the capital cost increases with flow area.

From Eq. (4-22), the length of the heat exchanger is related to the flow area as follows.

$$
L \propto A^{b-1}
$$

It means that the variation of the length is dependent on the value of the index, $b$.

(i) $\quad \mathrm{b}>1$ : $\mathrm{L}$ increases with flow area

(ii) $\quad b=1$ : L does not changes

(iii) $\quad \mathrm{b}<1$ : L decreases with flow area

According to the heat transfer references or handbooks (Bajan (2001), Heat Transfer Handbook), the index, $b$ is generally no more than unity. Therefore, we can consider that the increase of flow area leads to the decrease of heat exchanger length.

Heat exchanger operating cost can be assumed to be proportional to the pumping power.

$$
C_{o} \propto P_{\text {pumping }}
$$


Since the pumping power is proportional to the pressure drop,

$$
P_{\text {pumping }} \propto \Delta P
$$

It becomes

$$
P_{\text {pumping }} \propto \Delta P \propto A^{b-i-3}
$$

It means that the operating cost is the relation of flow area and indices $b$ and $i$.

$$
C_{o} \propto A^{b-i-3}
$$

According to this relation, the variation of the operating cost with the flow area is dependent on the two indices, $\mathrm{b}$ and $\mathrm{i}$, as follows.

(i) $\quad \mathrm{b}-\mathrm{i}-3>0: C_{o}$ increases with the flow area

(ii) $\quad \mathrm{b}-\mathrm{i}-3=0: C_{o}$ is not dependent on the flow area

(iii) $\quad \mathrm{b}-\mathrm{i}-3<0$ : $C_{o}$ decreases with the flow area

However, since the values of $b$ and $i$ are usually less than 1.00 according to the heat transfer references (Bajan (2001), Heat Transfer Handbook), the value of (b-i-3) can be considered to be less than zero. It means the operating cost of heat exchanger decreases with flow area.

In summary, the increase of flow area at the given duty and operating conditions, qualitatively, leads to the following consequences.

$$
A(\uparrow) \Rightarrow h(\downarrow) \Rightarrow U(\downarrow) \Rightarrow V(\uparrow) \Rightarrow L(\downarrow) \Rightarrow C_{c}(\uparrow) \Rightarrow \Delta P(\downarrow) \Rightarrow C_{o}(\downarrow)
$$

This relation shows that the increase of flow rate increases the capital cost but reduces the operating cost. Therefore, it means that there exists an optimum flow area to minimize the total cost. The total cost of the heat exchanger can be expressed by the summation of the capital cost and the operating cost.

$$
C_{\text {total }}=K_{1} \cdot A^{b}+K_{2} \cdot A^{b-i-3}
$$

To find out the optimum flow area, differentiation of Eq. (4-37) was obtained.

$$
\frac{d C_{\text {total }}}{d A}=K_{1} \cdot b \cdot A^{b-1}+K_{2} \cdot(b-i-3) \cdot A^{b-i-4}
$$

At the optimum point, since the differentiation is zero, it satisfies

$$
K_{1} \cdot b \cdot A_{o p t}^{b-1}+K_{2} \cdot(b-i-3) \cdot A_{o p t}^{b-i-4}=0 .
$$

Therefore, the optimum surface area can be written as 


$$
A_{o p t}=\left(\left(\frac{3-b+i}{b}\right) \cdot\left(\frac{K_{2}}{K_{1}}\right)\right)^{\frac{1}{3+i}}
$$

It means that the optimum flow area increases with the operating cost but decreases with the capital cost. If we determine $K_{1}$ and $K_{2}$, we can calculate the optimum surface area. The determination of those two parameters was explained in the next section.

\subsection{Optimum Sizing Model For Minimum Cost of Compact Heat Exchanger}

In this section, we developed the analytic model to determine the total cost and optimum heat exchanger size, and finally determined $K_{1}$ and $K_{2}$ in Eq. (4-25). In this study, it is assumed that the hot and cold channel has the same geometry and portion in the heat exchanger. So, the hot and cold channel properties can be expressed as follows.

(i) frontal area

$$
\begin{aligned}
& A_{f, h}=0.5 A_{f} \text { (hot channel) } \\
& A_{f, c}=0.5 A_{f} \text { (cold channel) }
\end{aligned}
$$

(ii) flow area

$A_{h}=0.5 A$ (hot channel)

$A_{c}=0.5 A$ (cold channel)

(iii) heat transfer surface

$S_{h}=0.5 A_{H}$ (hot channel)

$S_{c}=0.5 A_{H}$ (cold channel)

(iv) equivalent diameter

$d_{e, h}=d_{e}$ (hot channel)

$d_{e, c}=d_{e}$ (cold channel)

From Eq (4-10),

$$
S_{h}=0.5 A_{H}=\frac{Q}{U_{h} \cdot \theta_{m}}
$$

The overall heat transfer coefficient can be expressed as follows,

$$
U_{h}=\frac{1}{\frac{1}{h_{h}}+S_{h} R_{w}+\frac{S_{h}}{h_{c} S_{c}}}
$$


If we assume that the heat resistance of the CHE wall is negligible compared to the convective heat resistance, (usually, the heat resistance in the flow area is much larger than the solid wall (Song (2005)),

$$
U_{h} \approx \frac{1}{\frac{1}{h_{h}}+\frac{S_{h}}{h_{c} S_{c}}}
$$

Then,

$$
S_{h}=S_{c}=0.5 A_{H}
$$

Therefore, Eq (4-43) becomes

$$
U_{h} \approx \frac{1}{\frac{1}{h_{h}}+\frac{1}{h_{c}}} .
$$

The heat transfer coefficients is usually expressed as shown in Eq. (4-14),

$$
N u=\frac{h \cdot d_{e}}{k}=a \operatorname{Re}^{b} \operatorname{Pr}^{c}
$$

Therefore,

$$
\begin{aligned}
& h_{h}=\left[\left(\frac{a k_{h}}{d_{e}}\right)\left(\frac{d_{e} \cdot \dot{m}_{h}}{\mu}\right)^{b} \operatorname{Pr}_{h}^{c}\right] \cdot A_{h}^{-b}=\left[\left(\frac{a k_{h}}{d_{e}}\right)\left(\frac{d_{e} \cdot \dot{m}_{h}}{0.5 \mu}\right)^{b} \operatorname{Pr}_{h}^{c}\right] \cdot A^{-b}=F A C T 1 \cdot A^{-b} \\
& h_{c}=\left[\left(\frac{a k_{c}}{d_{e}}\right)\left(\frac{d_{e} \cdot \dot{m}_{c}}{\mu}\right)^{b} \operatorname{Pr}_{c}^{c}\right] \cdot A_{c}^{-b}=\left[\left(\frac{a k_{c}}{d_{e}}\right)\left(\frac{d_{e} \cdot \dot{m}_{c}}{0.5 \mu}\right)^{b} \operatorname{Pr}_{c}^{c}\right] \cdot A^{-b}=F A C T 2 \cdot A^{-b}
\end{aligned}
$$

If we insert Eq (4-47) and Eq (4-48) into Eq (4-45), the overall heat transfer coefficient can be expressed by

$$
U_{h}=\frac{1}{\frac{A^{b}}{F A C T 1}+\frac{A^{b}}{F A C T 2}}=\left(\frac{1}{\frac{1}{F A C T 1}+\frac{1}{F A C T 2}}\right) \cdot A^{-b}=F A C T 3 \cdot A^{-b} .
$$

From Eq (4-41), the heat transfer surface area of the compact heat exchanger is 


$$
S_{h}=0.5 A_{H}=\frac{Q}{U_{h} \cdot \theta_{m}}
$$

And

$$
A_{H}=\frac{2 \cdot Q}{U_{h} \cdot \theta_{m}}
$$

From the definition of surface area density (Eq. (4-5)), the volume of the CHE can be expressed by

$$
A_{H}=\beta \cdot V=\frac{2 \cdot Q}{U_{h} \cdot \theta_{m}}
$$

Therefore, the volume of the CHE volume becomes

$$
V=\frac{1}{\beta} \cdot \frac{2 Q}{F A C T 3 \cdot A^{-b} \cdot \theta_{m}}=\left(\frac{2 \cdot Q}{\beta \cdot F A C T 3 \cdot \theta_{m}}\right) \cdot A^{b}=F A C T 4 \cdot A^{b} .
$$

If we only consider the metal volume, the volume of metal can be expressed by

$$
V_{\text {Material }}=(1-\sigma) \cdot V=(1-\sigma) \cdot F A C T 4 \cdot A^{b} .
$$

Since the volume of the heat exchanger is

$$
V=A_{f r} \cdot L=\frac{A}{\sigma} \cdot L
$$

The length becomes

$$
L=\frac{\sigma}{A} \cdot V=\frac{\sigma}{A} \cdot F A C T 4 \cdot A^{b}=(\sigma \cdot F A C T 4) \cdot A^{b-1} .
$$

The friction loss of the heat exchanger is expressed by Eq. (4-23) and (4-24) as follows,

where

$$
\Delta P=f \frac{G^{2}}{2 \rho} \frac{S}{A}=f \frac{G^{2}}{2 \rho} \frac{4 L}{d_{e}}
$$

$$
f=f_{2}(\mathrm{Re})=e \operatorname{Re}^{i} .
$$

The hot channel pressure drop can be obtained by inserting Eq. (4-24) into Eq. (4-23),

$$
\Delta P_{h}=\left[e\left(\frac{d_{e} \dot{m}_{h}}{\mu_{h}}\right)^{i}\left(\frac{\dot{m}_{h}^{2}}{2 \rho_{h}}\right)\left(\frac{4}{d_{e}}\right)\right] \cdot \frac{L}{A_{h}^{i+2}}=\left[e\left(\frac{d_{e} \dot{m}_{h}}{0.5 \mu_{h}}\right)^{i}\left(\frac{\dot{m}_{h}{ }^{2}}{\rho_{h}}\right)\left(\frac{4}{d_{e}}\right)\right] \cdot \frac{L}{A^{i+2}}
$$

Replacing $L$ in Eq. (4-59) with Eq. (4-56), it becomes 


$$
\begin{aligned}
\Delta P_{h}=\left[e\left(\frac{d_{e} \dot{m}_{h}}{0.5 \mu_{h}}\right)^{i}\left(\frac{\dot{m}_{h}^{2}}{\rho_{h}}\right)\left(\frac{4}{d_{e}}\right)\right] \cdot \frac{(\sigma \cdot F A C T 4) \cdot A^{b-1}}{A^{i+2}} \\
=\left[e\left(\frac{d_{e} \dot{m}_{h}}{0.5 \mu_{h}}\right)^{i}\left(\frac{\dot{m}_{h}{ }^{2}}{\rho_{h}}\right)\left(\frac{4}{d_{e}}\right)\right] \cdot(\sigma \cdot F A C T 4) \cdot A^{b-i-3}=F A C T 5 \cdot A^{b-i-3} .
\end{aligned}
$$

The pressure drop of the cold channel can be obtained by the same method.

$$
\Delta P_{c}=\left[e\left(\frac{d_{e} \dot{m}_{c}}{0.5 \mu_{c}}\right)^{i}\left(\frac{\dot{m}_{c}^{2}}{\rho_{c}}\right)\left(\frac{4}{d_{e}}\right)\right] \cdot(\sigma \cdot F A C T 4) \cdot A^{b-i-3}=F A C T 6 \cdot A^{b-i-3}
$$

From the pressure drops, the pumping power can be approximately calculated as follows,

$$
\begin{aligned}
& P_{\text {power }, h}=\frac{\dot{m}_{h} \cdot \Delta P_{h}}{\rho_{h}}=\frac{\dot{m}_{h} \cdot F A C T 5}{\rho_{h}} \cdot A^{b-i-3} \\
& P_{\text {power }, c}=\frac{\dot{m}_{c} \cdot \Delta P_{c}}{\rho_{c}}=\frac{\dot{m}_{c} \cdot F A C T 6}{\rho_{c}} \cdot A^{b-i-3}
\end{aligned}
$$

The cost of heat exchanger is the summation of the capital cost and operating cost. The capital cost of the compact heat exchanger is determined based on the mass. From Eq (4-54), the mass of the heat exchanger is

$$
M_{C H E}=\rho_{\text {Material }} \cdot V_{\text {Material }}=\rho_{\text {Materal }} \cdot(1-\sigma) \cdot F A C T 4 \cdot A^{b}
$$

Therefore, the capital cost can be expressed by

$$
C P=C_{\text {CHEmass }} \cdot M_{\text {CHE }}=C_{\text {CHEmass }} \cdot \rho_{\text {Materal }} \cdot(1-\sigma) \cdot F A C T 4 \cdot A^{b}
$$

where:

$C P$ : capital cost of CHE

$C_{\text {CHEmass }}:$ price $(\$)$ per CHE unit mass $(\mathrm{kg})$

The operating cost can be assumed to be proportional to the pumping power. Therefore,

$$
O P=C_{o p} \cdot\left(P_{\text {power }, h}+P_{\text {power }, c}\right) \cdot Y
$$

where:

Therefore,

$$
\begin{aligned}
& O P: \text { operating cost of } \mathrm{CHE} \\
& C_{o p}: \operatorname{cost}(\$) \text { per watt-hour } \\
& Y: \text { total duration of operation }
\end{aligned}
$$




$$
O P=C_{o p} \cdot Y \cdot\left(\frac{\dot{m}_{h} \cdot F A C T 5}{\rho_{h}}+\frac{\dot{m}_{c} \cdot F A C T 6}{\rho_{c}}\right) \cdot A^{b-i-3}
$$

The total cost becomes

$$
\begin{aligned}
C_{\text {total }}=C P+O P=( & \left.C_{\text {CHEmass }} \cdot \rho_{\text {Materal }} \cdot(1-\sigma) \cdot F A C T 4\right) \cdot A^{b} \\
& +\left(C_{o p} \cdot Y \cdot\left(\frac{\dot{m}_{h} \cdot F A C T 5}{\rho_{h}}+\frac{\dot{m}_{c} \cdot F A C T 6}{\rho_{c}}\right)\right) \cdot A^{b-i-3}
\end{aligned}
$$

It can be simplified as follows

$$
C_{\text {total }}=K_{1} \cdot A^{b}+K_{2} \cdot A^{b-i-3}
$$

This is the same correlation as Eq. (4-37), and $K_{1}$ and $K_{2}$ are determined as follows.

$$
\begin{aligned}
& K_{1}=C_{\text {CHEmass }} \cdot \rho_{\text {Materal }} \cdot(1-\sigma) \cdot F A C T 4 \\
& K_{2}=C_{o p} \cdot Y \cdot\left(\frac{\dot{m}_{h} \cdot F A C T 5}{\rho_{h}}+\frac{\dot{m}_{c} \cdot F A C T 6}{\rho_{c}}\right)
\end{aligned}
$$

where,

$$
\begin{aligned}
F A C T 1= & \left(\frac{a k_{h}}{d_{e}}\right)\left(\frac{d_{e} \cdot \dot{m}_{h}}{0.5 \mu}\right)^{b} \operatorname{Pr}_{h}^{c} \\
F A C T 2= & \left(\frac{a k_{c}}{d_{e}}\right)\left(\frac{d_{e} \cdot \dot{m}_{c}}{0.5 \mu}\right)^{b} \operatorname{Pr}_{c}{ }^{c} \cdot \\
\text { FACT3 }= & \frac{1}{F A C T 1}+\frac{1}{F A C T 2} \\
\text { FACT } 4= & \frac{2 \cdot Q}{\beta \cdot F A C T 3 \cdot \theta_{m}} \\
\text { FACT5 }= & {\left[e\left(\frac{d_{e} \dot{m}_{h}}{0.5 \mu_{h}}\right)^{i}\left(\frac{\dot{m}_{h}{ }^{2}}{\rho_{h}}\right)\left(\frac{4}{d_{e}}\right)\right] \cdot(\sigma \cdot F A C T 4) } \\
\text { FACT6 }= & {\left[e\left(\frac{d_{e} \dot{m}_{c}}{0.5 \mu_{c}}\right)^{i}\left(\frac{\dot{m}_{c}{ }^{2}}{\rho_{c}}\right)\left(\frac{4}{d_{e}}\right)\right] \cdot(\sigma \cdot F A C T 4) }
\end{aligned}
$$

As derived in Eq. (4-40), the optimum flow surface is

$$
A_{\text {opt }}=\left(\left(\frac{3-b+i}{b}\right) \cdot\left(\frac{K_{2}}{K_{1}}\right)\right)^{\frac{1}{3+i}}
$$


The optimum aspect ratio is

$$
\left.\frac{H}{L}\right|_{o p t}=\frac{\left(A_{o p t} / \sigma\right)^{0.5}}{\sigma \cdot F A C T 4 \cdot A_{o p t}^{b-1}}=\frac{A_{o p t}^{1.5-b}}{\sigma^{1.5} \cdot F A C T 4} .
$$

\subsection{Reference IHX Conditions and Input Parameters}

Figure 4-3 shows a reference design of $600 \mathrm{MWt}$ VHTR/HTSE system. In this system, the core part and PCU are connected through an IHX. And VHTR and HTSE are integrated by a SHX at the ternary loop (intermediate heat exchange loop). It means that the heat generated in the reactor core is transferred to PCU through IHX, and it is re-transferred in the PCU to HTSE through SHX. The advantage of this configuration is for being able to achieve the highest temperature at both HTSE and PCU, maximizing the efficiency. For high efficiency, regenerating and inter-cooling systems are adapted. The heat in the turbine outlet could be effectively recovered to the turbine inlet. A total of 5 heat exchangers were used in this system, and the main focus has been on the IHX among them, which transfers $600 \mathrm{MWt}$ heat from primary side to secondary side.

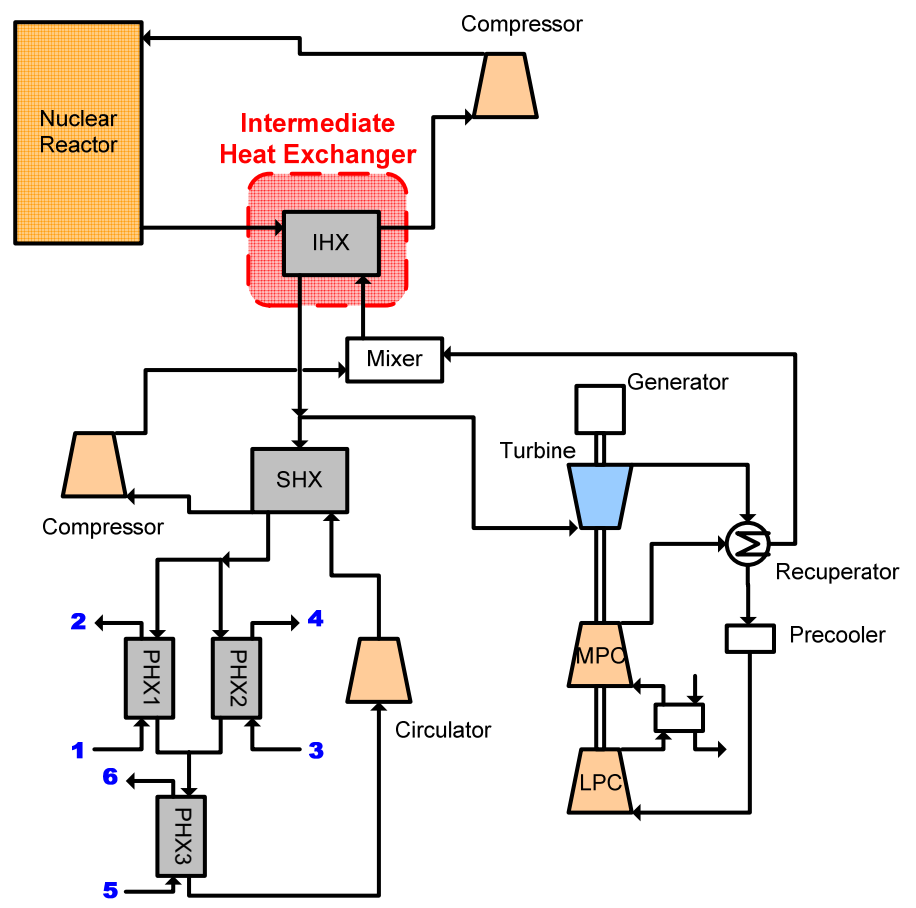

Figure 4-3 Reference configuration of a 600 MWt VHTR/HTSE system

Table 3 summarizes the design conditions for the IHX. These design parameters were calculated and optimized by HYSYS 3.2, a process analysis code. The fluid properties such as density and viscosity were obtained from NIST Chemistry Web Book. 
Table 3. IHX operating conditions for the reference system

\begin{tabular}{|c|c|c|c|c|}
\hline & \multicolumn{2}{|c|}{ Hot Channel (Primary) } & \multicolumn{2}{|c|}{ Cold Channel (Secondary) } \\
\hline & In & Out & In & Out \\
\hline Fluid Type & Helium & Helium & Helium & Helium \\
\hline Temperature $\left({ }^{\circ} \mathrm{C}\right)$ & 900 & 594 & 579 & 885 \\
\hline Pressure (MPa) & 7 & 6.95 & 7.97 & 7.92 \\
\hline Flow rate $(\mathrm{kg} / \mathrm{s})$ & 385 & 385 & 385 & 385 \\
\hline Density $\left(\mathrm{kg} / \mathrm{m}^{3}\right)$ & 2.86 & 3.83 & 4.25 & 3.12 \\
\hline Heat Capacity (kJ/kg K) & 5.19 & 5.19 & 5.19 & 5.19 \\
\hline $\begin{array}{l}\text { Thermal Conductivity } \\
(\mathrm{W} / \mathrm{m} \mathrm{K})\end{array}$ & 0.4 & 0.33 & 0.326 & 0.4 \\
\hline Viscosity (Pa s) & $5.17 \mathrm{e}-5$ & $5.17 e-5$ & $4.13 e-5$ & $4.13 \mathrm{e}-5$ \\
\hline
\end{tabular}

INCONEL ${ }^{\circledR}$ Alloy 617 was selected for heat exchanger material. Alloy 617 is a solid-solution, strengthened nickel-chromium-cobalt-molybdenum alloy with an exceptional combination of high temperature strength and oxidation resistance. The alloy also has excellent resistance to a wide range of corrosive environments, and it is readily formed and welded by conventional techniques. The combination of high strength and oxidation resistance at temperature over $980{ }^{\circ} \mathrm{C}$ makes this an attractive material for VHTR/HTSE system. Melting range and some physical properties are summarized in Table 4.

Table 4 Properties of Alloy 617

\begin{tabular}{cc}
\hline Properties & Values \\
\hline \hline Density $(\mathrm{Mg} / \mathrm{m} 3)$ & 8.36 \\
Melting Ranges $\left({ }^{\circ} \mathrm{C}\right)$ & $1332 \sim 1380$ \\
Specific Heat $(\mathrm{J} / \mathrm{kg} \mathrm{C})$ & 636 \\
at $900 \mathrm{C}$ & 27.1 \\
Thermal Conductivity $(\mathrm{W} / \mathrm{m} \mathrm{C})$ at & \\
$900 \mathrm{C}$ & \\
\hline
\end{tabular}

Friction factor and heat transfer coefficients are very important parameters, which determine the size of the heat exchangers. In this study, PCHE type of compact heat exchanger was selected. Some correlations applicable for PCHE are summarized in Table 5 and 6. In this study, Oyakawa \& Shinzato (1989)'s correlations were selected, which were originally developed for wavy channels. The main advantage of them is that the waviness effect of channel is considered. These considerations can lead to more physically acceptable consequences. Although Oyakawa \& Shinzato's correlation showed reasonable agreement with wide ranges of wavy channel experimental data, as shown in Figure 4-4 and 4-5, they have still some deviation from the real PCHE experimental data from Nikitin et al. (2006) and Song (2005). Therefore, the improvement of heat transfer and friction model for PCHE is required in the future. 
Table 5. Friction factor (Fanning) correlations for compact heat exchanger

\begin{tabular}{cc}
\hline Type & Correlations \\
\hline \hline Laminar Flow & $f=16 \cdot \mathrm{Re}^{-1}$ (for circular straight pipe) \\
Blasius & $f=0.0791 \cdot \mathrm{Re}^{-0.25}$ \\
Song (2005) & $f=4.17 \cdot \mathrm{Re}^{-0.76}$ (for PCHE) \\
Kays and London (1984) & $f=0.6 \cdot \mathrm{Re}^{-0.425}$ (for wavy compact heat exchanger) \\
Oyakawa \& Shinzato (1989) & $f=2.0 \cdot \mathrm{Re}^{-0.4} \cdot\left(\frac{2 b}{\Lambda}\right)^{0.25}$ (for wavy channel) \\
Hesselgreaves (2001) & $f=11 \cdot \mathrm{Re}^{-0.53}$ (for PCHE) \\
Nikitin et al. (2006) & $f=0.1 \cdot \mathrm{Re}^{-0.152}$ (for PCHE) \\
\hline
\end{tabular}

Table 6. Heat transfer correlations for compact heat exchanger

\begin{tabular}{cc}
\hline Type & Correlations \\
\hline \hline Laminar Flow & $N u=4.089($ for circular straight pipe) \\
Dittus-Boelter & $N u=0.021 \cdot \operatorname{Re}^{0.8} \operatorname{Pr}^{0.4}$ (for circular straight pipe) \\
Song (2005) & $N u=0.08 \cdot \operatorname{Re}^{0.74} \operatorname{Pr}^{2.69}$ (for PCHE) \\
Oyakawa \& Shinzato (1989) & $N u=0.4 \cdot \operatorname{Re}^{0.6} \operatorname{Pr}^{0.33} \cdot\left(\frac{2 b}{\Lambda}\right)^{0.25}$ (for wavy channel) \\
Hesselgreaves (2001) & $N u=0.125 \cdot \operatorname{Re}^{0.64} \operatorname{Pr}^{0.33}$ (for PCHE) \\
\hline
\end{tabular}

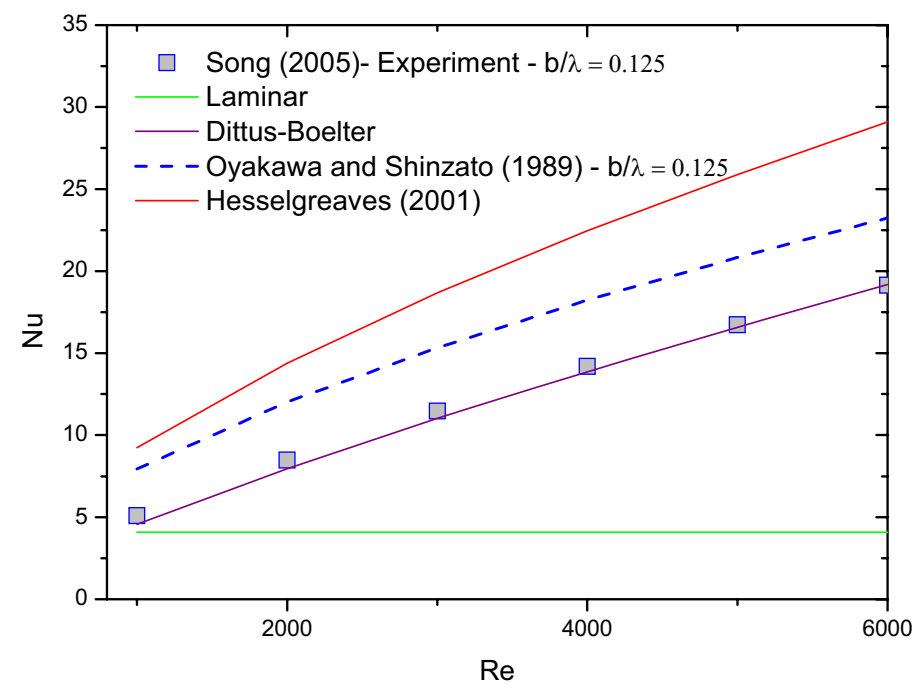

Figure 4-4. Heat Transfer correlations 


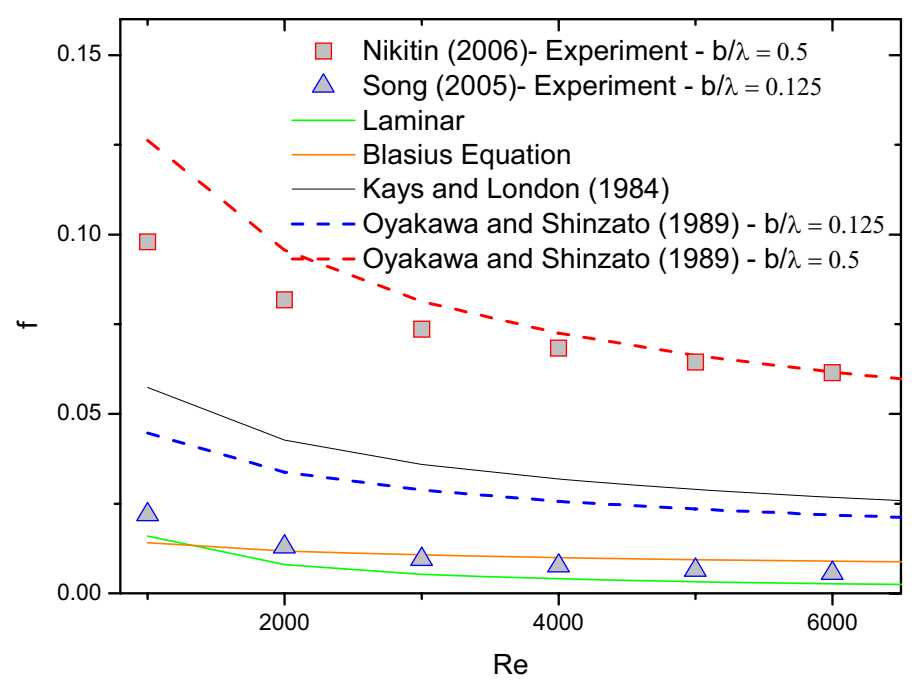

Figure 4-5. Friction factor correlations

The two input parameters, $C_{C H E m a s s}$ and $C_{o p}$ were determined for cost estimation. Currently, the PCHE is being sold on a $\$ / \mathrm{kg}$ basis; $30 \$$ for stainless steel and $120 \$$ for titanium (Dostal et al. (2004). For Inconel, the heat exchanger is quoted for $120 \$ / \mathrm{kg}$ (Song (2005)).

The value of $C_{o p}$ was obtained from consumer price index average price data (EIA, 2007). According to this reference, the electricity cost is $0.0000612 \$ /$ Watt-hour for the industrial sector. The reference operating period is determined to be 20 years.

\subsection{Optimum Sizing of Compact Heat Exchanger for Reference IHX}

The optimum size of the IHX has been estimated. Figure 4-6 illustrates the cost variations with flow area for the reference IHX. As shown in this figure, the capital cost increases with flow area. It is due to the increase of volume. On the other hand, the operating cost exponentially decreases with flow area because of the decreased pumping power. The total cost is sharply decreasing at the beginning due to the operating cost effect and reaches minimum cost, and then gradually increases with the capital cost. For the reference IHX (600 MWt), the optimum flow area was estimated to be $28 \mathrm{~m}^{2}$. 


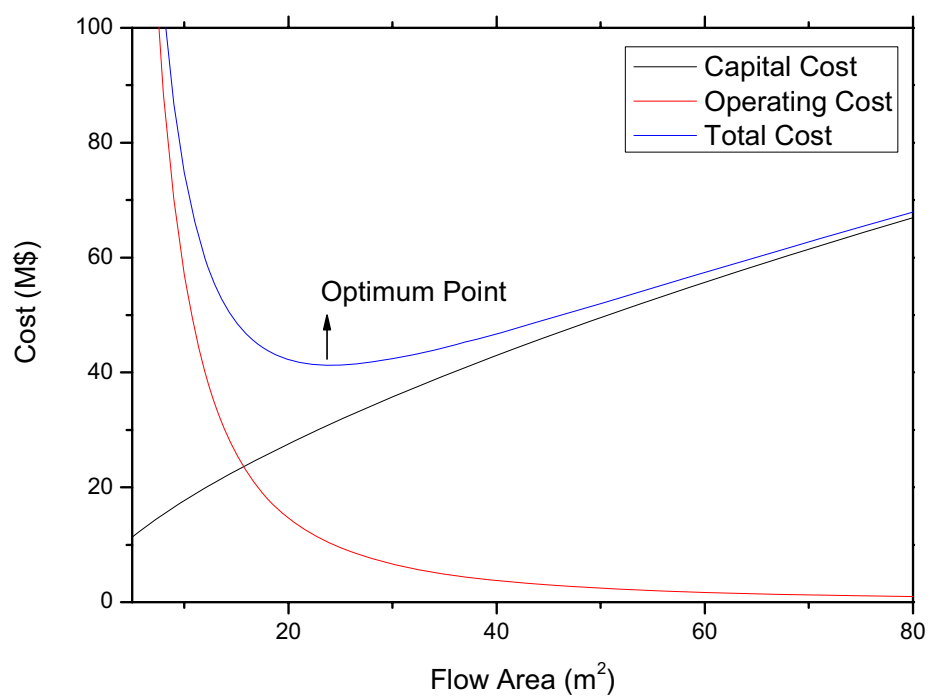

Figure 4-6. Optimum flow area for reference IHX

Figure 4-7 shows that the total cost is very slightly increasing with the flow area when it is larger than the optimum size. It means that the size of IHX can be flexibly determined if the flow area is larger than the optimum. However, at the low flow area, especially lower than the intersection point between the capital cost and the operating cost, the total cost is dramatically increased, and the IHX becomes uneconomic. Therefore, the flow area of the IHX should not be reduced lower than this value. We named this surface area as the minimum allowable flow area, and it can be calculated from Eq. (4-65) and (4-67).

$$
\begin{aligned}
& A_{\min }=\left(\frac{K_{2}}{K_{1}}\right)^{\frac{1}{3+i}}=\left(\frac{3-b+i}{b}\right)^{\frac{1}{3+i}} \cdot A_{\text {opt }} \\
& \frac{A_{\min }}{A_{\text {opt }}}=\left(\frac{K_{2}}{K_{1}}\right)^{\frac{1}{3+i}}=\left(\frac{3-b+i}{b}\right)^{\frac{1}{3+i}}
\end{aligned}
$$

For the reference IHX, the minimum allowable area is calculated to be $18.43 \mathrm{~m}^{2}$. Therefore, we recommend that the flow area of the reference IHX should not be selected below $18.43 \mathrm{~m}^{2}$. 


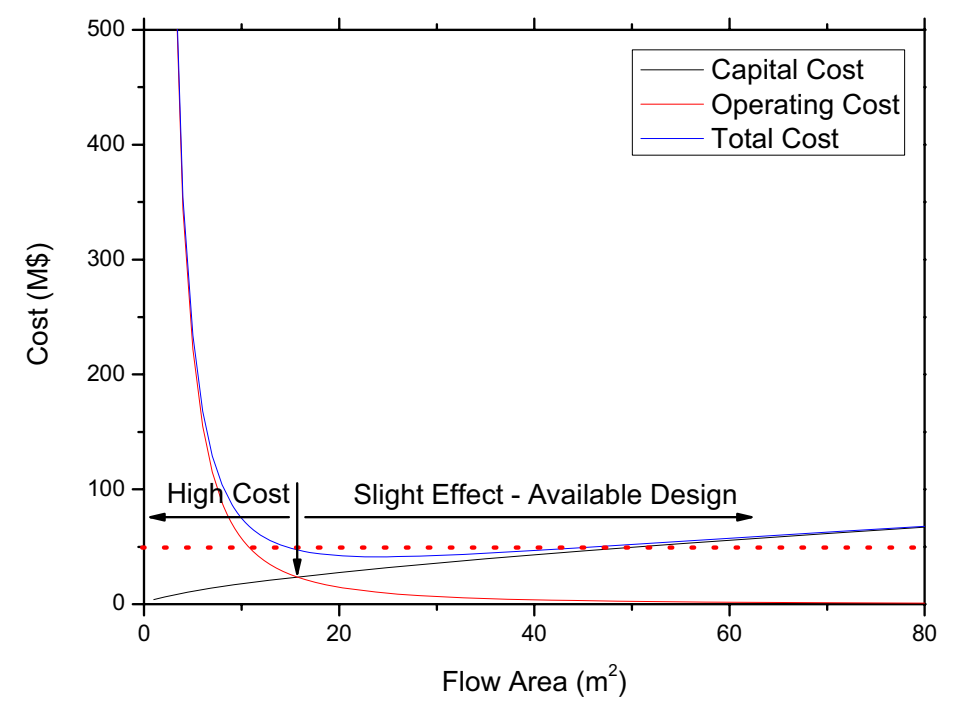

Figure 4-7. Minimum Allowable flow area for reference IHX

Figure 4-8 shows the aspect ratio with flow area. The optimum aspect ratio for the reference IHX is estimated to be 13.5. It means that the length of the heat exchanger is much smaller than the height and width (length $=0.71 \mathrm{~m}$, height and width $=9.59 \mathrm{~m}$ ). This is very unrealistic design for heat exchangers. So, we tried to decrease the aspect ratio (below 1.00) by decreasing flow area. However, in this case, as mentioned above, the total cost is sharply increased more than 100 times. Therefore, it makes the design of the IHX very difficult.

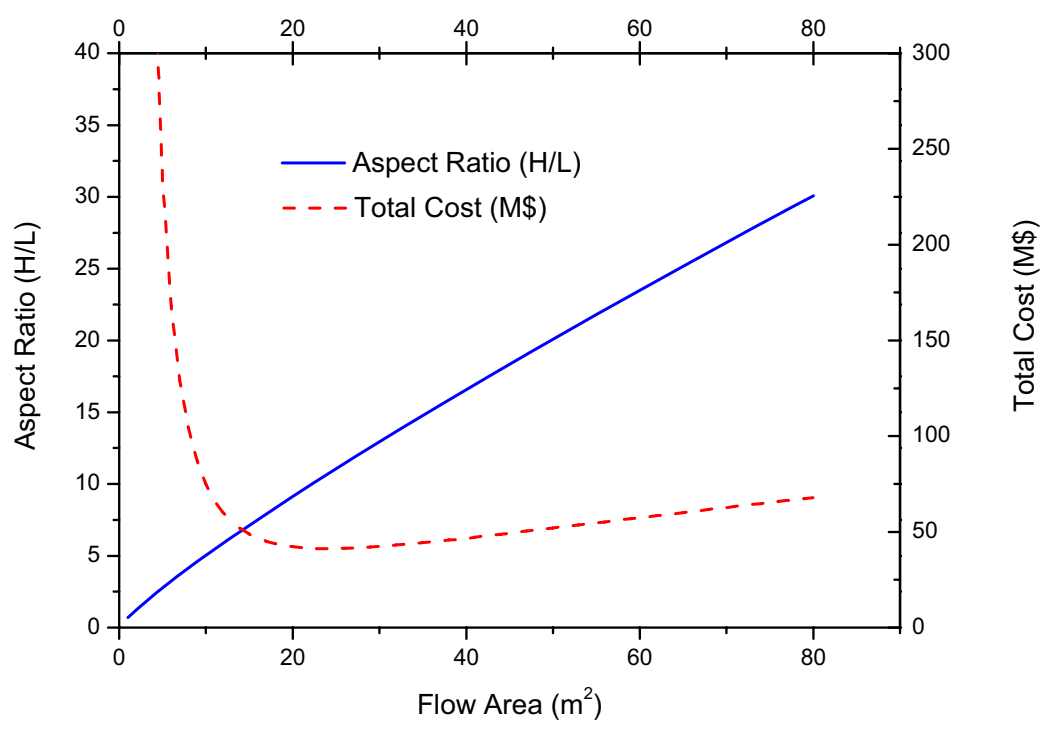

Figure 4-8. Aspect ratio variations with flow area

Figure 4-9 shows the variation of the total cost with aspect ratio. As shown in this figure, the total cost sharply increases lower than the aspect ratio $(=9.32)$ at the minimum allowable flow area $\left(=18.43 \mathrm{~m}^{2}\right)$. 
The unrealistic aspect ratio is mainly caused by the size of channel diameter. In the PCHE, the micro-size channel leads to high surface density and heat transfer. However, it also reduces the boundary layer thickness severely increasing the pressure drop. To reduce the pressure drop, we should reduce the length of the channels, but it finally results in the unrealistic aspect ratio. Figure 4-10 shows the effect of the pressure drop of the IHX on the overall system efficiency. As shown in this figure, the overall efficiency linearly decreases with the pressure drop. The system overall efficiency reaches up to $45 \%$ at low pressure drop within $50 \mathrm{kPa}$, however it drops down to less than $40 \%$ at the higher pressure drop more than $200 \mathrm{kPa}(\sim 2 \mathrm{~atm})$. In the following sections, we discussed about this problem in more detail.

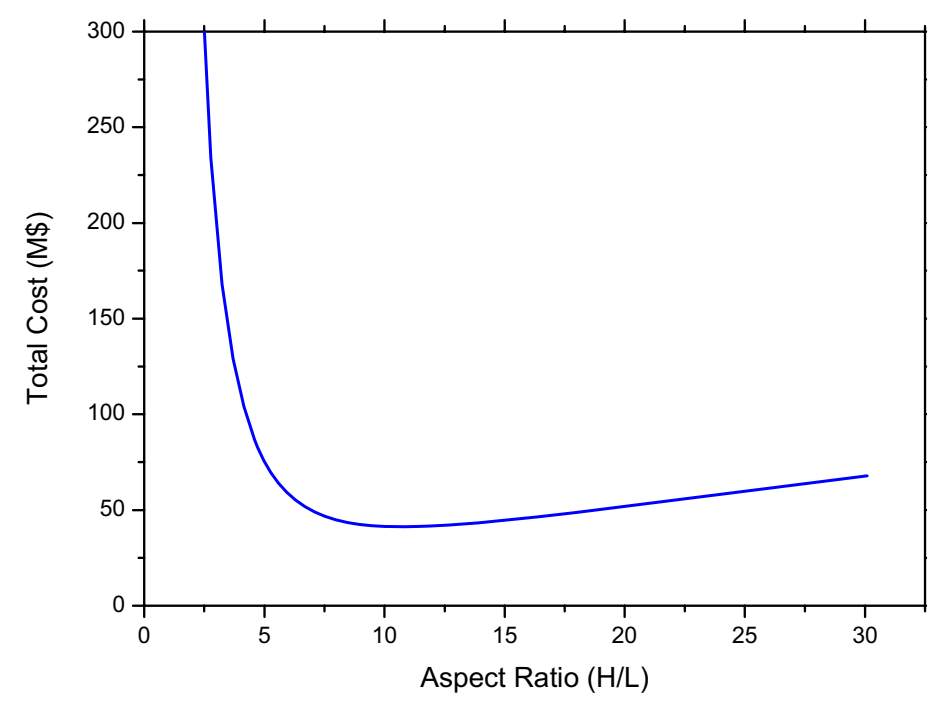

Figure 4-9. Aspect ratio vs. Total cost

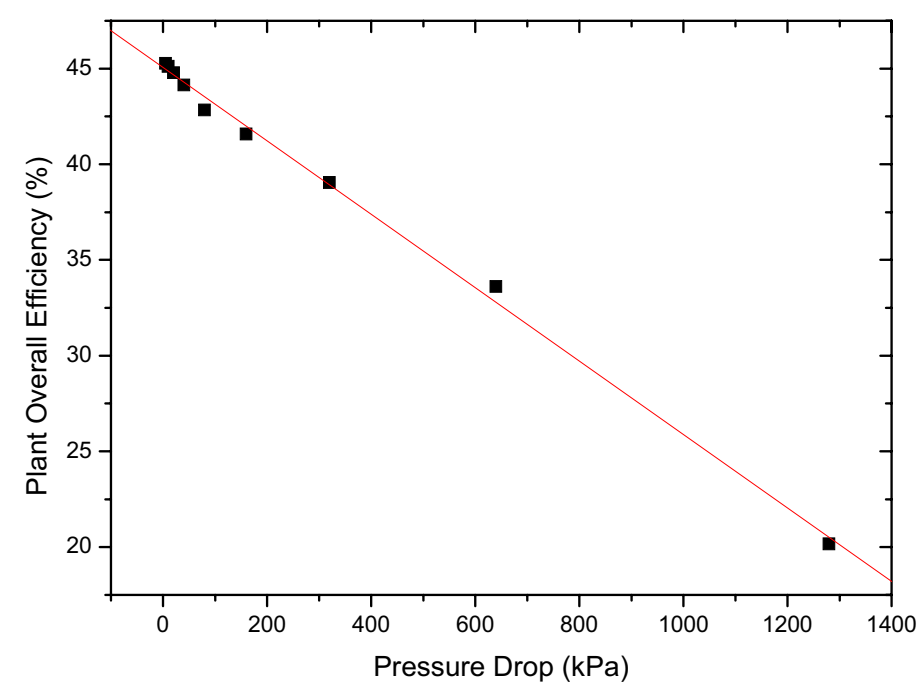

Figure 4-10. Effect of IHX pressure drop on the system overall efficiency 


\section{LOAD SCHEDULE FOR INTEGRATED SYSTEM}

The integrated system must be capable of operating to meet production demands that originate beyond the plant fence, most likely from the operator of a hydrogen pipeline or storage facility. This necessarily implies the plant must be able to startup and shutdown and meet partial production demands. In this section control schemes for operating the plant at partial production levels are described. It considers the quasi-static case where production levels are changed in a slow enough manner that dynamics are not excited. More rapid changes in load are addressed in the next section. Control schemes are developed for meeting hydrogen production rates that lie in the range 30 to 100 percent of full power production. It is possible that yet to be performed research on energy systems and their mix in the U.S. may conclude that there is a less stringent need for partial load operation. Perhaps operation between only 80 and 100 percent full power, as is typical for a chemical plant, will be all that is needed. The case for modeling and simulating startup and shutdown is more complex as described in Section 2.5.3. This task will be performed later in this project.

\subsection{Plant Design}

The integrated system studied is described in broad terms in Davis (2006) where it is labeled as Case 6. In Oh (2006) this design was selected as the reference case for the current project and in subsequent reports $(\mathrm{Oh}$ (2007)) the design of the HTSE process was expanded upon to include specification of configuration of components and individual component sizes. In the present report a GAS-PASS/H code (Vilim (2004)) model developed for the reference case and described in (Oh (2007)) is used to calculate the full power condition and the partial power load schedule. That model is represented by the network diagrams shown in Figures 5-1 through 5-3.

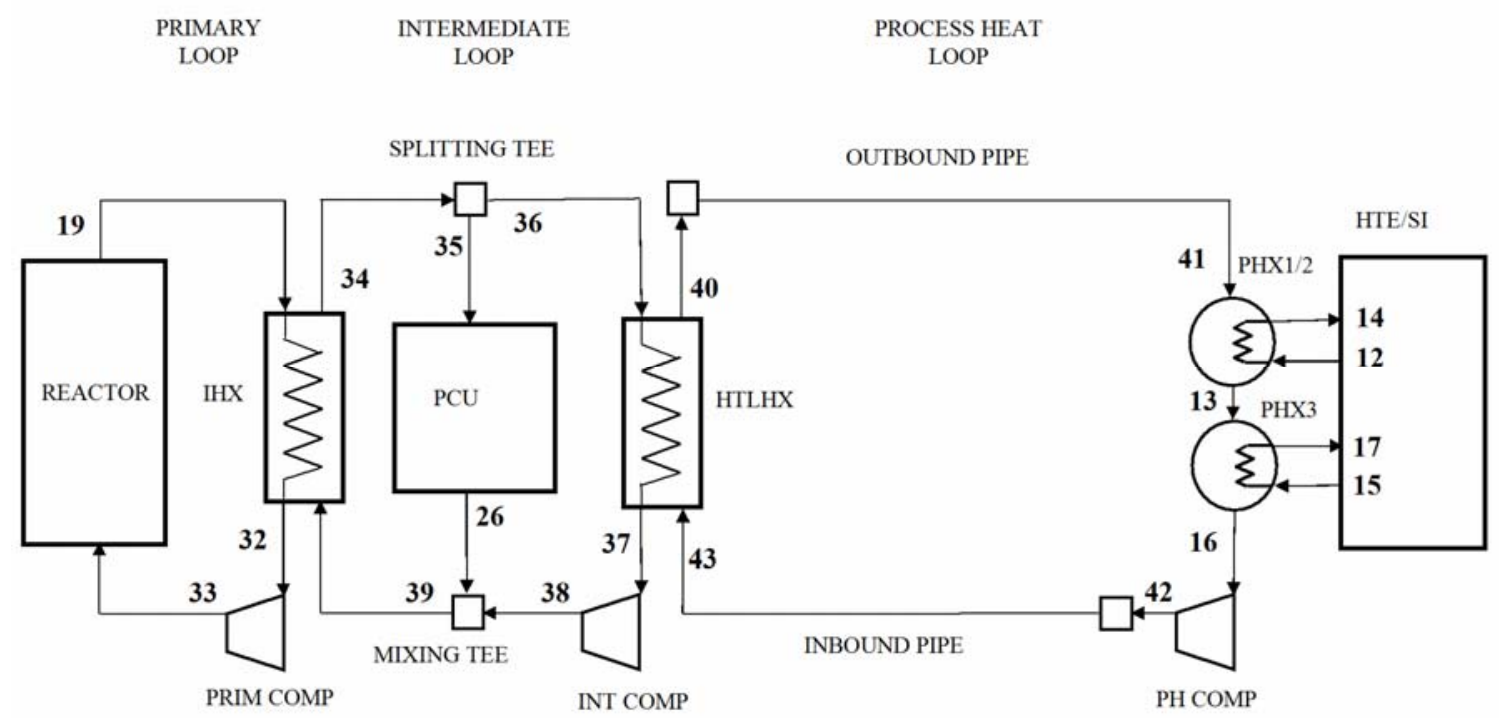

Figure 5-1 Overall Equipment Configuration for VHTR-HTSE Plant 


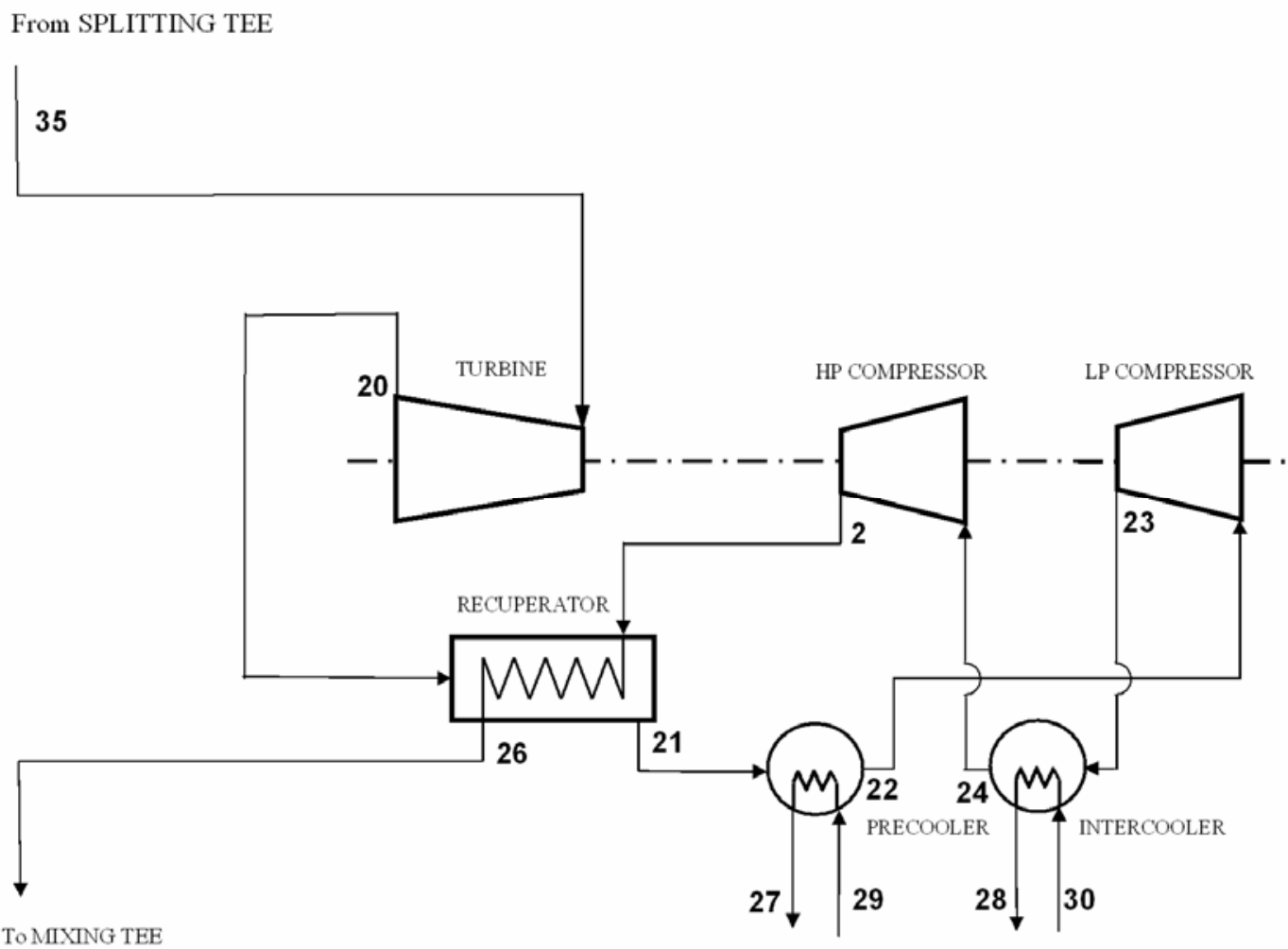

TOMIXING TEE

To Waste Heat Rejection

Figure 5-2 Power Conversion Unit Equipment Configuration

The first figure shows how the reactor, PCU, process heat loop, and HTSE plant are configured. The second figure shows the details of equipment layout for the PCU and the third figure the details of equipment layout for the HTSE plant.

The values of engineering parameters used in the simulation of the reference plant are given in Tables 5-1 through 5-3. Heat exchanger dimensions are given in Table 5-1. Compressor and turbine operating characteristics are given in Table 5-2. Electrolyser dimensions and operating characteristics are given in Table 5-3.

\subsection{Full power Operating Point}

A steady-state full power operating point was calculated with the GAS-PASS/H code model. The boundary conditions used are given in Table 5-4 and were selected based on consideration of the GTMHR design as described in Shenoy (1996), the operation of an HTSE plant as described in Stoots (2005), and the integrated operation of the plants as described in Davis (2006). The values of process variables are given in Table 5-5 through 5-8. Conditions in the primary system are given in Table 5-5, conditions in the intermediate system in Table 5-6, conditions in the PCU in Table 5-7, and conditions in the HTSE plant in Table 5-8. The GAS-PASS/H code provides for a sweep gas but none was used in this model. The product stream into the electrolyzer was a boundary condition set to 0.95 and 0.05 mode fractions of $\mathrm{H}_{2} \mathrm{O}$ and $\mathrm{H}_{2}$, respectively. The value for the current boundary condition was selected to give a electrolyzer product output of 0.05 and 0.95 mode fractions of $\mathrm{H}_{2} \mathrm{O}$ and $\mathrm{H}_{2}$, respectively 


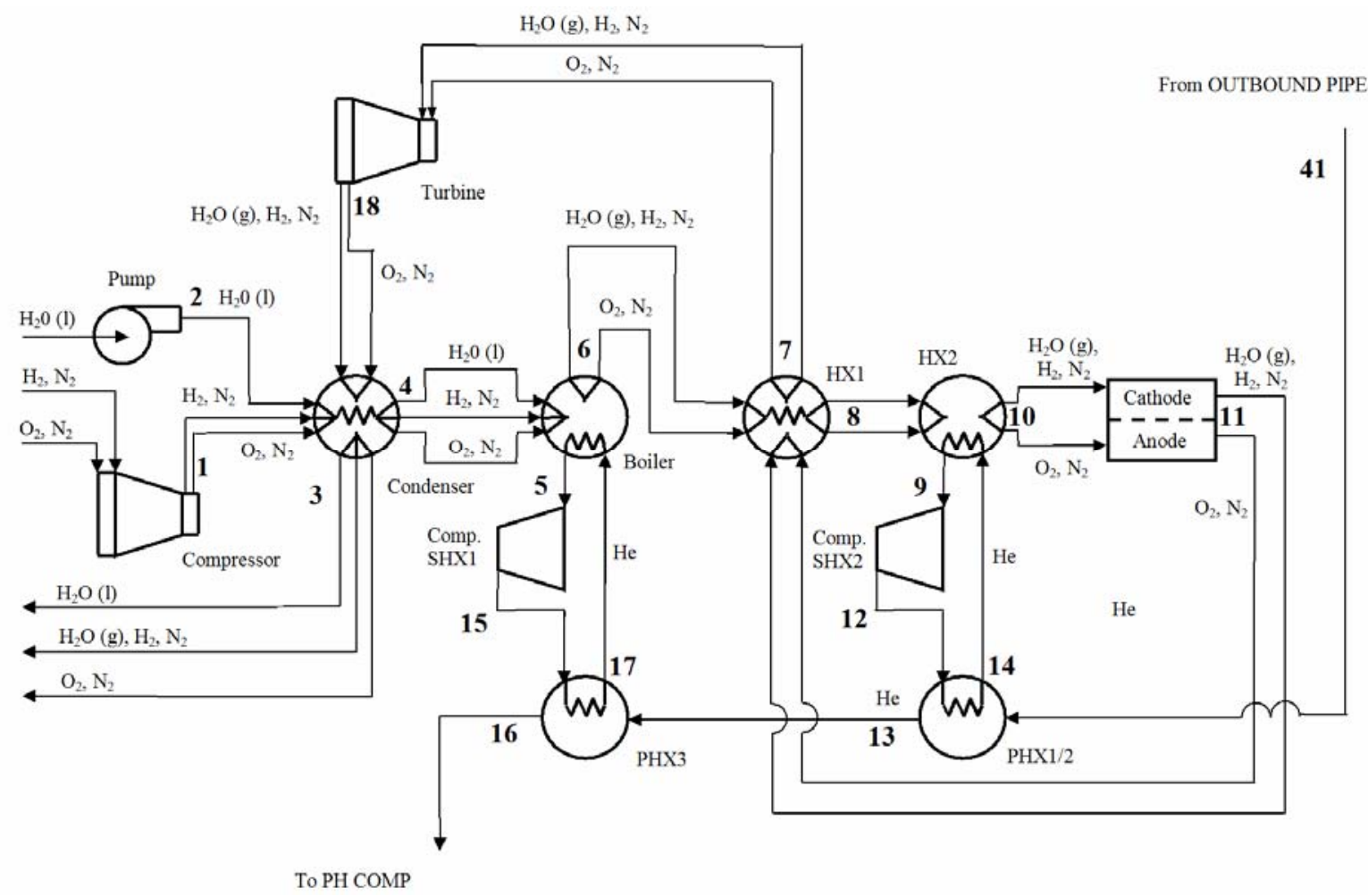

Figure 5-3 High Temperature Steam Electrolysis Equipment Configuration

Table 5-1. Design Data for Helium Printed Circuit Heat Exchangers

\begin{tabular}{|c|c|c|c|}
\hline & IHX & HTLHX & $\begin{array}{c}\text { PCU } \\
\text { Recuperator }\end{array}$ \\
\hline Channel Diameter, $2 r(\mathrm{~m})$ & $1.5 \mathrm{e}-03$ & $1.5 \mathrm{e}-03$ & $1.5 \mathrm{e}-03$ \\
\hline Channel Pitch, $P(\mathrm{~m})$ & $1.8 \mathrm{e}-03$ & $2.25 \mathrm{e}-03$ & $2.56 \mathrm{e}-03$ \\
\hline Plate Thickness, $t(\mathrm{~m})$ & $8.55 \mathrm{e}-04$ & $1.17 \mathrm{e}-03$ & $1.79 \mathrm{e}-03$ \\
\hline Channel Length, $l(\mathrm{~m})$ & 2.34 & 1.089 & 1.62 \\
\hline \multirow{3}{*}{$\begin{array}{l}\text { Number of Channels, } N_{\text {channels }} \text { (one } \\
\text { side) } \\
\text { In Width Direction } \\
\text { In Height Direction }\end{array}$} & $7.33 \mathrm{e} 06$ & $4.36 \mathrm{e} 05$ & $4.264 \mathrm{e} 06$ \\
\hline & 2639 & 673 & 2443 \\
\hline & 2778 & 648 & 1745 \\
\hline \multirow{2}{*}{$\begin{aligned} \text { Hot Side Flow, } & w(\mathrm{~kg} / \mathrm{s}) \text { - Total } \\
w_{\text {channel }} & - \text { Per Channel }\end{aligned}$} & 289 & 32.1 & 260 \\
\hline & $3.94 \mathrm{e}-05$ & $7.36 \mathrm{e}-05$ & $5.10 \mathrm{e}-05$ \\
\hline \multirow{2}{*}{$\begin{aligned} \text { Cold Side Flow, } & w(\mathrm{~kg} / \mathrm{s}) \text { - Total } \\
& w_{\text {channel }}-\text { Per Channel }\end{aligned}$} & 292 & 27.5 & 260 \\
\hline & $3.98 \mathrm{e}-05$ & $5.31 \mathrm{e}-05$ & $5.10 \mathrm{e}-05$ \\
\hline Width (m) & 4.75 & 1.52 & 5.23 \\
\hline Height (m) & 4.75 & 1.52 & 5.23 \\
\hline Volume $\left(\mathrm{m}^{3}\right)$ & 52.8 & 2.5 & 62.9 \\
\hline
\end{tabular}


Table 5-2. Full Power Turbine and Compressor Operating Characteristics

\begin{tabular}{|ll|cc|}
\hline & Pressure Ratio & Efficiency \\
\hline Turbine - & HTSE & 3.2 & 0.93 \\
Compressor - & PCU & 3.1 & 0.94 \\
& Primary Loop & 1.014 & 0.89 \\
& Intermediate Loop & 1.014 & 0.89 \\
& Process Heat Loop & 1.17 & 0.89 \\
& PCU Low Pressure & 1.83 & 0.89 \\
PCU High Pressure & 1.82 & 0.89 \\
\hline
\end{tabular}


Table 5.3. Electrolyzer Dimensions and Operating Characteristics (Vilim 2006)

\begin{tabular}{|c|c|c|c|c|c|c|}
\hline & $\mathrm{H}_{2} \mathrm{O}$ & $\mathrm{H}_{2}$ & $\mathrm{O}_{2}$ & & & \\
\hline $\mathrm{A}_{\mathrm{w}}(\mathrm{kg} / \mathrm{mol})$ & $18.0 \mathrm{e}-03$ & $2.02 \mathrm{e}-3$ & $32.0 \mathrm{e}-3$ & & & \\
\hline $\begin{array}{l}\mathrm{C}_{\rho} @ 950^{\circ} \mathrm{C} \\
(\mathrm{J} / \mathrm{kg}-\mathrm{K})\end{array}$ & $\begin{array}{l}2.45 \mathrm{e} 03 @ 50 \\
\text { atm }\end{array}$ & 15.1e3@1 atm & $917 @ 1 \mathrm{~atm}$ & & & \\
\hline $\mathrm{A}\left(\mathrm{m}^{2}\right)$ & $\mathrm{i}\left(\mathrm{amps} / \mathrm{m}^{2}\right)$ & $(\rho \mathrm{V})_{\mathrm{s}}^{\mathrm{a}}(\mathrm{kg})$ & $(\mathrm{C} \rho)_{\mathrm{s}}(\mathrm{J} / \mathrm{kg}-\mathrm{K})$ & $\mathrm{P} / \mathrm{P}_{\mathrm{STD}}$ & $\begin{array}{c}\mathrm{T} \\
(\mathrm{C})\end{array}$ & \\
\hline $64 e-4$ & 1880 & $13.9 \mathrm{e}-3$ & 400 & 50 & 816 & \\
\hline $\begin{array}{c}\mathrm{F} \\
(\mathrm{coul} / \mathrm{mol})\end{array}$ & $\begin{array}{c}\mathrm{R} \\
(\mathrm{J} / \mathrm{mol}-\mathrm{K})\end{array}$ & $\begin{array}{l}{\frac{(\partial \Delta G)^{o b}}{\partial T}}_{(\mathrm{J} / \mathrm{mol}-\mathrm{K})}\end{array}$ & $\begin{array}{c}\mathrm{ASR}^{\mathrm{oc}} \\
\left(\mathrm{ohms}-\mathrm{cm}^{2}\right)\end{array}$ & $\begin{array}{c}\mathrm{C}_{1}{ }^{\mathrm{c}} \\
\left(\text { ohms-m }{ }^{2} \text { ) }\right.\end{array}$ & $\begin{array}{l}\mathrm{C}_{2}{ }^{\mathrm{c}} \\
(\mathrm{K})\end{array}$ & $\frac{\Delta \mathrm{G}^{\mathrm{ob}}}{(\mathrm{J} / \mathrm{mol})}$ \\
\hline 96,485 & 8.31 & $\begin{array}{l}-55.5 @ 1 \mathrm{~atm}, \\
950^{\circ} \mathrm{C}\end{array}$ & 0 & $8.39 \mathrm{E}-4$ & 8,030 & $\begin{array}{l}2.02 \mathrm{e} 5 @ \\
1 \mathrm{~atm}, 950^{\circ} \mathrm{C}\end{array}$ \\
\hline
\end{tabular}

${ }^{\mathrm{a}}$ Hartivigsen (2006), ${ }^{\mathrm{b}}$ Ohta (1979), ${ }^{\mathrm{c}}$ Pradhan (2006)

Table 5-4. Boundary Conditions Used to Determine Full Power Operating Point

\begin{tabular}{|c|c|c|c|c|c|c|c|}
\hline \multirow[t]{2}{*}{ Power (MW) } & Reactor & Generator & & & & & \\
\hline & 594 & 280 & & & & & \\
\hline \multirow[t]{2}{*}{ Temperature $\left({ }^{\circ} \mathrm{C}\right)$} & $\begin{array}{l}\text { HTSE } \\
\text { Reactant } \\
\text { Inlet } \\
\end{array}$ & $\begin{array}{l}\text { Precooler Cold } \\
\text { Side Inlet }\end{array}$ & $\begin{array}{l}\text { Intercooler } \\
\text { Cold Side Inlet }\end{array}$ & & & & \\
\hline & 21 & 21 & 21 & & & & \\
\hline \multirow[t]{2}{*}{$\begin{array}{l}\text { Flowrate (all species) } \\
(\mathrm{kg} / \mathrm{s})\end{array}$} & $\begin{array}{l}\text { Electrolyzer } \\
\text { Inlet }\end{array}$ & $\begin{array}{l}\text { Compressor } \\
\text { SHX1 }\end{array}$ & $\begin{array}{l}\text { Compressor } \\
\text { SHX2 }\end{array}$ & $\begin{array}{l}\text { Precooler } \\
\text { Cold Side } \\
\text { Inlet }\end{array}$ & $\begin{array}{l}\text { Intercooler } \\
\text { Cold Side Inlet }\end{array}$ & $\begin{array}{l}\text { Primary } \\
\text { Compressor }\end{array}$ & $\begin{array}{l}\text { Process Heat Loop } \\
\text { Compressor }\end{array}$ \\
\hline & 21.5 & 51.8 & 10.4 & 21 & 21 & 288 & 25.1 \\
\hline \multirow[t]{2}{*}{ Mode Fractions } & $\begin{array}{l}\text { Electrolyzer } \\
\text { Inlet }-\mathrm{H}_{2} \mathrm{O}\end{array}$ & $\begin{array}{l}\text { Electrolyzer } \\
\text { Inlet }-\mathrm{H}_{2}\end{array}$ & & & & & \\
\hline & 0.95 & 0.05 & & & & & \\
\hline \multirow[t]{2}{*}{ Current (amps) } & Electrolyzer & & & & & & \\
\hline & 217 & & & & & & \\
\hline
\end{tabular}


Table 5-5. Primary System Full Power Conditions

\begin{tabular}{|l|c|c|c|}
\hline & Reactor & $\begin{array}{c}\text { IHX } \\
\text { Hot Side }\end{array}$ & $\begin{array}{c}\text { Primary System } \\
\text { Compressor }\end{array}$ \\
\hline $\begin{array}{l}\text { Power } \\
(\mathrm{MW})\end{array}$ & 594 & 601 & 7 \\
\hline $\begin{array}{l}\text { Outlet Temperature } \\
\left({ }^{\circ} \mathrm{C}\right)\end{array}$ & 887 & 485 & 490 \\
\hline $\begin{array}{l}\text { Outlet Pressure } \\
(\mathrm{MPa})\end{array}$ & 7.09 & 7.04 & 7.13 \\
\hline $\begin{array}{l}\text { Mass Flowrate } \\
(\mathrm{kg} / \mathrm{s})\end{array}$ & 288 & 288 & 288 \\
\hline
\end{tabular}

Table 5-5. Intermediate System Full Power Conditions

\begin{tabular}{|l|c|c|c|c|}
\hline & $\begin{array}{c}\text { IHX Cold } \\
\text { Side }\end{array}$ & $\begin{array}{c}\text { HTLHX } \\
\text { Hot Side }\end{array}$ & Mixing T & $\begin{array}{c}\text { Intermediate } \\
\text { Compressor }\end{array}$ \\
\hline $\begin{array}{l}\text { Power } \\
(\mathrm{MW})\end{array}$ & 601 & 436 & 0 & 0.9 \\
\hline $\begin{array}{l}\text { Outlet Temperature } \\
\left({ }^{\circ} \mathrm{C}\right)\end{array}$ & 485 & 611 & 478 & 617 \\
\hline $\begin{array}{l}\text { Outlet Pressure } \\
(\mathrm{MPa})\end{array}$ & 7.04 & 7.27 & 7.37 & 7.37 \\
\hline $\begin{array}{l}\text { Mass Flowrate } \\
(\mathrm{kg} / \mathrm{s})\end{array}$ & 288 & 32.4 & 291 & 32.4 \\
\hline
\end{tabular}

Table 5-7. Power Conversion Unit Full Power Conditions

\begin{tabular}{|l|c|c|c|c|c|c|c|}
\hline & Turbine & $\begin{array}{c}\text { Recuperator } \\
\text { Hot Side }\end{array}$ & $\begin{array}{c}\text { Recuperator } \\
\text { Cold Side }\end{array}$ & $\begin{array}{c}\text { HP } \\
\text { Compressor }\end{array}$ & $\begin{array}{c}\text { LP } \\
\text { Compressor }\end{array}$ & $\begin{array}{c}\text { Precooler } \\
\text { Hot Side }\end{array}$ & $\begin{array}{c}\text { Inter- } \\
\text { cooler Hot } \\
\text { Side }\end{array}$ \\
\hline $\begin{array}{l}\text { Power } \\
(\mathrm{MW})\end{array}$ & 534 & 462 & 462 & 126 & 127 & 151 & 127 \\
\hline $\begin{array}{l}\text { Outlet } \\
\text { Temperature } \\
\left({ }^{\circ} \mathrm{C}\right)\end{array}$ & 479 & 141 & 461 & 123 & 124 & 30 & 30 \\
\hline $\begin{array}{l}\text { Outlet } \\
\text { Pressure } \\
(\mathrm{MPa})\end{array}$ & 2.36 & 2.31 & 7.37 & 7.43 & 4.13 & 2.26 & 4.08 \\
\hline $\begin{array}{l}\text { Mass Flow } \\
\text { Rate } \\
(\mathrm{kg} / \mathrm{s})\end{array}$ & 263 & 263 & 263 & 263 & 263 & 263 & 263 \\
\hline
\end{tabular}


Table 5-8. High Temperature Steam Electrolysis Plant Full Power Conditions

\begin{tabular}{|c|c|c|c|c|c|c|c|c|c|}
\hline & & Condenser & Boiler & HX1 & HX2 & Turbine & Cell & PHX1/2 & PHX3 \\
\hline \multirow[t]{2}{*}{$\begin{array}{l}\text { Power } \\
\text { (MW) }\end{array}$} & $\begin{array}{l}\text { Hot } \\
\text { Side }\end{array}$ & 18.8 & 43.2 & 24.9 & 5.32 & \multirow{2}{*}{11.5} & \multirow{2}{*}{288} & 5.3 & 43.2 \\
\hline & $\begin{array}{l}\text { Cold } \\
\text { Side }\end{array}$ & 18.8 & 43.2 & 24.9 & 5.32 & & & 5.3 & 43.2 \\
\hline \multirow{2}{*}{$\begin{array}{l}\text { Outlet } \\
\text { Temperature } \\
\left({ }^{\circ} \mathrm{C}\right)\end{array}$} & $\begin{array}{l}\text { Hot } \\
\text { Side }\end{array}$ & 43 & 328 & 545 & 725 & \multirow{2}{*}{340} & \multirow{2}{*}{968} & 800 & 469 \\
\hline & $\begin{array}{l}\text { Cold } \\
\text { Side }\end{array}$ & 184 & 247 & 712 & 817 & & & 842 & 488 \\
\hline \multirow{2}{*}{$\begin{array}{l}\text { Outlet } \\
\text { Pressure } \\
(\mathrm{MPa})\end{array}$} & $\begin{array}{l}\text { Hot } \\
\text { Side }\end{array}$ & 1.53 & 5.0 & 5.0 & 5.0 & \multirow{2}{*}{1.56} & \multirow{2}{*}{5.0} & 1.76 & 1.71 \\
\hline & $\begin{array}{l}\text { Cold } \\
\text { Side }\end{array}$ & 5.00 & 5.0 & 5.0 & 5.0 & & & 5.0 & 5.0 \\
\hline \multirow{2}{*}{$\begin{array}{l}\text { Mass Flowrate } \\
\text { - All Species } \\
(\mathrm{kg} / \mathrm{s})\end{array}$} & $\begin{array}{l}\text { Hot } \\
\text { Side }\end{array}$ & 21.5 & 51.8 & 21.5 & 10.4 & \multirow{2}{*}{21.5} & \multirow{2}{*}{21.5} & 25.1 & 25.1 \\
\hline & $\begin{array}{l}\text { Cold } \\
\text { Side }\end{array}$ & 21.5 & 21.5 & 21.5 & 21.5 & & & 10.4 & 51.8 \\
\hline
\end{tabular}

\subsection{Load Schedule and Control Strategy}

A main objective in developing a control strategy for partial load operation is to maintain temperatures, particularly hot end temperatures $(\sim 900 \mathrm{C})$, constant with power over the $30-100$ percent power range. Another consideration is that peak efficiency occurs at full power since the plant is to operate there for the largest fraction of life. While partial load efficiency is important, maintaining constant temperatures over load at the hot end is probably more important since material capabilities at $900 \mathrm{C}$ are a limiting factor in plant lifetime. Development of a control strategy therefore focused on maintaining constant hot end temperatures.

The first control strategy examined makes use of the principle that the temperature change from inlet to outlet in a heat exchanger remains constant when the mass flowrate and power are varied in the same proportion. This is true for ideal-like gases such as helium, hydrogen, oxygen, and nitrogen for the liquid and gas phases of water. It is not true for water when there is a phase change as in the case. In the HTSE plant and its process heat loop there are a total of five compressor and pumps with which to manage mass flowrate in response to power in heat exchangers (to the first order heat exchanger power varies linearly with hydrogen production rate). In the PCU and primary system there is only one compressor to manage mass flowrate while there are several different circuits. To achieve the desired control of mass flowrate helium inventory control is used. Essentially because density is proportional to pressure for fixed temperature, by varying pressure and maintaining constant speed turbomachinery, gas velocity remains constant and mass flowrate (proportional to the product of density and velocity) is linear with pressure. Thus, pressure is manipulated through coolant mass inventory so that it is proportional to heat exchanger power so that in turn mass flowrate is proportional to heat exchanger power. The result for this control scheme is described below.

A load schedule was formulated to give the value of all process variables in terms of fraction of full power hydrogen production rate. The control scheme that realizes this prescribes all controlling process variables (i.e. forcing functions) as a function of fraction of full power hydrogen production rate which is 
taken as the independent variable (or equivalently, electrolyzer electrical current where it has been assumed all current goes to decompose water). The following controlling process variables were selected: reactor power, eight mass flowrates, plus the electrolyzer current, for a total of ten forcing functions. The need for ten forcing functions follows from the number of equations in the model and the dictate that there be a unique solution. As a cross check, the number of forcing functions needed was independently derived from consideration of the physics alone. Other sets of ten could be used but this set was appealing based on the discussion above. Each of these ten forcing functions was linearly ramped from its full power value at one end to a value of 30 percent of this at the other end. Hence, the load schedule covers the range of operation from 30 to 100 percent of the full power hydrogen production rate.

\subsection{Results and Discussion}

The load schedule is assessed primarily on the degree to which temperatures on the hot side of the combined plant are maintained constant. Also of interest are the pressures on the helium side for assessment of creep under pressure load. The pressures in the HTSE plant were maintained at $5 \mathrm{MPa}$ over the load schedule from downstream of where the reactant water in fed in up to the point where the products enter the pressure-work recovery turbine.

The temperatures in the end of the plant are shown in Figures 5-4 and 5-5. The first figure shows the temperatures in the HTSE plant and the second figure shows temperatures in the VHTR plant. The temperatures in the latter vary by no more than $30 \mathrm{C}$ over the load range. However, in the HTSE plant, the electrolyzer outlet varies by more than $400 \mathrm{C}$ over the load range. The inlet to the electrolyzer is essentially constant temperature. Other temperatures in the HTSE plant vary by 100 to $200 \mathrm{C}$. These temperature changes with load, especially at the electrolyzer outlet are probably not acceptable since they will limit the rate at which the plant could change power. Cold side temperatures in the combined plant are shown in Figure 5-5. The largest temperature change is about $150 \mathrm{C}$ in the process heat loop inbound pipe. Helium loop pressures are shown in Figure 5-7. Pressure is to a first order proportional to hydrogen production rate, a consequence of inventory control. The production and consumption of power by major system components is shown in Figure 5-8. Essentially all the thermal power produced by the VHTR is consumed in powering thermal and in generating electricity to power electrical loads which include the electrolyzer, pumps, and compressors.. But as described in Vilim (2006), there is a potential for supplanting some of the thermal load with waste heat so that the combined plant could be a net exporter of electricity to the grid. 


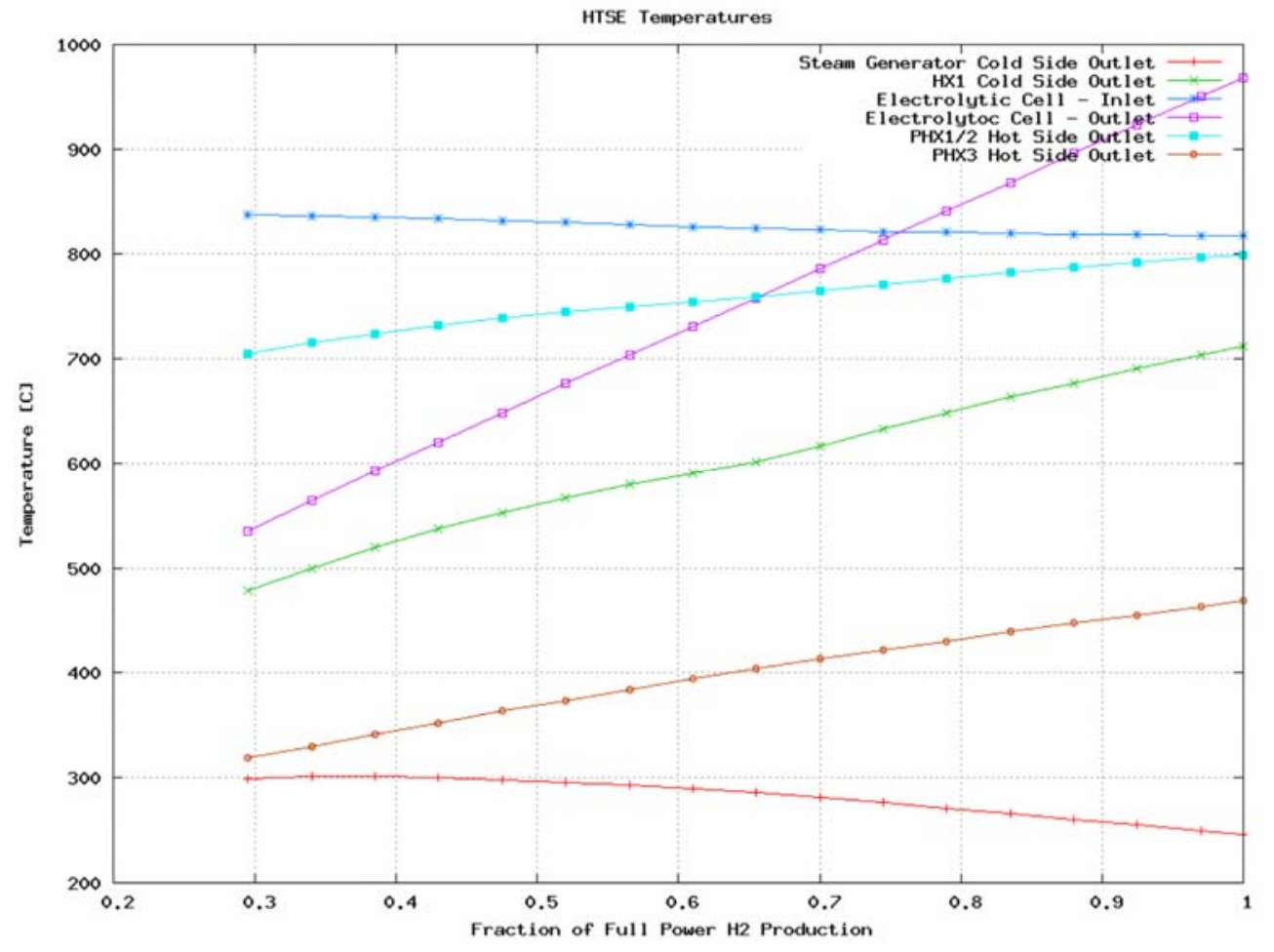

Figure 5-4 Temperatures in High Temperature Steam Electrolysis Plant

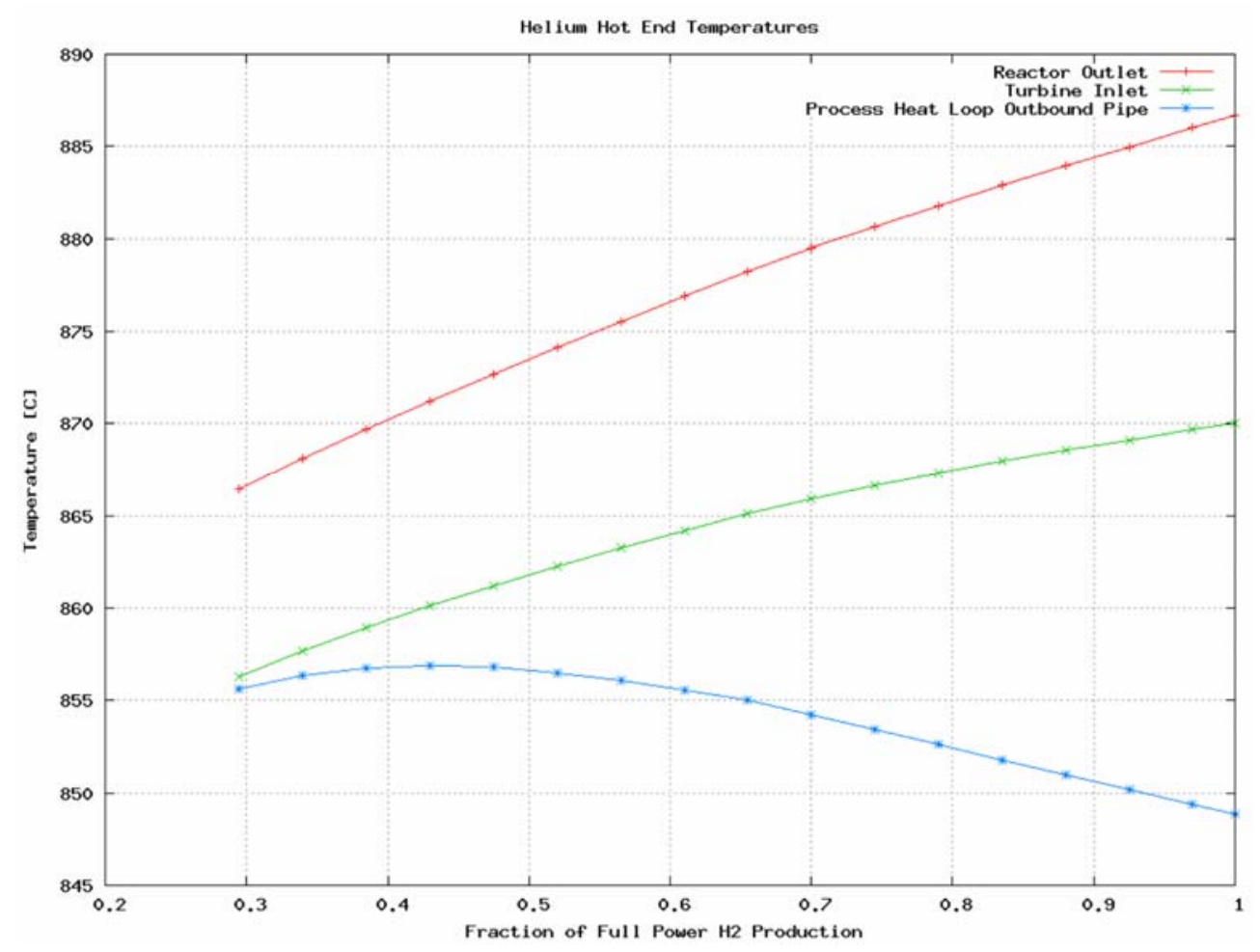

Figure 5-5 Temperatures in Hot End of VHTR Plant 


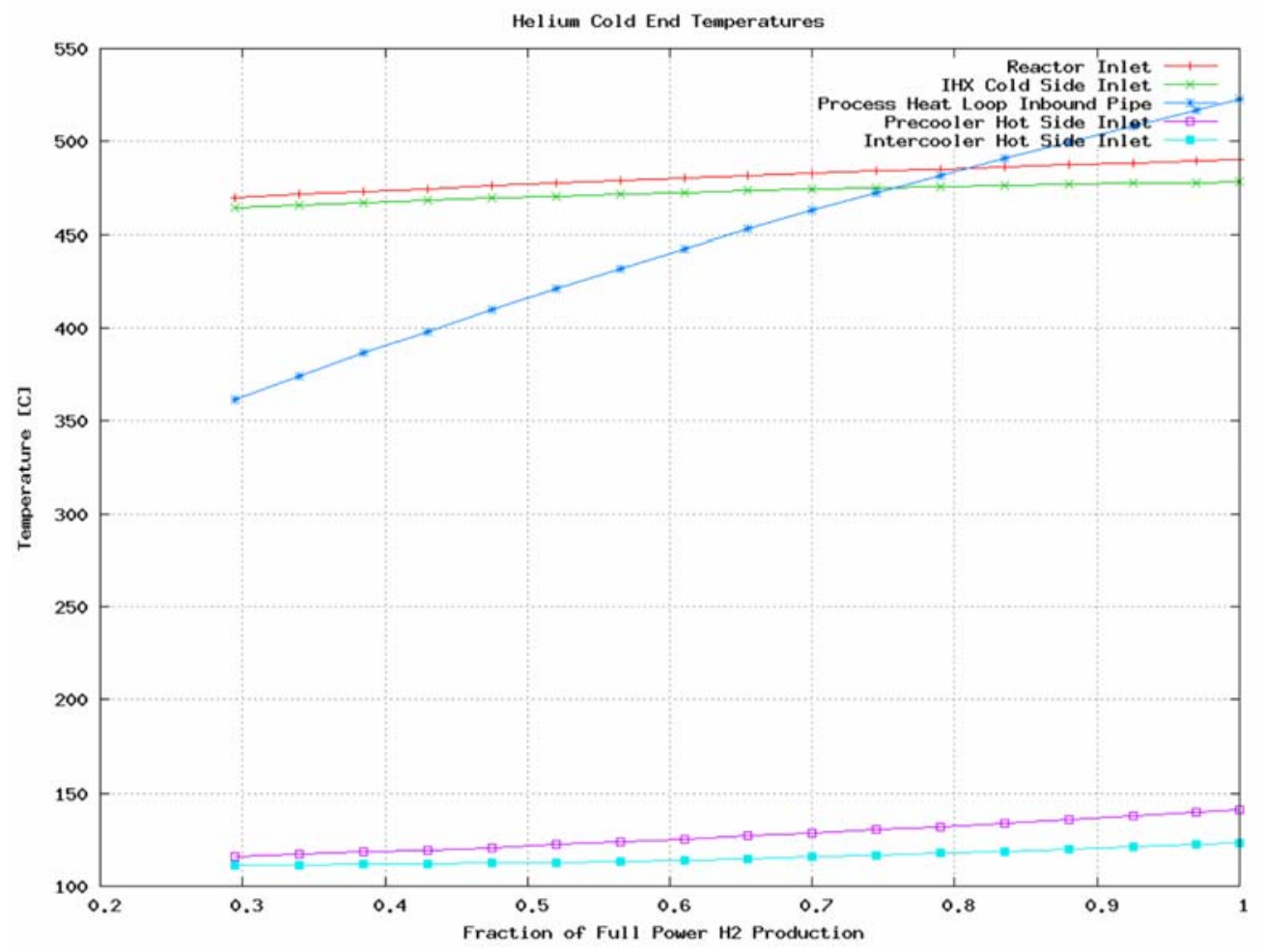

Figure 5-6 Temperatures in Cold End of VHTR Plant

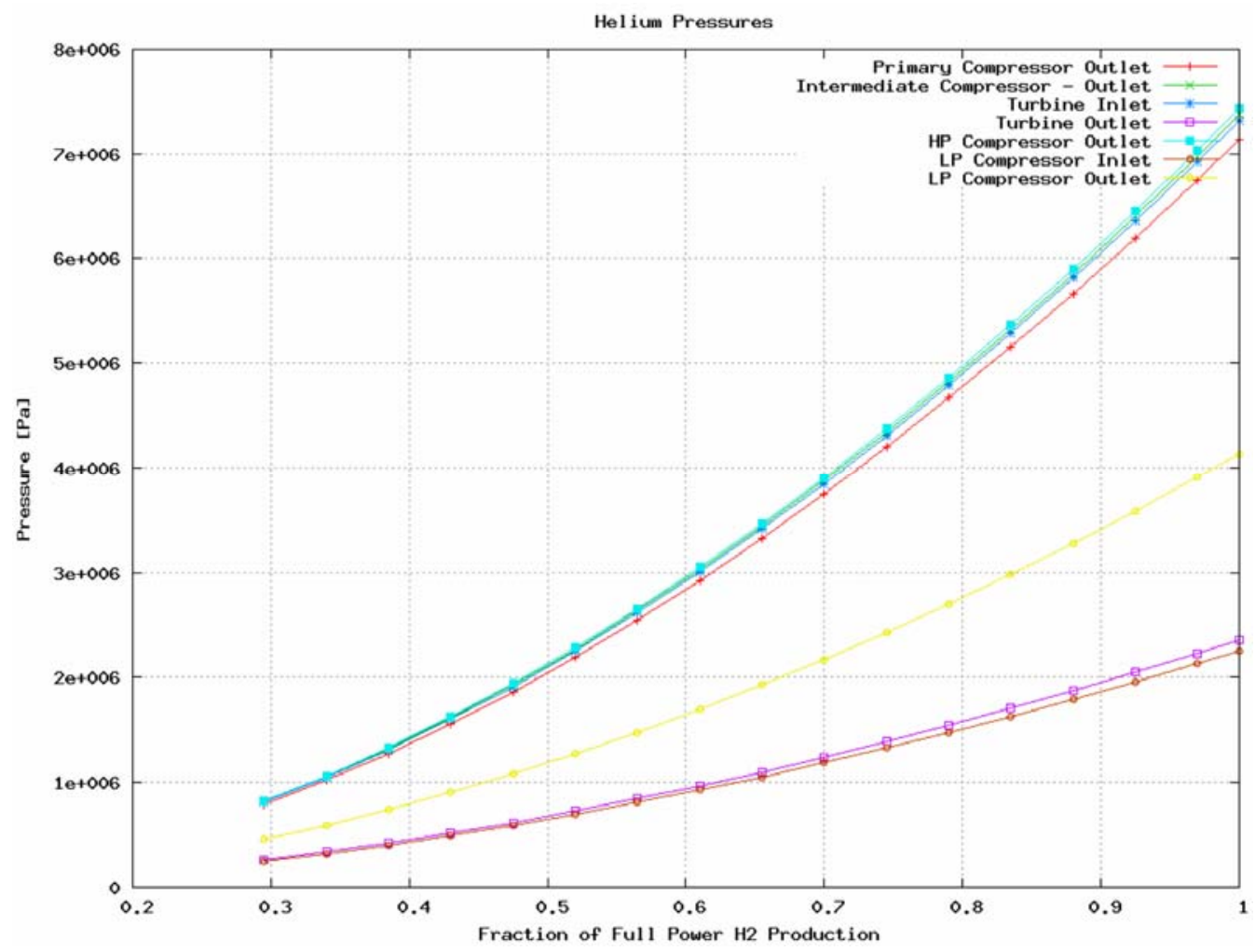

Figure 5-7 Pressures in Helium Loops 


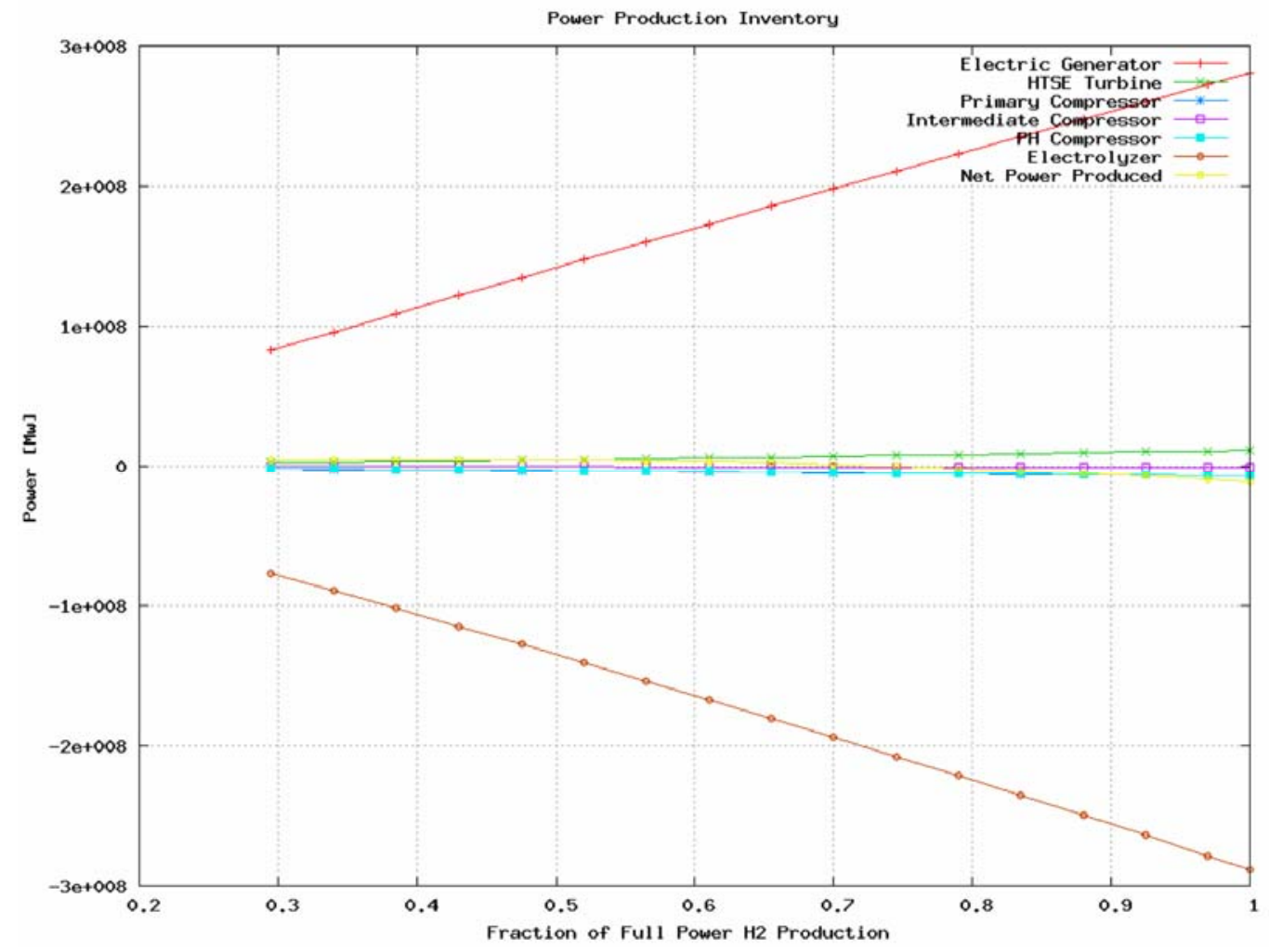

Figure 5-8 Power Production and Consumption in Major System Components

Because the electrolyzer sensible heat is recuperated externally at the exit of the recuperator, there is a significant temperature rise in the electrolyzer during full power operation. If the resulting spatial temperature gradient is not desirable, then either internal recuperation or operating the cell at a current density where there is no sensible heat generated along the length between inlet and outlet can be used to reduce the size of the gradient. The latter option has the disadvantage that the required current density will be lower resulting in an increase in cell area per unit hydrogen production rate and poorer economics. Internal recuperation would seem to be the preferred solution since it involves only passing a counter current gas flow over the individual cells lined up from inlet to outlet.

There is an additional disadvantage associated with the control strategy just described. Because the sensible heat available for external recuperation depends nonlinearly with hydrogen production rate, the inlet temperature to the electrolyzer varies significantly $(\sim 400 \mathrm{C})$ over the 30-100 percent hydrogen production range. One solution to this problem is to increase the current density at lower powers and generate more sensible heat per unit product mass flowrate. This can be achieved by reducing the active cell area per unit hydrogen production (i.e operate fewer cells). This scheme was explored with GAS$\mathrm{PASS} / \mathrm{H}$ to see how effective it might be. The results are shown in Figure 5-9 through 5-11. Clearly, this is effective as seen in Figure 5-9 where the ranges of electrolyzer inlet and outlet temperature have been significantly reduced. 


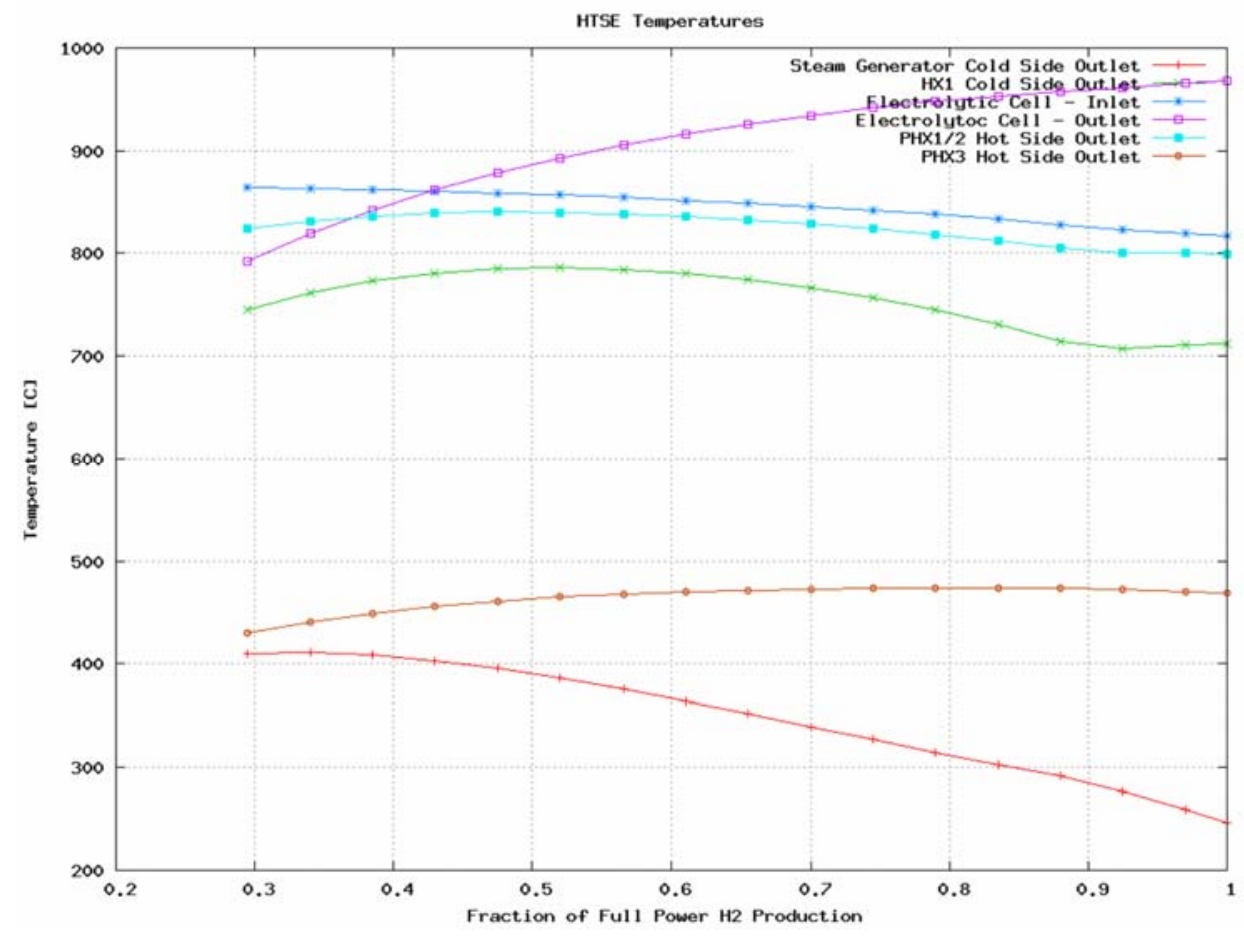

Figure 5-9 Temperatures in High Temperature Steam Electrolysis Plant for Reduced Cell Area

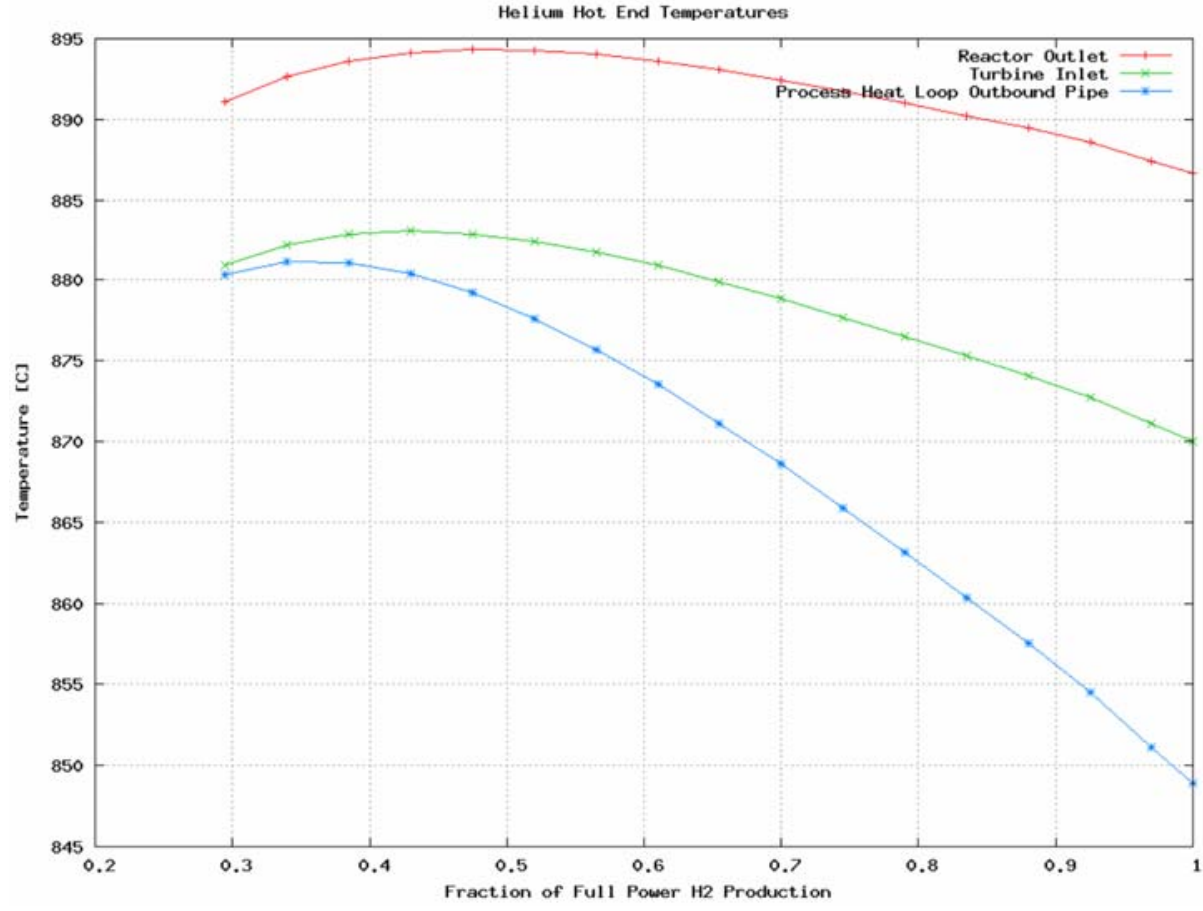

Figure 5-10 Temperatures in Hot End of VHTR Plant for Reduced Cell Area 


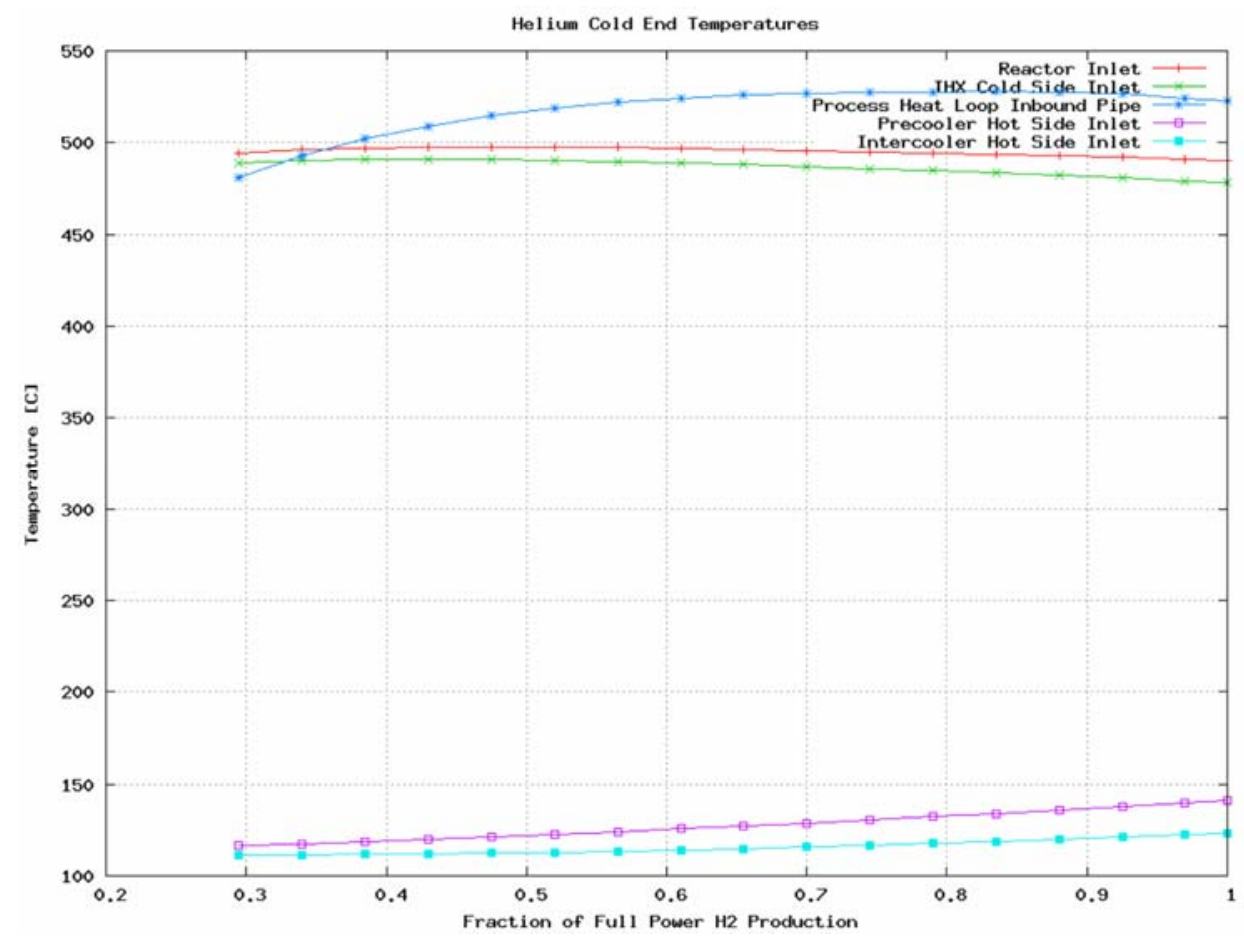

Figure 5-11 Temperatures in Cold End of VHTR Plant for Reduced Cell Area

The electrolyzer inlet temperature range is now $180 \mathrm{C}$, down from over $400 \mathrm{C}$. These results were obtained for a linear ramp in cell area starting with the previous value at full power value down to a fraction 0.4 at 30 percent hydrogen production rate. There is also a reduction in the temperature variation in the process heat inbound pipe as seen by comparing Figure 5-6 with Figure 5-11. In general then, managing active cell area during load change can lead to a reduction in temperature swings seen in components.

In Section 2.5.2 the mathematical basis for obtaining a desired load schedule is given. From this development it is clear that a combination of flowrate (compressor and pump) and current density control should permit the results in Figures 5-9 through 5-11 to be refined so that hot end temperature changes with load are further reduced. This is left for future work. 


\section{TRANSIENT RESPONSE OF INTEGRATED SYSTEM}

\subsection{Time Constants and Energy Capacitances}

Expressions for time constants and energy capacitances were derived previously and evaluated for the major components in the combined plant (Vilim 2006). The results are shown in Table 6-1 and are used in the following subsections to draw some preliminary conclusions about dynamic response.

Some simple observations are made. The reactor and PCU vessel walls have very large thermal capacitances $(1000 \mathrm{MJ} / \mathrm{C})$ but the time constant for these components as they interact with the helium coolant is almost an hour. Thus, upset events of the order of several minutes, these capacitances will not be particularly active. However, during startup this capacitance will be important. It will not be important for operational transients since the vessel walls are maintained at constant temperature.

The overall time response of the contents of the reactor vessel is largely a function of the fuel. The neutronics are essentially quasi-static compared to the fuel $(2.8 \mathrm{~s}$ versus $9.5 \mathrm{~s})$ while the fuel energy capacitance $(200 \mathrm{MJ} / \mathrm{C})$ is large. Judging from the physical space occupied by the fuel in the reactor vessel, it would appear to be greater than all other structure energy capacitances that are faster than a few tens of seconds. The helium coolant is insignificant $(4.7 \mathrm{MJ} / \mathrm{C})$ compared to the fuel.

In the HTE plant the energy capacitance of the electrolytic cells $(270 \mathrm{MJ} / \mathrm{C})$ is almost a factor of ten greater than all the other components combined $(\sim 30 \mathrm{MJ} / \mathrm{C})$. The time constant (206 s) is also roughly ten times greater than the other components (12-35 s). However, since the electrolytic cells are essentially downstream of the process heat components of the HTE this heat capacity will have little effect in dampening a transient there. It does mean that rapid transients (seconds) in that part of the plant will be muted in their impact on electrolytic cell temperature. Essentially, with the process heat components operating at a power level of $50 \mathrm{MW}$ small transients will be limited in the rates of temperature change they can induce in the electrolytic cells. Similarly, with the electrolysis process depositing only about 10 MW of thermal energy in the cells, transients in the electric generating part of the plant will result in limited rates of temperature change in the cells.

\subsection{Load Change}

In addition to partial power steady-state operation, a power reactor is typically designed to be able to meet an instantaneous change in generator power of ten percent. The initial and final states are given by the load schedule. However, in the interim, dynamics are excited and the plant deviates from equilibrium. The transient behavior is obtained from a dynamic simulation. However, a measure of the deviation is estimated in Vilim (2006). The main results are summarized here. 
Table 6-1 Summary of Thermal Time Constants and Capacitances

\begin{tabular}{|c|c|c|c|c|}
\hline & $\begin{array}{c}\text { Time } \\
\text { Constant } \\
(\mathrm{s})\end{array}$ & $\begin{array}{c}\text { Energy } \\
\text { Capacitance } \\
\left(\mathrm{MJ} /{ }^{\circ} \mathrm{C}\right)\end{array}$ & Ref. & Notes \\
\hline \multicolumn{5}{|l|}{ Reactor Vessel } \\
\hline \multicolumn{5}{|l|}{ Active Core } \\
\hline Fuel Elements & 9.5 & 200 & & \\
\hline Neutronics & 2.8 & - & & \\
\hline He Coolant & $2.8^{\mathrm{a}}$ & 4.7 & & Assumes 0.2 void fraction \\
\hline Internals & unknown & unknown & & \\
\hline Wall & 4000 & 1000 & & $<500 \mathrm{C}$ \\
\hline \multicolumn{5}{|l|}{ Intermediate System } \\
\hline IHX & 0.28 & 27 & & \\
\hline Flow Paths & unknown & unknown & & \\
\hline \multicolumn{5}{|l|}{ Power Conversion Unit } \\
\hline Turbine & - & $8.0^{\mathrm{b}}$ & & \\
\hline Recuperator & 1.9 & 95 & & \\
\hline Vessel Wall & 2300 & 1000 & & $<500 \mathrm{C}$ \\
\hline Coolers & - & - & & $<200 \mathrm{C}$ \\
\hline Compressors & - & - & & $<200 \mathrm{C}$ \\
\hline \multicolumn{5}{|l|}{ HTE Plant } \\
\hline HTLHX & 0.96 & 2.8 & & \\
\hline \multicolumn{5}{|l|}{ Outbound Pipe } \\
\hline Pipe Wall & 21 & 2.3 & & $100 \mathrm{~m}$; molten salt \\
\hline Coolant & 12 & 4.3 & & $100 \mathrm{~m}$; molten salt \\
\hline \multicolumn{5}{|l|}{ Inbound Pipe } \\
\hline Pipe Wall & 21 & 2.3 & & $100 \mathrm{~m}$; molten salt \\
\hline Coolant & 12 & 4.3 & & $100 \mathrm{~m}$; molten salt \\
\hline Condenser & 30 & 7 & & \\
\hline Boiler & 20 & 2.3 & & \\
\hline Superheater HX1 & 35 & 4.5 & & \\
\hline Electrolytic Cells & 206 & 270 & & \\
\hline
\end{tabular}

${ }^{a}$ Mixing ${ }^{b}$ Based on mass of rotor and static structure estimated to be $16,000 \mathrm{~kg}$

The load change considered is a ten percent step increase in hydrogen demand for the HTE plant of Figure 6-3. It is assumed that the reactants from Compressor 1and Pump 2 up to the Cell 11 inlet and the products from the Cell 1 output to Condenser 3 increase by this amount. All other flowrates in the combined plant and the electric power to the cell are assumed to remain constant. Of interest is the rate at which temperatures in the HTE plant change before the control system acts to bring control variables into agreement with the load schedule for the new hydrogen production level.

Inspection of Figure 6-3 reveals that the HTSE equipment components containing either water and/or cell products are all tightly coupled thermally to each other. The two recuperating heat exchangers are responsible. An approximate estimate for the rate of temperature change throughout these components (condenser, boiler, HX1, HX2, cell, and turbine) is obtained from Eq. (2-24). Before the load change the thermal power provided by PHX1 and PHX2 is $50 \mathrm{MWt}$ while the thermal output from the electrolyzer is 
about $5 \mathrm{MWt}$. The energy capacitance from Table 6-1 is $270 \mathrm{MJ} / \mathrm{C}$ for the electrolyzer and about $30 \mathrm{MJ} / \mathrm{C}$ for the other components. The temperature rates of change amongst the components will range from 0.08 $\mathrm{C} / \mathrm{s}$ to $0.17 \mathrm{C} / \mathrm{s}$.

In summary, the rate of temperature change in each component will be limited to $0.1-0.2 \mathrm{C} / \mathrm{s}$. This is about a factor of ten $(1.0 \mathrm{C} / \mathrm{s})$ below rates that might lead to accumulated fatigue at the tube sheet in a large (hundreds of MW) tube and shell heat exchanger operating at $500 \mathrm{C}$. The HTE heat exchangers are smaller (tens of MW) so temperature rates of change would have to be greater yet than $1.0 \mathrm{C} / \mathrm{s}$ to create a fatigue problem. The exception may, however, be HX2 which operates at an outlet temperature of $850 \mathrm{C}$.

\subsection{Reactor Stability}

\subsubsection{Simplified Analysis}

General stability criteria for an at-power core coupled to a heat sink were developed in Section 2.6.1. Essentially three criteria must be met, one of which relates the perturbation to core outlet temperature in the steady state to a temperature perturbation at the inlet. A necessary condition for core power to tend toward stable operation is that the temperature feedback processes attenuate the effect of an inlet temperature perturbation on the outlet temperature of the core.

Eq. (2-22) provides a quantitative measure of the attenuation.

The magnitude and sign of the attenuation of inlet temperature perturbation was calculated for the VHTR core. The quantity in parenthesis in Eq. (2-22) was evaluated at full power conditions. Table 6-2 presents the estimate for rod differential worth. Normally the Operating Control Rods are inserted into the top of the core to maintain criticality. An increase in vessel temperature causes the rods to be move upward relative to the top of the core adding reactivity. An increase in fuel element temperature causes the core length to increase effectively causing the rods to move further into the core adding negative reactivity. The reactivity coefficients associated with these differential expansions are derived in Table 6-3. The attenuation coefficient of Eq. (2-22) for these values has a value of +0.16 indicating strong in phase attenuation of inlet temperature perturbations. On the basis of this one would expect the VHTR core coupled to a heat source to be very stable with respect to neutronic power.

Another stability assessment was made by comparing the values of two parameters identified in Depiante (1994) as being important for controlling stability. These parameters and their values are plotted on a stability map taken from Depiante. According to this map the core power again is stable with respect to coupling to a heat sink.

This stability criterion is probably of greater significance for the SI plant compared to the HTE plant. Approximately 92 percent of the core thermal power is delivered to the PCU for the HTE implementation. The core power has a time constant of about $20 \mathrm{~s}$ (Table 6-1) while the transit time from the core outlet through the IHX and through the turbine and recuperator of the PCU and back to the core inlet is probably less than this (Table 6-1). The thermal energy delivered to the HTE plant while having a transit time of greater than $20 \mathrm{~s}$ is small in comparison and thus the reactor inlet temperature perturbation introduced through this path will be small. On the other hand, the SI plant is a heat sink that consumes a much larger fraction of the core thermal energy and the transit time is longer than the core time constant.

Future work should re-derive Eq. (2-22) for the more general case of reduced primary flowrate to investigate how this changes the attenuation. The transit time through the PCU will increase to a value that exceeds the core power time constant violating one of the three stability criteria. 


\subsubsection{Simulation}

This section describes the model developed for the reactor core and its application for simulating the response of the core to temperature perturbations that originate in the hydrogen plant.

\subsubsection{Core Temperatures}

The reactor core is a collection of fueled hexagonal columns with each column having axial coolant holes that connect the inlet plenum to the outlet plenum. The distribution of coolant flow among the columns is influenced by the presence of leakage paths between adjacent columns. A detailed prediction of the distribution of coolant is the subject of other work. (Vilim 2004) In the present work we note that the flow of coolant is predominantly axially through the column holes. Then a one-dimensional representation of the core provides the main dependence of core temperatures on coolant inlet temperature and flowrate.

An averaged thermal-hydraulic behavior of the graphite column with its array of coolant holes and fuel holes is obtained by transforming into a unit cell annular geometry. This cell is shown in Figure 6-1. The radii of the three regions in the annular model are selected to preserve the areas in the original fuel element matrix and the number of unit cells is set equal to the number of coolant holes so that

$$
n_{c l} A_{c l}=n_{c l} \pi\left(r_{c l}{ }^{2}-r_{g r}{ }^{2}\right) \quad n_{c l} A_{g r}=n_{c l} \pi\left(r_{g r}{ }^{2}-r_{f}{ }^{2}\right) \quad n_{c l} A_{f}=n_{c l} \pi r_{f}{ }^{2}
$$

where the left-hand side of each equation is the area in the original fuel element and the right side is an equal area distributed across a number of unit cells (i.e. annular fuel elements) equal to the number of coolant channels. Here

$$
\begin{array}{lll}
A & = & \text { cross-sectional area in the original fuel element on a per unit cell basis, } \\
n & = & \text { number of holes in the original fuel element, and } \\
r & = & \text { equivalent outer radius for annular pin representation }
\end{array}
$$

and $f, g r, c l$ represent fuel, graphite, and coolant, respectively. This transformation yields an effective one-dimensional conduction distance for the graphite.

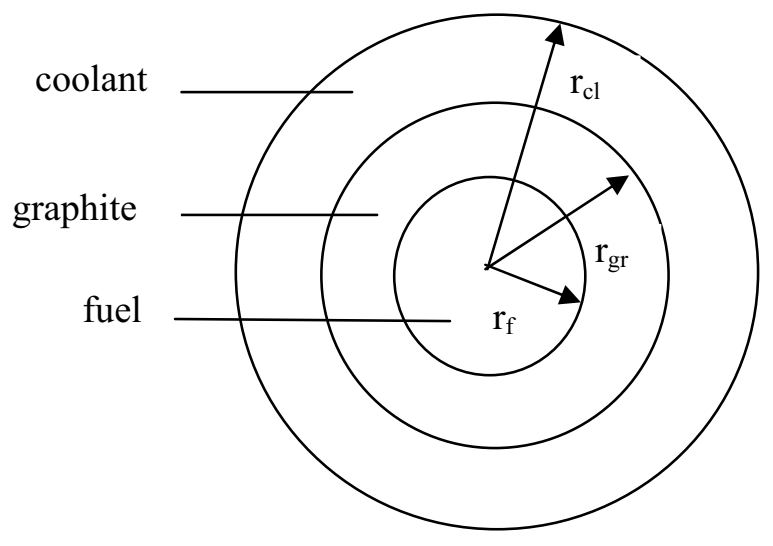

Figure 6-1 Transformed Fuel Element Geometry 
Adopting this annular geometry the energy equation for the fuel in contact with the graphite is

$$
\left(\rho \mathrm{C}_{\mathrm{p}}\right)_{\mathrm{f}} \frac{\mathrm{dT}_{\mathrm{f}}}{\mathrm{dt}}=\mathrm{Q}_{\mathrm{f}}-\frac{\mathrm{h}_{\mathrm{f}-g r} 2 \pi \mathrm{r}_{\mathrm{f}}}{\mathrm{A}_{\mathrm{f}}}\left(\mathrm{T}_{\mathrm{f}}-\mathrm{T}_{\mathrm{gr}}\right)
$$

where

$\begin{array}{lll}\mathrm{T}_{\mathrm{f}} & = & \text { fuel temperature, } \\ \mathrm{Q}_{\mathrm{f}} & = & \text { volumetric heat generation rate, } \\ \mathrm{h}_{\mathrm{f}-\mathrm{gr}} & = & \text { fuel to graphite heat transfer coefficient, } \\ \mathrm{r}_{\mathrm{f}} & = & \text { radius of fuel, } \\ \mathrm{A}_{\mathrm{f}} & = & \text { cross sectional area of fuel, and } \\ \mathrm{T}_{\mathrm{gr}} & = & \text { graphite temperature. }\end{array}$

An expression for the heat transfer coefficient is obtained as follows. The analytic solution to the steadystate one-dimensional heat conduction problem gives the heat flux at the graphite-fuel interface as onehalf of the graphite and fuel temperature rise times the heat transfer coefficient

$$
\frac{1}{\mathrm{~h}_{\mathrm{f}-\mathrm{gr}}}=\frac{\mathrm{r}_{\mathrm{f}}}{4 \mathrm{k}_{\mathrm{f}}}+\frac{\Delta \mathrm{r}_{\mathrm{gr}}}{2 \mathrm{k}_{\mathrm{gr}}}+\frac{1}{\mathrm{~h}_{\mathrm{gap}}}
$$

where

$$
\begin{array}{lll}
\mathrm{k}_{\mathrm{f}} & = & \text { fuel conductivity, } \\
\Delta \mathrm{r}_{\text {gr }} & = & \text { graphite thickness, and } \\
\mathrm{h}_{\text {gap }} & = & \text { gap conductivity. }
\end{array}
$$

But one-half the graphite and fuel temperature rise is approximately the difference between the average fuel and average graphite temperature, $\mathrm{T}_{\mathrm{f}}-\mathrm{T}_{\mathrm{gr}}$. Thus, the heat transfer coefficient given above will result in Eq. (6-1) being very nearly satisfied at steady state.

The energy equation for the graphite is

$$
\left(\rho \mathrm{C}_{\mathrm{p}}\right)_{\mathrm{gr}} \frac{\mathrm{dT}_{\mathrm{gr}}}{\mathrm{dt}}=\frac{\mathrm{h}_{\mathrm{f}-\mathrm{gr}} 2 \pi \mathrm{r}_{\mathrm{f}}}{\mathrm{A}_{\mathrm{gr}}}\left(\mathrm{T}_{\mathrm{f}}-\mathrm{T}_{\mathrm{gr}}\right)-\frac{\mathrm{h}_{\mathrm{gr}-\mathrm{cl}} 2 \pi \mathrm{r}_{\mathrm{gr}}}{\mathrm{A}_{\mathrm{gr}}}\left(\mathrm{T}_{\mathrm{gr}}-\mathrm{T}_{\mathrm{cl}}\right)
$$

where

$$
\begin{array}{lll}
\mathrm{T}_{\mathrm{cl}} & = & \text { coolant temperature } \\
\mathrm{h}_{\mathrm{gr}-\mathrm{cl}} & = & \text { cladding to coolant heat transfer coefficient } \\
\mathrm{r}_{\mathrm{gr}} & = & \text { outer radius of graphite, and } \\
\mathrm{A}_{\mathrm{gr}} & = & \text { cross sectional area of graphite. }
\end{array}
$$

The graphite to coolant heat transfer coefficient is given by

$$
\frac{1}{\mathrm{~h}_{\mathrm{gr}-\mathrm{cl}}}=\frac{\Delta \mathrm{r}_{\mathrm{gr}}}{2 \mathrm{k}_{\mathrm{gr}}}+\frac{1}{\mathrm{~h}_{\mathrm{cl}}}
$$


where $\Delta \mathrm{r}_{\mathrm{gr}}$ is the graphite thickness,

$$
\mathrm{h}_{\mathrm{cl}}=\frac{\mathrm{k}_{\mathrm{cl}}}{\mathrm{D}_{\mathrm{h}-\mathrm{cl}}} \mathrm{Nu}_{\mathrm{cl}}
$$

and where

$\mathrm{D}_{\text {h-cl }}=$ hydraulic diameter of the coolant channel, and

$\mathrm{Nu}_{\mathrm{cl}}=$ Nusselt number.

The values of engineering parameters that appear in the above equations are given in Table 6-1 and 6-2. The values are taken from the GT-MHR design.

The fuel and graphite temperature during a transient are obtained by solving Eq. (6-1) and (6-3) with the coolant temperature treated as a forcing function. The coolant temperature is assumed to be given by

$$
\mathrm{T}_{\mathrm{cl}}=\frac{\mathrm{T}_{\mathrm{in}}+\mathrm{T}_{\mathrm{out}}}{2}
$$

where $T_{\text {in }}$ is the core inlet temperature and $T_{\text {out }}$ is the outlet temperature. These two quantities are obtained from an energy balance on the core solved in parallel with the conservation equations for the rest of the primary system. Implicitly differencing Eq. (6-1) gives

$$
\mathrm{T}_{\mathrm{f}}{ }^{\mathrm{n}+1}-\mathrm{T}_{\mathrm{f}}{ }^{\mathrm{n}}=\Delta \mathrm{t} \mathrm{Q}_{\mathrm{f}}{ }^{\mathrm{n}}-\Delta \mathrm{tA} \mathrm{A}_{11} \mathrm{~T}_{\mathrm{f}}^{\mathrm{n}+1}+\Delta \mathrm{tA}_{11} \mathrm{~T}_{\mathrm{c}}^{\mathrm{n}+1}
$$

where

$$
A_{11}=\frac{\mathrm{h}_{\mathrm{f}-\mathrm{gr}} 2 \pi \mathrm{r}_{\mathrm{f}}}{\mathrm{A}_{f}\left(\rho \mathrm{C}_{\mathrm{p}}\right)_{f}} .
$$

Rearranging Eq. (6-7)

$$
\mathrm{C}_{11} \mathrm{~T}_{\mathrm{f}}^{\mathrm{n}+1}+\mathrm{C}_{12} \mathrm{~T}_{\mathrm{gr}}^{\mathrm{n}+1}=\mathrm{D}_{1}
$$

where

$$
\begin{aligned}
& \mathrm{C}_{11}=1+\Delta \mathrm{tA}_{11} \\
& \mathrm{C}_{12}=-\Delta \mathrm{tA}_{11} \\
& \mathrm{D}_{1}=\mathrm{T}_{\mathrm{f}}{ }^{\mathrm{n}}+\Delta \mathrm{tQ}_{\mathrm{f}}{ }^{\mathrm{n}} .
\end{aligned}
$$

Implicitly differencing Eq. (6-3) gives

$$
\mathrm{T}_{\mathrm{gr}}{ }^{\mathrm{n}+1}-\mathrm{T}_{\mathrm{gr}}{ }^{\mathrm{n}}=\Delta \mathrm{t} \mathrm{A}_{21}\left(\mathrm{~T}_{\mathrm{f}}^{\mathrm{n}+1}-\mathrm{T}_{\mathrm{gr}}{ }^{\mathrm{n}+1}\right)-\Delta \mathrm{t} \mathrm{A}_{23}\left(\mathrm{~T}_{\mathrm{gr}}{ }^{\mathrm{n}+1}-\mathrm{T}_{\mathrm{cl}}{ }^{n+1}\right)
$$


where

$$
\begin{aligned}
& A_{21}=\frac{h_{f-g r} 2 \pi r_{f}}{A_{g r}\left(\rho C_{p}\right)_{g r}} \\
& A_{23}=\frac{h_{g r-c l} 2 \pi r_{g r}}{A_{g r}\left(\rho C_{p}\right)_{g r}} .
\end{aligned}
$$

Rearranging Eq. (6-9)

$$
\mathrm{C}_{21} \mathrm{~T}_{\mathrm{f}}^{\mathrm{n}+1}+\mathrm{C}_{22} \mathrm{~T}_{\mathrm{gr}}^{\mathrm{n}+1}=\mathrm{D}_{2}
$$

where

$$
\begin{aligned}
& \mathrm{C}_{21}=-\Delta \mathrm{tA}_{21} \\
& \mathrm{C}_{22}=\Delta \mathrm{tA}_{21}+\Delta \mathrm{tA}_{23}+1 \\
& \mathrm{D}_{2}=\Delta \mathrm{tA}_{23} \mathrm{~T}_{\mathrm{cl}}{ }^{n+1}+\mathrm{T}_{\mathrm{gr}}{ }^{n}
\end{aligned}
$$

Solving Eq. (6-8) and (6-10) simultaneously gives

$$
\begin{aligned}
& \mathrm{T}_{\mathrm{gr}}^{\mathrm{n}+1}=\frac{\mathrm{D}_{1} \mathrm{C}_{21}-\mathrm{D}_{2} \mathrm{C}_{11}}{\mathrm{C}_{12} \mathrm{C}_{21}-\mathrm{C}_{22} \mathrm{C}_{11}} \\
& \mathrm{~T}_{\mathrm{f}}^{\mathrm{n}+1}=\frac{\mathrm{D}_{1}-\mathrm{T}_{\mathrm{gr}}{ }^{\mathrm{n}+1} \mathrm{C}_{12}}{\mathrm{C}_{11}}
\end{aligned}
$$


Table 6-1 Values of Design Parameters for Annular Unit-Cell Representation of Fuel Element

\begin{tabular}{|c|c|c|c|c|c|c|c|}
\hline \multirow[t]{2}{*}{ Coolant } & $n_{c l}$ & $\begin{array}{c}A_{c l} n_{c l} \\
\left(\mathrm{~m}^{2}\right)\end{array}$ & $\begin{array}{l}A_{c l} \\
\left(\mathrm{~m}^{2}\right)\end{array}$ & $\begin{array}{l}r_{c l} \\
(\mathrm{~m})\end{array}$ & $\begin{array}{c}C_{p-c l} \\
(\mathrm{j} / \mathrm{kg}-\mathrm{C})\end{array}$ & $\begin{array}{c}k_{c l} \\
(\mathrm{w} / \mathrm{m}-\mathrm{C})\end{array}$ & - \\
\hline & 106 & $102 \frac{\pi}{4} 0.016^{2}=0.022$ & $2.1 \mathrm{E}-04$ & $26 \mathrm{E}-03$ & 5200 & 0.37 & \\
\hline \multirow[t]{2}{*}{ Graphite } & - & $\begin{array}{c}A_{g r} n_{c l} \\
\left(\mathrm{~m}^{2}\right)\end{array}$ & $\begin{array}{l}A_{g r} \\
\left(\mathrm{~m}^{2}\right)\end{array}$ & $\begin{array}{l}r_{g r} \\
(\mathrm{~m})\end{array}$ & $\begin{array}{c}C_{p-g r} \\
(\mathrm{j} / \mathrm{kg}-\mathrm{C})\end{array}$ & $\begin{array}{c}k_{g r} \\
(\mathrm{w} / \mathrm{m}-\mathrm{C})\end{array}$ & $\begin{array}{c}\rho_{g r} \\
\left(\mathrm{~kg} / \mathrm{m}^{3}\right)\end{array}$ \\
\hline & & $\begin{array}{c}\sqrt{ } 3(0.360)^{2}-0.022- \\
\quad 0.027=0.175\end{array}$ & $1.7 \mathrm{E}-03$ & $25 \mathrm{E}-03$ & 1100 & 80 & 1,740 \\
\hline \multirow[t]{2}{*}{ Fuel } & - & $\begin{array}{l}A_{f} n_{c l} \\
\left(\mathrm{~m}^{2}\right)\end{array}$ & $\begin{array}{c}A_{f} \\
\left(\mathrm{~m}^{2}\right)\end{array}$ & $\begin{array}{c}r_{f} \\
(\mathrm{~m})\end{array}$ & $\begin{array}{c}C_{p-f} \\
(\mathrm{j} / \mathrm{kg}-\mathrm{C})\end{array}$ & $\begin{array}{c}k_{f} \\
(\mathrm{w} / \mathrm{m}-\mathrm{C})\end{array}$ & $\begin{array}{c}\rho_{f} \\
\left(\mathrm{~kg} / \mathrm{m}^{3}\right)\end{array}$ \\
\hline & & $210 \frac{\pi}{4} 0.0127^{2}=0.027$ & $2.5 \mathrm{E}-04$ & $8.9 \mathrm{E}-03$ & $\begin{array}{c}160 \\
\left(C p_{U C_{2}} \sim C p_{U C}\right)\end{array}$ & $\begin{array}{c}20 \\
(\mathrm{UC})\end{array}$ & 13,600 \\
\hline
\end{tabular}

Table 6-2 Values of Design Parameters for Coolant Channel in Fuel Element

\begin{tabular}{|c|c|c|c|c|}
\hline \multirow[t]{2}{*}{$\begin{array}{l}\text { Coolant Mass } \\
\text { Flow Rate }\end{array}$} & $\begin{array}{c}\text { Number of Coolant Holes per Fuel } \\
\text { Element }\end{array}$ & $\begin{array}{c}\text { Number of Fuel Element } \\
\text { Columns }\end{array}$ & $\begin{array}{c}\text { Coolant Mass Flow Rate in } \\
\text { Fueled Elements } \\
(\mathrm{kg} / \mathrm{s})\end{array}$ & $\begin{array}{c}\text { Coolant Mass Flow Rate } \\
\text { per Coolant Channel } \\
(\mathrm{kg} / \mathrm{s})\end{array}$ \\
\hline & 106 & $72+30=102$ & $288 * 0.85=244$ & 0.023 \\
\hline \multirow[t]{2}{*}{$\begin{array}{l}\text { Coolant Heat } \\
\text { Transfer } \\
\text { Coefficient }\end{array}$} & $(\mathrm{Re})_{\mathrm{He}}$ & $(\mathrm{Pr})_{\mathrm{He}}$ & $\begin{array}{l}D_{c l} \\
(\mathrm{~m})\end{array}$ & $\begin{array}{c}h_{c l}=\frac{k_{H e}}{D_{c l}} 0.023 \operatorname{Re}^{0.8} \operatorname{Pr}^{0.3} \\
\left(\mathrm{~W} / \mathrm{m}^{2}-\mathrm{C}\right)\end{array}$ \\
\hline & 41,000 & -1 & $\begin{array}{c}0.016 \\
\text { (coolant channel diameter) }\end{array}$ & 2600 \\
\hline
\end{tabular}




\subsubsection{Reactivity Feedback}

\subsection{Control Rods}

The arrangement of control rods and core structures within the reactor vessel has an effect on reactivities feedbacks. The effect is derived here for the GT-MHR upon which the VHTR is based. The key features are 1) the reactor inlet coolant enters the core at the top and flows vertically down, 2) the control rod drive mechanisms are fixed to the top of the vessel and the rods enter at the top of the core, 3) the core rests on the bottom of the vessel, 4) the vessel wall is cooled by the coolant entering the reactor vessel, 5) the physical dimensions of the core are large compared to the neutron mean free path such that reactivity chage associated with a change in leakage due to core temperature expansion is insignificant, and 6) the reactivity feedback associated with coolant density is negligable.

Temperature changes in the core introduce control rod reactivity through mateiral thermal expansion in two ways. First, the vessel temperature is assumed equal to the reactor inlet temperature so a change in the vessel length in response to a change in reactor inlet temperature results in a change in control rod position relative to the top of the core. Second, as the temperature of the graphite-fueled blocks changes the core exapnds/contracts in the axial direction resulting in a change in control rod position relative to the top of the core. The net change in reactivity is then

$$
\delta \rho=\left(-(L \beta)_{v}\left(T_{i}-T_{i, 0}\right)+(L \beta)_{g r}\left(T_{g r}-T_{g r, 0}\right)\left(\frac{d \rho}{d L}\right)_{c r}\right.
$$

where

$$
\begin{array}{ll}
L & =\text { length, } \\
B & =\text { coefficient of linear expansion } \\
T_{i} & =\text { reactor inlet coolant temperature and } \\
T_{g r} & =\text { reactor midplane graphite temperature, and }
\end{array}
$$

and where the last term is the differential rod worth, the change in reactivity per unit change in the length of that part of the rod that is inserted in the core. This term is typically negative for an increase in length. The subscripts $v, g r, c r$ represent vessel, graphite, and control rod, respectively. The above expression is rewritten as

$$
\delta \rho=\alpha_{c r-v}\left(T_{i}-T_{i, 0}\right)+\alpha_{c r-g r}\left(T_{g r}-T_{g r, 0}\right)
$$

where $\quad \alpha_{c r-v}=-(L \beta)_{v}\left(\frac{d \rho}{d L}\right)_{c r}$ and $\quad \alpha_{c r-g r}=(L \beta)_{g r}\left(\frac{d \rho}{d L}\right)_{c r}$.

A value for the differential rod worth for the VHTR is estimated in Table 6-2. The Operating Control Rods normally must be inserted into the top of the core to achieve criticality.

Table 6-2 Upper Bound for Differential Worth of Operating Control Rods for GT-MHR

\begin{tabular}{|l|l|}
\hline Number of Operating Control Rods & a \\
\hline Upper limit on worth per $\operatorname{rod}^{\mathrm{b}}(\$)$ & 36 \\
\hline
\end{tabular}




\begin{tabular}{|l|l|}
\hline Absorber length of Operating Control $\operatorname{Rod}^{\mathrm{c}}(\mathrm{in} / \mathrm{m})$ & $229 / 5.8$ \\
\hline Worth per absorber per unit absorber length $(\$ / \mathrm{m})$ & $0.5 / 5.8=0.086$ \\
\hline $\begin{array}{l}\text { Combined worth of Operating Control Rods per unit absorber length, } \\
\left(\frac{d \rho}{d L}\right)_{c r}(\$ / \mathrm{m})\end{array}$ & $0.086(36)=3.1$ \\
\end{tabular}

${ }^{\text {a }}$ Startup control rods are withdrawn before criticality: p.4-5 and p. 4-12 of Shenoy (1996).

Operating control rods are inserted to varying heights during operation: p.4-22 of Shenoy (1996).

${ }^{b}$ Each control rod has its own independent drive: p.4-26 of Shenoy (1996). Any single drive, for

safety reasons, should be limited to less then one dollar.

${ }^{c}$ Figs. 4.1-12, 4.1-13, and 4.2-2 Shenoy (1996). Scaled from these figures.

The values of reactivity coefficients associated with this differential expansion are estimated in Table 6-3. An increase in vessel temperature causes the rods to be move upward relative to the top of the core adding reactivity. An increase in fuel element temperature causes the core length to increase effectively causing the rods to move further into the core adding negative reactivity.

Table 6-3 Control Rod Reactivity Coefficients for VHTR

\begin{tabular}{|c|c|}
\hline $\begin{array}{l}\text { Operating Control Rods }- \text { Vessel: } \alpha_{\mathrm{cr}-\mathrm{v}} \\
\text { Length, } \mathrm{L}(\mathrm{m}) \quad(\text { hot duct to top of core) } \\
\text { Steel coefficient of thermal expansion, } \beta(\mathrm{m} / \mathrm{m} / \mathrm{C}) \\
\text { Differential worth, d } \mathrm{d} / \mathrm{dL}(\$ / \mathrm{m})[\text { Table } 6-2] \\
\alpha_{\mathrm{cr}-\mathrm{v}},\left(\$ /{ }^{\circ} \mathrm{C}\right)[\text { Eqs. }(6-12) \text { and }(6-13)]\end{array}$ & $\begin{array}{l}437 \cdot 2.54 \mathrm{e}-2=11.1 \\
1.5 \mathrm{e}-5 \\
3.1 \\
11.1 \cdot 1.5 \mathrm{e}-5 \cdot 3.1=5.2 \mathrm{e}-4\end{array}$ \\
\hline $\begin{array}{l}\text { Operating Control Rods - Graphite: } \alpha_{\mathrm{cr}-\mathrm{gr}} \\
\text { Length }, \mathrm{L}(\mathrm{m}) \quad(\text { active core height }), \\
\text { Graphite coefficient of thermal expansion, } \\
\beta(\mathrm{m} / \mathrm{m} / \mathrm{C}) \\
\text { Differential worth, d } / \mathrm{dL}(\$ / \mathrm{m})[\text { Table } 6-2] \\
\alpha_{\text {cr-gr }},\left(\$ /{ }^{\circ} \mathrm{C}\right)[\text { Eqs. }(6-12) \text { and }(6-13)]\end{array}$ & $\begin{array}{l}7.93 \\
0.3 e-5 \\
3.1 \\
-7.93 \cdot 0.3 e-5 \cdot 3.1=-0.74 \mathrm{e}-4\end{array}$ \\
\hline
\end{tabular}

\subsection{Graphite Moderation}

The neutron flux spectrum and neutron leakage change with graphite temperature creating a source of reactivity. Assuming the fuel temperature is maintained constant, the reactivity introduced relative to a reference graphite temperature is represented by

$$
\delta \rho=\alpha_{g r-m}\left(T_{g r}-T_{g r, 0}\right)
$$

where $T_{g r}$ is the graphite midplane temperature. An estimate for the graphite moderator temperature coefficient of reactivity, $\alpha_{\mathrm{gr}-\mathrm{m}}$ is given in Table 6-4. 
Table 6-4 Graphite Moderator and Fuel Doppler Reactivity Coefficients

Graphite, $\alpha_{\mathrm{gr}-\mathrm{m}}(\mathrm{dk} / \mathrm{dT}) @ 770^{\circ} \mathrm{C}^{\mathrm{a}}$ (Fig. 37 MacDonald 2003) $\quad[-1.0 \mathrm{e}-5,+4.0 \mathrm{e}-5]$ $\alpha_{\text {gr-m }}\left(\$ /{ }^{\circ} \mathrm{C}\right)$

$[-1.67 \mathrm{e}-3,+6.67 \mathrm{e}-3]$, mean $=2.5 \mathrm{e}-03$

Doppler, $\alpha_{\mathrm{D}}(\mathrm{dk} / \mathrm{dT}) @ 820^{\circ} \mathrm{C}^{\mathrm{a}}$ (Fig. 35 MacDonald 2003 ) $\alpha_{\mathrm{D}}\left(\$ /{ }^{\circ} \mathrm{C}\right)$

${ }^{\mathrm{a}}$ Average graphite and fuel temperature from Table ii MacDonald (2003).

\subsection{Coolant Density}

A coolant density reactivity coefficient, $\alpha_{H e}$, is defined through

$$
\rho_{\text {void }}-\rho_{0}=\alpha_{H e}\left(\theta_{\text {void }}-\theta_{0}\right)
$$

where

$$
\begin{array}{lll}
\rho & = & \text { reactivity, and } \\
\theta & = & \text { density. }
\end{array}
$$

The subscript void denotes the core with no coolant present and the subscript 0 denotes the full power reference condition. At the reference condition $\rho_{0}$ is taken as zero. The ideal gas law gives for the coolant at the core midplane,

$$
\theta=\frac{P}{R T_{c l, K}}
$$

where $T_{\mathrm{cl}}$ is the reactor midplane coolant mixed-mean temperature in degrees Kelvin and $\mathrm{P}$ is the gas pressure. The reactivity change relative to the reference state for a change in temperature and pressure is then from Eq. (6-16) and (6-17)

$$
\rho=\frac{\alpha_{H e}}{R}\left(\frac{P}{T_{c l}}-\left(\frac{P}{T_{c l}}\right)_{0}\right) .
$$

The coolant density reactivity coefficient can be solved for using Eqs. (6-16) and (6-18) is

$$
\alpha_{H e}=-R\left(\frac{T_{c l}}{P}\right)_{0} \rho_{v o i d} .
$$

Typically, the coolant density reactivity coefficient is negligible in the thermal gas reactor and is set to zero in this work.

\subsection{Fuel Doppler}

The change in k-effective with the temperature of the fuel at the core midplane, $T_{f}$, is given by 


$$
\frac{d k_{e f f}}{d T_{f}}=\frac{K_{D}}{T_{f}}
$$

where the left-hand side is the Doppler coefficient and $K_{D}$ is the Doppler constant. Integrating the above expression gives

$$
\delta k_{e f f}=K_{D} \ln \left(\frac{T_{f}}{T_{f, 0}}\right)
$$

where the subscript 0 denotes the full power steady-state condition. At this condition the net reactivity of the core is zero and $k_{\text {eff }}$ is unity. For a change from this state the new values of $\rho$ and $k_{\text {eff }}$ are related by

$$
\rho=\frac{k_{e f f}-1}{k_{e f f}} \approx \delta k_{e f f}
$$

where $\delta k_{\text {eff }}$ is the change in k-effective in going from full power steady state to the new state. Then from Eqs. (6-21) and (6-22), the reactivity in dollars from the change in fuel temperature is

$$
\rho=\frac{K_{D}}{\beta_{\text {eff }}} \ln \left(\frac{T_{f}}{T_{f, 0}}\right) \approx \alpha_{D}\left(T_{f}-T_{f, 0}\right)
$$

where

$$
\alpha_{D}=\frac{K_{D}}{\beta_{e f f} T_{f, 0}} .
$$

An estimate for the Doppler temperature coefficient of reactivity, $\alpha_{D}$, is given in Table 6-4,

\subsection{Net Reactivity}

The net reactivity is the sum of the individual components given by Eqs. (6-13), (6-15), (6-18), and (6$23)$, plus any reactivity added through control rod motion not related to thermal expansion,

$$
\begin{aligned}
\rho=\alpha_{c r-v} & \left(T_{i}-T_{i, 0}\right)+\left(\alpha_{c r-g r}+\alpha_{g r-m}\right)\left(T_{g r}-T_{g r, 0}\right) \\
+ & \frac{\alpha_{H e}}{R}\left(\frac{P}{T_{c l}}-\left(\frac{P}{T_{c l}}\right)_{0}\right)+\alpha_{D}\left(T_{f}-T_{f, 0}\right)+\rho_{r o d} .
\end{aligned}
$$

The values for reactivity coefficients appearing in the above equation are taken from the preceding tables. The values are summarized in Table 6-5. 
Table 6-5 Summary of Reactivity Feedback Coefficients

\begin{tabular}{|c|c|c|c|c|}
\hline $\begin{array}{c}\alpha_{c r-v} \\
(\$ / \mathrm{C})\end{array}$ & $\begin{array}{c}\alpha_{c r-g r} \\
(\$ / \mathrm{C})\end{array}$ & $\begin{array}{c}\alpha_{g r-m} \\
(\$ / \mathrm{C})\end{array}$ & $\alpha_{H e}$ & $\begin{array}{c}\alpha_{D} \\
(\$ / \mathrm{C})\end{array}$ \\
\hline $5.2 \mathrm{E}-04$ & $-0.74 \mathrm{E}-04$ & $25 \mathrm{E}-04$ & 0 & $-83 \mathrm{E}-04$ \\
\hline
\end{tabular}

\section{HYPEP V\&V PLAN}

One of the most important parts in code development is validation and verification (V\&V). This section describes the methods to validate and verify HyPEP code developed in the current research. The V\&V process will be carried out divided into three parts. Firstly, the gas property models, the most basic parameters in thermal hydraulics analysis are validated by comparisons with reference data, and then the system component models like pump, turbine, reactor and etc. are validated. Finally, the integration of each system component will be validated. The details are described as follows.

\subsection{Validation of Gas Property Model}

The validation of gas property models is the first V\&V process. The accuracy of the property models is the most fundamental part in thermal hydraulics analysis. Although we have very good component and system models, reliable analysis is impossible without accurate property models. The validation of gas properties are divided into two parts. One is the validation of single gas property model, and the other of mixture property model. Two gas properties, density and heat capacity are compared with the reference data since HyPEP code is basically a 1-D steady state code. In a 1-D steady state code, thermal conductivity and viscosity are not used for analysis. For single gas property validation, NIST chemistry database and HYSYS Peng-Robins Equation-of-State model will be used as the references. For mixture gas property, only HYSYS code mixture model is available since NIST does not provide mixture gas property data. Figure 7-1 and 7-2 shows the NIST fluid property database and HYSYS flowsheet for validation of gas properties, respectively. 


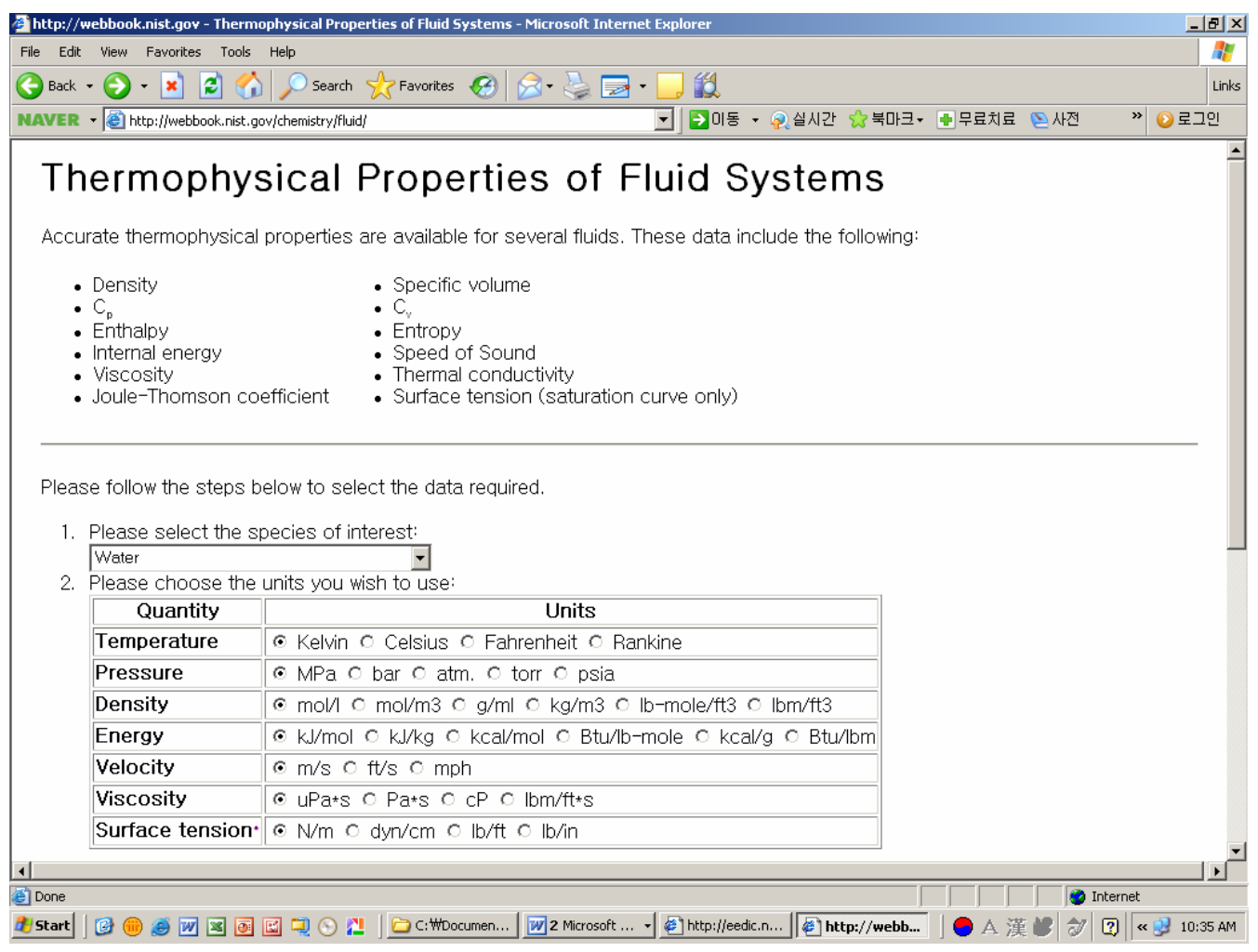

Figure 7-1. NIST chemistry webbook (http://webbook.nist.gov/chemistry/fluid/)

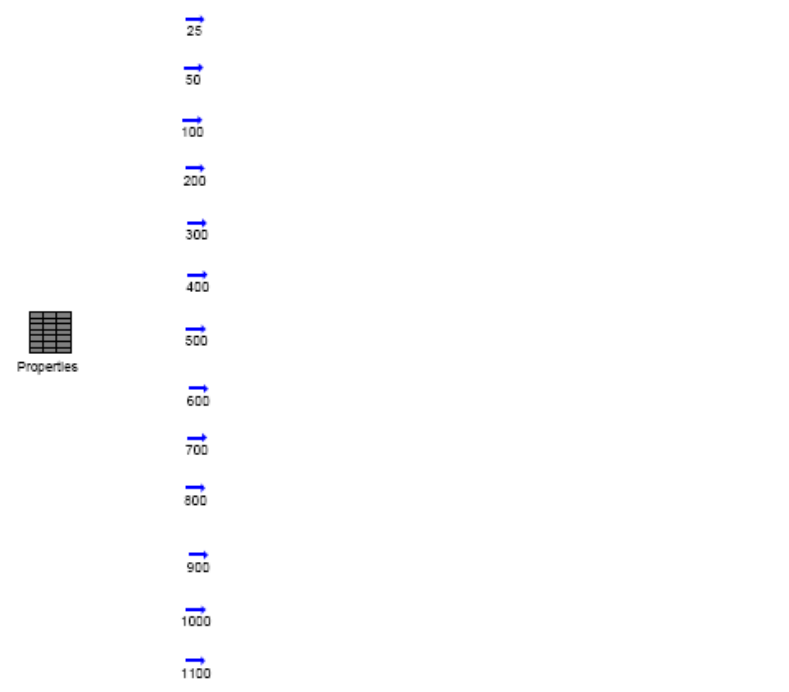

Figure 7-2. HYSYS simple flowsheet for validation of property model

In this work, the properties of five gas species are compared with the reference data. The gases are $\mathrm{He}, \mathrm{CO} 2, \mathrm{H} 2, \mathrm{O} 2$ and $\mathrm{H} 2 \mathrm{O}$. Helium is a favorable coolant material considered in VHTR due to its high heat capacity and thermal conductivity. It can be used all over the system components. Carbon dioxide is one alternative material for helium. It can be used for PCU system providing high efficiency even at lower operating temperature. However, it is not available for primary coolant because of its reactivity 
to the graphite materials in the reactor core. Hydrogen, oxygen and steam are the important gases to be validated for integrated VHTR/HTSE system, because their thermal properties are highly associated with the total hydrogen generation efficiency. The ranges of validations are $0.1 \sim 32 \mathrm{MPa}$ in pressure and $300 \sim 1350 \mathrm{~K}$ in temperature. Therefore, the following gas species and properties are scheduled to be validated in the next work year. Figure 7-3 and 7-4 shows some sample reference data to be used for property validation.

\section{a. Gas species and properties to be validated}

i. Helium

- Density

- Heat Capacity

ii. $\mathrm{CO}_{2}$

- Density

- Heat Capacity

iii. $\mathrm{H}_{2}$

- Density

- Heat Capacity

iv. $\mathrm{O}_{2}$

- Density

- Heat Capacity

v. $\mathrm{H}_{2} \mathrm{O}$

- Density

- Heat Capacity

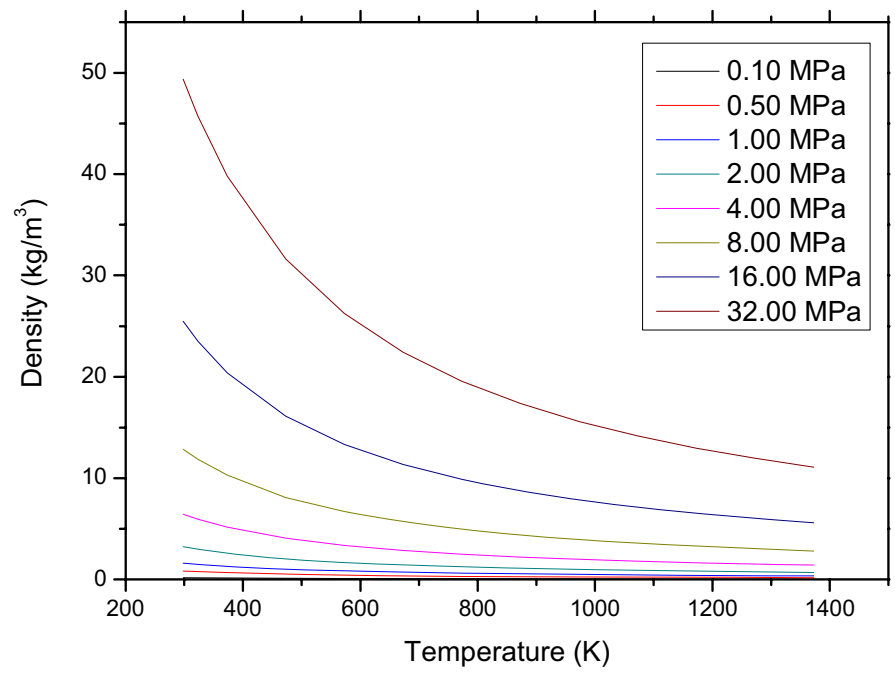

Figure 7-3. Reference density (Helium) calculated by Peng Robins EOS Model (HYSYS) 


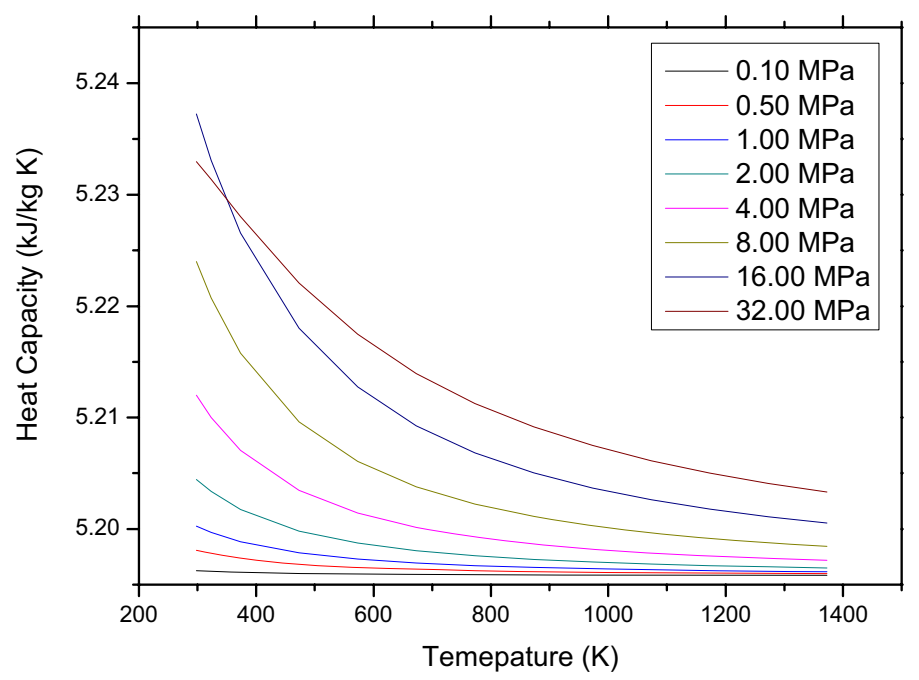

Figure 7-4. Reference heat capacity (Helium) calculated by Peng Robins EOS Model (HYSYS)

Once the single gas properties are validated, mixture gas properties should be validated. The mixture properties are determined by the mixing law used in the mixture model. HYSYS code calculation is used as the reference data to validate the HyPEP mixture property model, since the mixture property database is not provided by NIST chemistry webbook. Validation will be carried out on the binary and ternary mixture, and some selected gas combinations and concentrations will be used here because of the time and cost limitations. Helium/CO2, Helium/O2 and Helium/CO2/O2 mixtures will be validated as follows. Figure 7-5 through 7-9 show some reference data for mixture gas properties.

\section{b. Multi-gas properties}

i. Binary gas mixture

- Helium $/ \mathrm{CO}_{2}$ mixture

- Density

- Heat Capacity

- Helium $/ \mathrm{O}_{2}$ mixture

- Density

- Heat Capacity

ii. Ternary gas mixture

- Helium $/ \mathrm{CO}_{2} / \mathrm{O}_{2}$ mixture

- Density

- Heat Capacity 


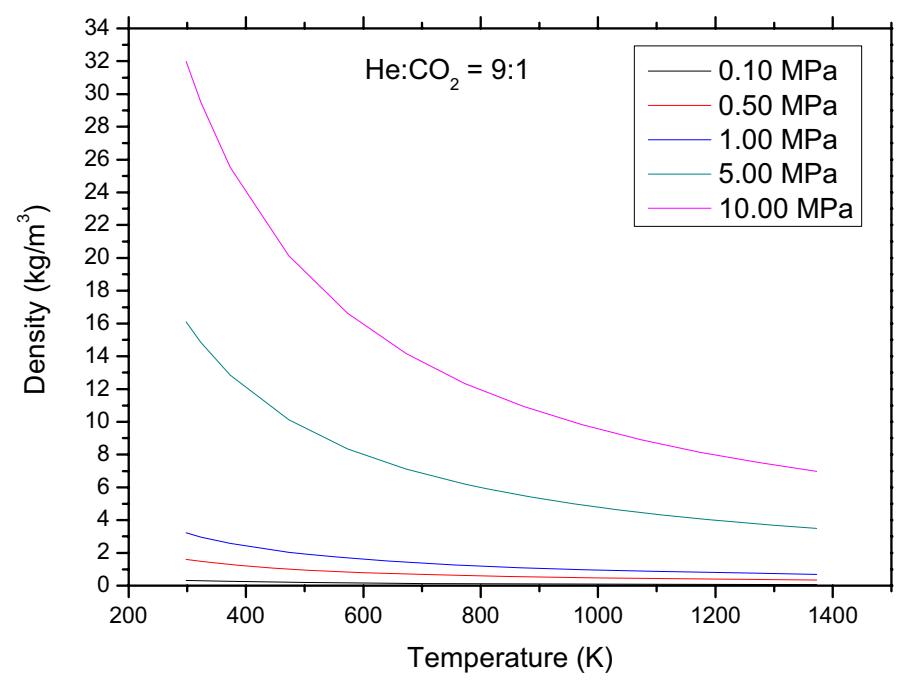

Figure 7-5. Reference density calculated for $\mathrm{He} / \mathrm{CO} 2$ mixture (He:CO2=9:1) by Peng Robins EOS Model (HYSYS)

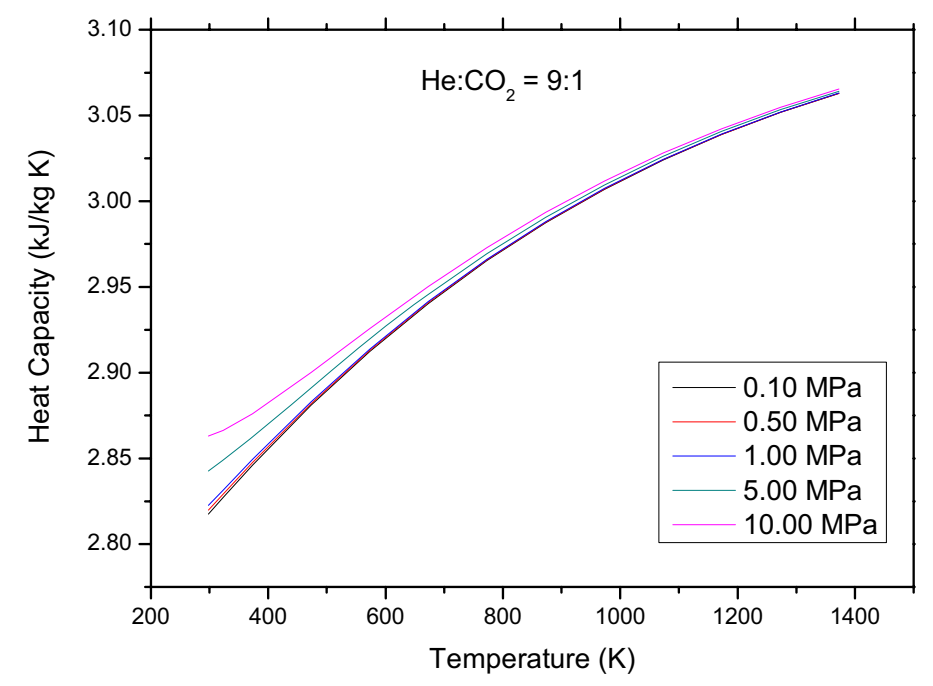

Figure 7-6. Reference heat capacity calculated for $\mathrm{He} / \mathrm{CO} 2$ mixture (He:CO2=9:1) by Peng Robins EOS Model (HYSYS) 


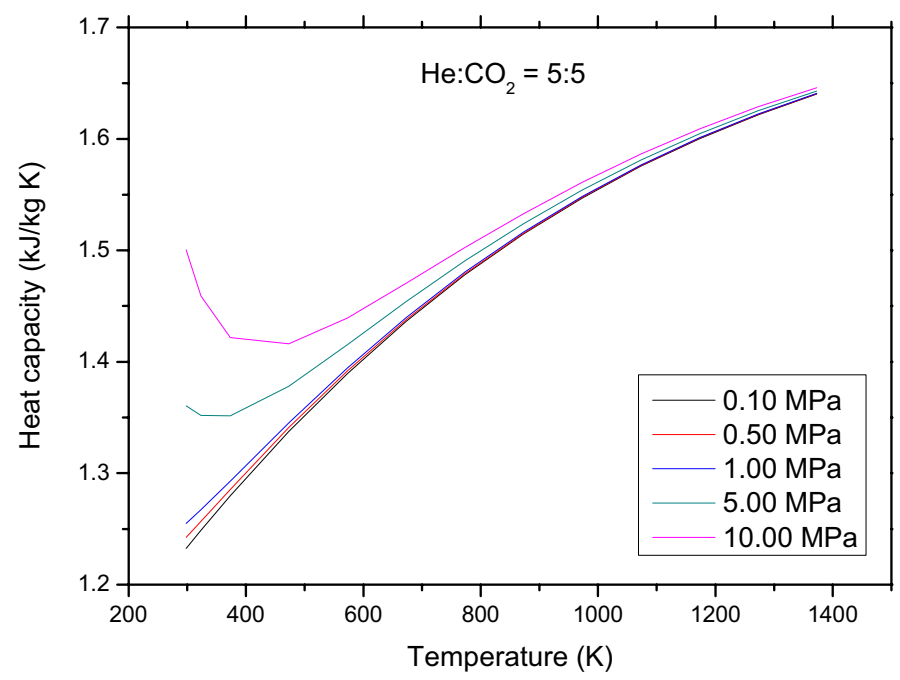

Figure 7-7. Reference heat capacity calculated for $\mathrm{He} / \mathrm{CO} 2$ mixture (He:CO2=5:5) by Peng Robins EOS Model (HYSYS)

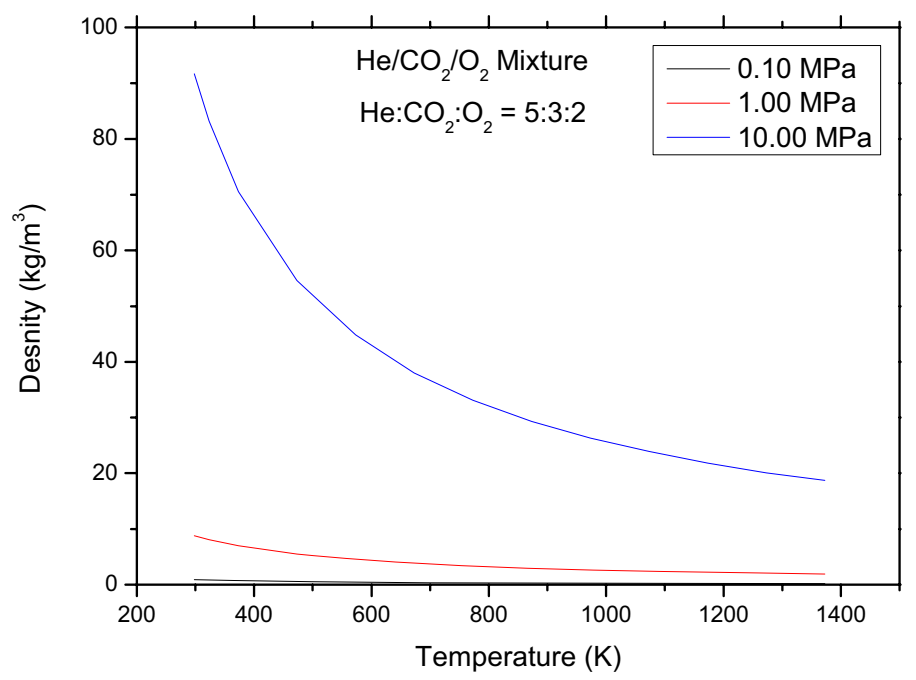

Figure 7-8. Reference heat capacity calculated for $\mathrm{He} / \mathrm{CO} 2$ mixture $(\mathrm{He}: \mathrm{CO} 2: \mathrm{O} 2=5: 3: 2)$ by Peng Robins EOS Model (HYSYS) 


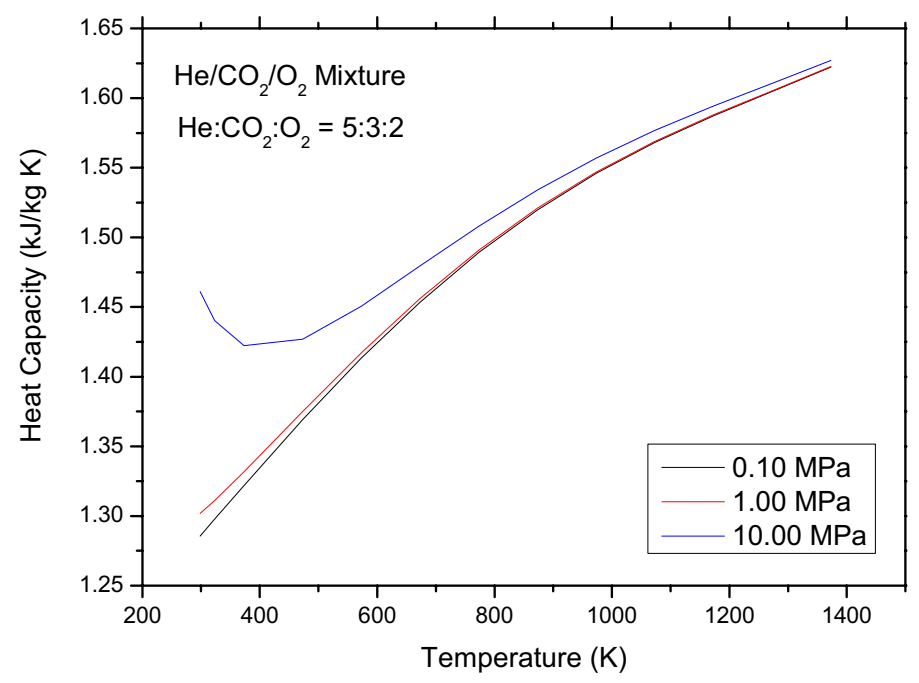

Figure 7-9. Reference heat capacity calculated for $\mathrm{He} / \mathrm{CO} 2$ mixture $(\mathrm{He}: \mathrm{CO} 2: \mathrm{O} 2=5: 3: 2)$ by Peng Robins EOS Model (HYSYS)

\subsection{Validation of System Component Model}

Once the properties models are validated, the system component models should be validated next. To validate the component model, HYSYS code is used to generate the reference data. There are some important system components that should be validated in system modeling; heat exchanger, turbo machinery, reactor, heater/cooler and etc. Each component has different system parameters and they should be extensively tested.

\section{a. Reactor System Components}

The reactor system components will include the specialized components for the pebble bed reactors and the prismatic reactors. The reactor component models the nuclear reactor. For the hydrogen production efficiencies, the main differences of the reactor systems to consider are the core and vessel pressure drops. The pebble bed reactor component and the prismatic reactor component will have empirically derived correlations suitable to each design for estimating the core and vessel-wide pressure drop. The following parameters should be considered to validate reactor component model.

- Heat duty

- Pressure drop

\section{b. Heat Exchanger Components}

Heat exchanger is the most basic component in integration system. It transfers heat from one side to the other side making the heat used for generating electrical works and increasing hydrogen production system. Heat exchanger has the following essential parameters to be validated.

- Overall heat transfer coefficient

- Effectiveness 
- Log mean temperature

- Heat transfer duty

- $\quad$ Minimum temperature approach

\section{c. PCU Components}

PCU components will include Brayton cycle component and Rankin cycle component. Reheats and the superheating circuits may be modeled using the base component of HyPEP. The PCU components will calculate the electricity generation efficiencies. Turbine and compressor are the most essential components in the PCU system. The following parameters should be validated here.

- Turbine and compressor efficiency (isentropic or polytropic)

- Pressure ratio

\section{d. Electrolyzer}

HTSE components will be provided to model the high temperature steam electrolysis. The HTSE will be formed by the electrolyzer, separator, condenser, heat exchanger, etc. Among these components, electrolyzer is the key component in this system. To validate this components, the following parameters should be considered.

- Electrical power input

- ASR

- Operating temperature and pressure

\subsection{Validation of System Integration}

After validation of the components models, the integration of the system components will be finally validated. The integration systems previously developed in this study will be used for this validation work; a direct serial system, a direct parallel system, an indirect serial system, an indirect parallel system, a steam combined system, a reheat system and etc. This work will extensively confirm the validity of this code for application to the VHTR and hydrogen production systems by benchmark with the commercial process analysis codes such as HYSYS and ASPEN Plus.

\section{SUMMARY}

Various parts of system integration were investigated in this research concerning with a nuclear reactor and a hydrogen production system. First of all, direct integration methods of a high temperature Rankin cycle (HTRC) and HTSE system was thermodynamically estimated as alternatives for the VHTR/HTSE system. Despite of its lower efficiency, the direct combination of HTRC and HTSE systems has some advantages compared with VHTR/HTSE system. Firstly, it requires no additional steam generation loop because the steam generated in the secondary side to produce electricity is used for electrolysis as well. Therefore, the configuration of this system can be highly simplified reducing its size, complexity and capital cost. Secondly, the steam Rankin cycle is well proven technology. The system has been used for several decades in the most commercial nuclear reactors. It means that we have lots of design and operating experiences on this reactor, even though high temperature application requires more severe operating conditions than the current one. It will cause the reduction of the uncertainties for the newly 
developed technology. In this work, the efficiency of this system has been estimated by HYSYS code, commercial process analysis software. As a result, $41.6 \%$ of maximum efficiency was obtained for a specific configuration (Configuration 2) described in the section 2. This efficiency looks much smaller than the reference VHTR/HTSE system ( $49 \%)$. However, more investigations on the economical and technical aspects are necessary for better estimation.

The heat generation loop and the heat transfer loops were integrated into the Aspen Plus ${ }^{\circledR}$ SI model created by General Atomics (GA). Helium was used as the working fluid in the heat transfer loop from the nuclear reactor. The original model contained heaters, coolers, and other types of blocks with specified or calculated heat duties. The energy supplied to the system was ambiguously added through these blocks. Replacing the heaters and coolers with heat exchangers allowed the SI process model to also demonstrate the transfer of heat from the helium to the process streams. Hot helium was used to heat streams via heat exchangers in place of heaters while a combination of cool helium and cooling water was used to cool streams to the appropriate temperatures. Sensitivity analyses were used vigorously to minimize the heat lost to water and to increase the system's efficiency. The heat generation loop based off a HYSYS ${ }^{\circledR}$ example was created in Aspen Plus ${ }^{\circledR}$ to supply hot helium to the heat transfer loops. It also validated Aspen Plus ${ }^{\circledR}$ as a useful tool in modeling the SI process. Once the system is fully integrated and pieced together, the Balance of Plant (BOP) will be analyzed.

In this study, the optimum size of the compact heat exchanger, a key component of VHTR and HTSE system integration, has been investigated from the economic point of view. The optimum sizing model developed based on the capital and operating cost was used for estimation on the heat exchanger size and cost of the reference 600 MWt VHTR system.

Lastly, we set up the strategy and plan for V\&V of HyPEP code, the final product in this research. The validation process is divided into three parts; property model validation, system component model validation and system integration model validation. The property models are validated by comparisons with NIST chemistry data and Peng-Robins EOS model in HYSYS. Single and mixture gas properties are all planned to be validated in the next work year. After property validation, the system component models such as turbo machinery, reactor and electrolyzer will be validated. The flowsheets and component models in HYSYS code will be used here for this purpose. If the component models are successfully validated, the integration of the components will be finally validated by the well-made process analysis data in the previous work years. Various flowsheets from VHTR/HTSE to HTRC/HTSE system will be extensively used for this validation work.

\section{ACKNOWLEDGMENTS}

This work was supported through the Department of Energy's ROK/US-INERI Program under DOE Idaho Operations Office Contract DE-AC07-99ID13727. 


\section{REFERENCES}

Aspen Technology, HYSYS User's Manual, Version 2.2.2, 2001.

Bajan A., Klaus A.D., Heat Transfer Handbook, John Wiley \& Sons, 2003

Davis, C. B., Oh, C. H., Barner, R. B., Sherman, S. R., Wilson, D. F., 2005, Thermal-Hydraulic Analyses of Heat Transfer Fluid Requirements and Characteristics for Coupling A Hydrogen Production Plant to a High-Temperature Nuclear Reactor, INL/EXT-05-00453.

Depiante E.V., Stability analysis of a liquid-metal reactor and its primary heat transport system, Nuclear Engineering and Design, 152, pp.261-377, 1994.

Dewson J. J., Grady C., HEATRICTM Workshop at MIT, Cambridge, Ma, USA., October 2nd, 2003

Dostal V., Driscoll M.J., Hejzler P., A Supercritical Carbon Dioxide Cycle for Next Generation Nuclear Reactor, MIT-ANP-TR-100, 2004

Energy Information Administration (EIA), Average Retail Price of Electricity to Ultimate Consumers by End-Use Sector, www.eia.doe.gov, 2007

Hartvigsen J., personal communication, Ceramatec, November 28, 2006.

Hesselgreaves, J.E., Compact Heat Exchangers, Selection, Design and Operation, 1st edition, Pergamon, 2001

Independent Technology Review Group, Design Features and Technology Uncertainties for the Next [2] Generation Nuclear Plant, INEEL/EXT-04-01816, June 30, 2004.

Kakac S., Liu H., Heat Exchangers - Selection, Rating, and Thermal Design, CRC Press, 2002

Kays W.M. and London A.L., Compact Heat Exchagners, 3rd ed., McGraw-Hill, New York, 1984

MacDonald P., NGNP Point Design - Results of the Initial Neutronics and Thermal-Hydraulics Assessments during FY-03, INEEL/EXT-03-00870 Ref. 1, September 2003.

Mckellar, M.G., Optimization of a Household Refrigerator Considering Alternative Refrigerants, Ph.D. Thesis, Department of Mechanical Engineering, Purdue University, August 1992.

Nikitin K., Kato Y., Ngo L., Printed circuit heat exchanger thermal-hydraulic performance in supercritical CO2 experimental loop, International Journal of Refrigeration, Vol. 29, pp. 807-814, 2006

NIST Chemistry WebBook, http://webbook.nist.gov/chemistry

Oh, C.H., C.B. Davis, J. Han, R. Barner, S. Sherman, R. Vilim, Y.J. Lee, and W.J. Lee, INEEL, 2006, HyPEP FY06 Report: Models and Method, INEEL/EXT-06-11725, September 2006a.

Oh, C.H., T. Lillo, W. Windes, T. Totemeier, B. Ward, R. Moore, and R. Barner, Development of a Supercritical Carbon Dioxide Brayton Cycle: Improving VHTR Efficiency and Testing Material Compatibility, Final Report, INL/EXT-06-01271, March 2006b. 
Oh C.H., Kim E.S., Sherman S.R., and Vilim R.B., HyPEP FY-07 Report: System Model Integration Model Development, INL/EXT-07-12470, April 2007

Ohta T., Solar-Hydrogen Energy Systems, Pergamon Press, 1979.

Oyakawa K., Shinzato, T. and Mabuchi I., The effect of the channel width on heat transfer augmentation in sinusoidal wave channel, JSME International Journal, Series II, Vol. 32, no. 3, pp 403-410, 1989.

Pradhan S. , et al., Effects of Electrical Feedbacks on Planar Solid-Oxide Fuel Cells, ASME Transactions on Fuel Cell Science and Technologies, vol. 3, issue 4, November 2006.

Shenoy A., Gas Turbine-Modular Helium Reactor (GT-MHR) Conceptual Design Report, Report number 910720/1, General Atomics, July 1996.

Stoots C.M., Engineering Process Model for High-Temperature Electrolysis System Performance Evaluation, Idaho National Laboratory, June 2005.

Sung Chu, Song, Thermal-hydraulic performance of a printed circuit heat exchanger in an air test loop, M.S. Thesis of Korea Advanced Institute of Science and Technology (KAIST), 2005

The MathWorks, Inc., Matlab User's Manual, Version 7.3, 2006.

Vilim R.B., Cahalan J., and Mertyurek U., GAS-PASS/H: A Simulation Code for Gas Reactor Plant Systems, ICAPP 2004, Pittsburgh, PA, June 2004.

Vilim R.B., Dynamic Modeling Efforts for System Interface, ANL-07/16, Argonne National Laboratory, December 2006.ANL-07/16,

Vilim R.B., GAS-NET: A Two-Dimensional Network Code for Prediction of Core Flow and Temperature Distribution in the Prismatic Gas Reactor, Proceedings of ICAPP 2007 Nice, France, May 13-18, 2007.

Yildiz, B., K. J. Hohnholt, and M. S. Kazimi, "Hydrogen Production Using High-Temperature Steam Electrolysis Supported by Advanced Gas Reactors with Supercritical CO2 Cycles," Nuclear Technology, Vol. 155, July 2006. 